(a)

\title{
Spatiotemporal effects of Hurricane Ivan on an endemic epiphytic orchid: 10 years of follow-up
}

Iván A. Ortiz-Rodríguez, Jose Raventós, Ernesto Mújica, Elaine GonzálezHernández, Ernesto Vega-Peña, Pilar Ortega-Larrocea, Andreu Bonet \& Cory Merow

To cite this article: Iván A. Ortiz-Rodríguez, Jose Raventós, Ernesto Mújica, Elaine GonzálezHernández, Ernesto Vega-Peña, Pilar Ortega-Larrocea, Andreu Bonet \& Cory Merow (2019): Spatiotemporal effects of Hurricane Ivan on an endemic epiphytic orchid: 10 years of follow-up, Plant Ecology \& Diversity, DOI: 10.1080/17550874.2019.1673495

To link to this article: https://doi.org/10.1080/17550874.2019.1673495

Accepted author version posted online: 30 Sep 2019.

Submit your article to this journal $\widetilde{ }$

山 Article views: 33

Q View related articles $\asymp$

View Crossmark data $₫$ 
Publisher: Taylor \& Francis \& Botanical Society of Scotland and Taylor \& Francis

Journal: Plant Ecology \& Diversity

DOI: $10.1080 / 17550874.2019 .1673495$

Spatiotemporal effects of Hurricane Ivan on an endemic epiphytic orchid: 10 years of follow-up

Iván A. Ortiz-Rodríguez ${ }^{\mathbf{a}, \mathbf{b}^{*}}$, Jose Raventós ${ }^{\mathbf{c}}$, Ernesto Mújica ${ }^{\mathbf{d}}$, Elaine González-Hernández Ernesto Vega-Peña ${ }^{\mathbf{b}}$, Pilar Ortega-Larrocea ${ }^{\mathbf{f}}$, Andreu Bonet $^{\mathbf{c}}$ and Cory Merow ${ }^{\mathbf{g}}$

${ }^{\mathbf{a}}$ Classe di Scienze, Scuola Normale Superiore, Pisa, Italia; ${ }^{\mathbf{b}}$ Instituto de Investigaciones en Ecosistemas y Sustentabilidad, Universidad Nacional Autónoma de México, Morelia, Michoacán, México; ' Departamento de Ecología, Universidad de Alicante, Alicante, España; ${ }^{\mathbf{d}}$ Jardín Botánico Orquideario Soroa, Candelaria, Cuba; ${ }^{\mathbf{e}}$ Jardín Botánico de Pinar del Río. ECOVIDA, Pinar del Río, Cuba; ${ }^{\mathbf{f}}$ Instituto de Geología, Universidad Nacional Autónoma de México, Ciudad México, México; ${ }^{\mathrm{g}}$ Department of Ecology and Evolutionary Biology, Yale University, New Haven, USA.

*Corresponding author. E-mail: ivan.ortizrodriguez@sns.it 


\section{Abstract}

Background: Hurricanes have a strong influence on the ecological dynamics and structure of tropical forests. Orchid populations are especially vulnerable to these perturbations due to their canopy exposure and lack of underground storage organs and seed banks.

Aims: We evaluated the effects of Hurricane Ivan on the population of the endemic epiphytic orchid Encyclia bocourtii to propose a management strategy.

Methods: Using a pre- and post-hurricane dataset (2003-2013), we assessed the population asymptotic and transient dynamics. We also identified the individual size-stages that maximise population inertia and E. bocourtii's spatial arrangement relative to phorophytes and other epiphytes.

Results: Hurricane Ivan severely affected the survival and growth of individuals of $E$. bocourtii, and caused an immediate decline of the population growth rate from $\lambda=1.05$ to $\lambda=0.32$, which was buffered by a population reactivity of $\rho_{1}=1.42$. Our stochastic model predicted an annual population decrease of $14 \%$. We found an aggregated spatial pattern between E. bocourtii and its host trees, and a random pattern relative to other epiphytes.

Conclusion: Our findings suggest that E. bocourtii is not safe from local extinction. We propose the propagation and reintroduction of reproductive specimens, the relocation of surviving individuals, and the establishment of new plantations of phorophytes.

Keywords: Caribbean; cyclones; integral projection models; management strategies; plant population dynamics; stochastic growth rate, transient behaviour, transfer functions 


\section{Introduction}

Hurricanes are high-impact disturbance events that exert a strong influence on the ecological dynamics and structure of tropical forests. In the context of climate change, hurricanes have been receiving increasing attention due to an expected increase in their frequency and intensity in the coming decades, which could negatively impact biodiversity in the tropics (IPCC 2012). As an extrinsic factor, hurricanes represent short-term disturbances that influence the population dynamics of plants, altering their suryival, growth, and reproduction and thus define their distribution and abundance in the mediumto long term (Tanner et al. 2014). For epiphytic orchids, hurricanes can be devastating, as they can cause partial or complete loss of their populations (Rodríguez-Robles et al. 1990; Migenis and Ackerman 1993; Tremblay 2008; Raventós et al. 2011; Wiegand et al. 2013); their canopy exposure, wind dispersal, host specificity, and the absence of underground storage organs and seed banks, limit their survival and regrowth after disturbances (Oberbauer et al. 1996; Raventós, González, Mújica, and Doak 2015).

In the Caribbean Sea Basin, hurricanes represent the most common natural ecological disturbance. In the twentieth century, more than 200 events occurred, of which ca. $15 \%$ reached category 5, the highest on the Saffir-Simpson Hurricane Wind Scale (Walker et al. 1991; Landsea et al. 1999; NOAA, 2016). Monitoring of plant populations of endemic and rare species in frequently disturbed ecosystems is particularly important since their vulnerability to extinction due to their restricted distribution (Işik 2011; Crain and Tremblay 2014). It is essential to understand and predict their population recovery trajectories, the changes in their vital rates (survival, growth and fecundity), and their spatial structure after perturbation, in order to design effective management schemes for 
their conservation (Tremblay and Hutchings 2003; Pfeifer et al. 2006; Zotz and Schmidt 2006; Jacquemyn et al. 2007; Jacquemyn et al. 2009; Raventós et al. 2011).

To understand the dynamics of structured populations and guide efforts towards their effective management, ecologists have commonly used demographic projection models such as Matrix Projection Models (Caswell 2001; Crone et al. 2011) and, more recently, Integral Projection Models (Easterling et al. 2000; Salguero Gómez and Plotkin 2010; Merow et al. 2014). Both approaches, however, have mainly focused on the description of the dynamics of populations after reaching a stable size structure, i.e., their asymptotic dynamics, but only few studies have assessed the dynamics of populations with no stable size structure, i.e., the transient dynamics (but see Koons et al. 2005; Ezard et al. 2010; Raventós, González, Mújica, and Bonet 2015). Transient dynamics (the short-term, non-stable fluctuations in population growth and density) is of particular relevance for populations that grow in unstable environments. Such populations are usually far removed from the structure that they display at their stable population size (Tremblay et al. 2015) and analyses of transient dynamics have been highly recommended for management purposes (Stott et al. 2011; McDonald et al. 2016). On the other hand, sensitivity and elasticity analyses have been extensively used as a tool to understand the population-level effect of changing the parameters of a life cycle transition or a vital rate from a linear approach, but it has been shown that these effects can follow a very non-linear pattern (Stott et al. 2012). As an alternative to the classical sensitivity analysis, transfer functions, a more recent approach, have been able to capture the true relationship between perturbation magnitude and population parameters through non-linear extrapolation (Hodgson and Townley 2004; Stott et al. 2012; Stott 2016). 
Hurricanes can alter critical aspects of the spatial structure of epiphytic populations, causing the extinction of clusters and hindering the colonisation of unoccupied phorophytes (Wiegand et al. 2013). Point pattern analyses have proven useful for assessing spatial patterns within one population, as well as the interaction among different populations, identifying possible changes due to disturbances. Analysing the spatial patterns after disturbances allows us to test hypotheses on the processes that caused the observed spatial pattern and can help inform management strategies (Wiegand and Moloney 2004).

In this study, we present an assessment of pre- and post-hurricane dynamics for the endemic epiphytic orchid Encyclia bocourtii Mújica \& Pupulin, based on 10 years of monitoring, exploring both the individual and population-level trends. Using demographic and small-scale spatial approaches, we addressed the following questions: (1) What was the immediate effect of Hurricane Ivan on the population size of $E$. bocourtii and its vital rates (survival, growth and fecundity), and on its spatial patterns?; (2) How did changes in vital rates affect the population dynamics of the orchid?; (3) Is the population resilient to this kind of pervasive disturbance?; and (4) If the population is decreasing, what conservation measures should be taken to minimise the probability of species extinction?

\section{Materials and methods}

\section{Study site and species}

Our study was carried out in Cape San Antonio, located in the Guanahacabibes National

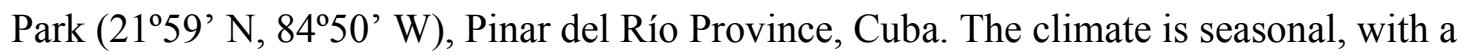
dry period from November to April. Mean annual rainfall has been estimated at $1436 \mathrm{~mm}$ year ${ }^{-1}$ and mean annual temperature varies from 22.7 and $27.5^{\circ} \mathrm{C}$ (Hernández et al. 2013). 
Soils in most of the study area derived from crack reef limestone materials (AcevedoGonzález 1999). The Guanahacabibes National Park has a high diversity of orchids, with at least 30 different species identified (18 species present in the Cabo San Antonio), all of which are protected from commercial collectors (Mújica 2008).

Encyclia bocourtii is a recently described epiphytic orchid (Pupulin and Mújica 2005). It has a mean height of $60 \mathrm{~cm}, 1-2$ leaves that vary in size $(5-30 \times 1-2 \mathrm{~cm})$, clustered and ovoid pseudobulbs (4-7 cm long), and a slender inflorescence (20-50 cm long). Flowers are showy, medium in size, with yellowish green sepals. The petals have brownish apices and yellow margins, and the lip is creamy-white striped with purple; they emit no detectable smell. This species is endemic to the westernmost end of Guanahacabibes peninsula, Cuba, and it can be found mostly in the xeromorphic forest in karstic limestone areas along the coast. E. bocourtii mainly grows on the canopy trees Erythroxylum areolatum (Erythroxylaceae), Plumeria tuberculata (Apocynaceae), Chrysobalanus icaco (Chrysobalanaceae), Metopium brownii (Anacardiaceae) and Thrinax radiata (Arecaceae) (Mújica and González 2007).

\section{Sampling design and data collection}

\section{Hurricane occurrence in Guanahacabibes National Park}

In the last 45 years a total of 31 hurricanes have affected the Guanahacabibes Peninsula (see Table S1 for the 14 most destructive among these). The most destructive ones have been Hurricane Ivan, which struck Guanahacabibes Peninsula in September 2004 and had the highest possible intensity (F-5 category), followed by hurricane Wilma in September 
2005, which was a Category F-4 storm (unpublished data, Meteorological Institute of Pinar del Río province, Cuba,).

In the specific case of Hurricane Ivan, the maximum wind speed registered was $270 \mathrm{~km} \mathrm{~h}^{-1}$. A defoliation of $>90 \%$ of the trees occurred. The effects on tree communities varied according to the type of vegetation (Mujica 2008). The coastal xeromorphic vegetation was less affected: $3.7 \%$ of its trees were completely lost, while the semideciduous forest and the sandy coast vegetation were more affected, $8.8 \%$ and $22.6 \%$ loss respectively. E. bocourtii populations suffered severe damage on the three species of phorophytes that they occupy most commonly (Table 1).

Sampling design before and after Hurricane Ivan

In July 2003, 14 months before Hurricane Ivan, we established three plots $(20 \mathrm{~m} \times 20 \mathrm{~m})$ in the study site, based on similarity of vegetation and lack of apparent differences in topography, orientation, or elevation (Figure S1). The plots were 1.5-2.5 km apart and we assume that the intensity of Hurricane Ivan did not greatly vary among them. Within each plot, all woody plants with a diameter at breast height $(\mathrm{DBH})>2.5 \mathrm{~cm}$ were identified and examined for the presence of epiphytes. Within each plot, all E. bocourtii orchids $\left(n_{2003}=\right.$ 251 plants) were individually tagged and monitored annually until 2006, registering their status (alive or dead), leaf area, and number of fruits. Each year, all recruits in the study plots were individually labelled and measured. To estimate the leaf area, we measured the length $\times$ width of all leaves for each individual. We used leaf area as a size-state variable because it is a good predictor of size in epiphytic orchids (Gregg and Kéry 2006; Mújica 2008). 
In 2006, after the passage of Hurricane Ivan, the number of E. bocourtii individuals in these three plots was very low. In fact, one of the plots had lost all its plants and another plot had been completely isolated. The study area is small, approximately $6 \mathrm{~km}$ long $\times 4 \mathrm{~km}$ wide, and all species and plants were equally impacted by Hurricane Ivan.

In 2007, in order to follow up on the post-hurricane dynamics of the demography of $E$. bocourtii, we enlarged our sampling and established a permanent monitoring system in five permanent plots of $100 \mathrm{~m}$ long $\times$ variable width from 10 to $20 \mathrm{~m}$ (Fig. S1; $n_{2007}=547$ individuals). These five permanent plots were located in the same area, near our previous three plots, with no apparent differences in vegetation composition or topographic attributes. Although three hurricanes struck western Cuba after our study began (two in 2007 and one in 2010), none of them showed an evident effect on our study sites.

\section{Structured population modelling}

\section{Vital rates estimation}

We estimated E. bocourtii vital rates as continuous functions of a single size-based state variable - foliar area - as is favoured for the construction of integral projection models (IPMs; Easterling et al. 2000; Ellner and Rees 2006; Coulson 2012; Metcalf et al. 2013; Merow et al. 2014; Raventos et al. 2015). We fitted vital rate functions: annual survival; mean size after a year (i.e., mean growth); probability of reproducing; and, conditional on reproduction, the number of fruits produced (for an extensive and didactic introduction to

IPMs and their programming in R, see Supplementary Information in Merow et al. 2014).

Integral Projection Models (IPMs) 
To parameterise IPMs, we estimated the vital rates of $E$. bocourtii using Generalised Linear Mixed Models (GLMMs) with random year effects. For this, we assessed the relationship between log-transformed size at time $t$ and the following dependent variables: (i) survival probability from time $t$ to $t+1$, (ii) log-transformed size of surviving individuals at time $t+1$, (iii) probability of reproduction at time $t+1$, and (iv) fruit production by reproductive individuals at time $t+1$. To construct the statistical models, we fitted a set of polynomial functions for individual size (linear, quadratic and cubic) using appropriate error distributions (Gaussian for growth, binomial for survival and probability of reproduction, and Poisson for the number of fruits), and the best model was selected based on the Akaike Information Criterion (AIC).

The best statistical model for each vital rate was fitted to each pair of years using year-specific parameters. We numerically integrated them using the midpoint rule upon a $50 \times 50$ grid covering the kernel (hereafter 'kernel-matrix'). Analyses were made using IPMpack ver. 2.1 (Metcalf et al. 2013), a free open-source package for R v. 3.4 .4 (R Core Team 2018).

We built IPMs for each pair of successive years using the demographic data recorded from 2003 to 2013. IPMs were constructed using a kernel function, $K\left(z^{\prime}, z\right)$, describing how the size distribution of individuals at time $t$ changes over one time-step $(t+1)$ based on survival, change in foliar area (hereafter 'size'), and fecundity (see vital rates estimation section). Our model took the form:

$$
n_{t+1}\left(z^{\prime}\right)=\int_{\Omega} K\left(z^{\prime}, z\right) n(z) d z \text { (Eq. 1a) }
$$


where $z$ is individual size at time $t, z^{\prime}$ is individual size at time $t+1$, and $\Omega$ represents the range of sizes throughout the species life cycle. The probability density function $n(z)$ describes the size distribution of individuals at time $t$; and the integral of $n(z)$ over a size interval I $\left(\int_{\mathrm{I}} n(z) \mathrm{d} z\right)$ represents the number of individuals in that interval. The kernel is composed of a survival-growth sub-kernel, $P\left(z^{\prime}, z\right)$, describing the survival probability for an average individual during the census interval and its probability of growing to size $z^{\prime}$ at $t+1$; and by a fecundity sub-kernel, $F\left(z^{\prime}, z\right)$, representing the production of $z^{\prime}$-sized recruits in $t+1$ by reproductive individuals of size $z$ in $t$ (Eq. $1 \mathrm{~b}$ ).

$n_{t+1}\left(z^{\prime}\right)=\int_{\Omega}^{\cdot}\left[P\left(z^{\prime}, z\right)+F\left(z^{\prime}, z\right)\right] n(z) d z($ Eq. $1 b)$

Sub-kernel $P\left(z^{\prime}, z\right)$ was constructed by combining the models fitted for the survival $[s(z)]$ and growth $\left[g\left(z, z^{\prime}\right)\right]$ processes (Eq. 2, below). Sub-kernel $F\left(z^{\prime}, z\right)$ was estimated as the product of the models fitted for the probability of reproduction $\left[p_{f}(z)\right]$, the number of fruits per flower produced by a reproductive plant of size $z\left[f_{f r}(z)\right]$, the probability of germination $\left[p_{G}\right]$, and the size distribution of the seedlings $\left[f_{d}\left(z^{\prime}\right)\right]$ (Eq. 3). To our knowledge, due to the minuscule size of the seeds, there is no available information on the survival and germination rates of seeds of any epiphytic orchid species (Jacquemyn et al. 2009; Schödelbauerová et al. 2010; Rasmussen et al. 2015). As an estimation of the probability of germination, we computed the ratio between the number of newly established seedlings in each year and the number of fruits produced by all plants in the previous year, which can be considered as an 'effective' germination rate.

$$
P\left(z^{\prime}, z\right)=s(z) * g\left(z, z^{\prime}\right) \quad(\text { Eq. } 2)
$$


$F\left(z^{\prime}, z\right)=p_{f}(z) * f_{f r}(z) * p_{G} * f_{d}\left(z^{\prime}\right)$

(Eq. 3)

\section{Long-term population dynamics}

Asymptotic growth rates

We estimated the asymptotic growth rates of the population during the studied period, computing the kernel-matrix dominant eigenvalue $(\lambda)$ for each pair of years. For each $\lambda$ we also estimated the confidence intervals using a resampling (or parametric bootstrap) approach; for this, we constructed 1,000 replicate projection kernel-matrices, with each element drawn from its corresponding likelihood distribution, and confidence intervals for $\lambda$ were taken as the range encompassing the central $95 \%$ of $\lambda$ estimates.

Stochastic growth rate after perturbation

To summarise the temporal variability in demographic rates after Hurricane Ivan, we estimated the stochastic population growth rate $\left(\lambda_{\mathrm{s}}\right)$ by applying Tuljapukar's approximation considering all the kernel-matrices from 2004 to 2013 (see Tuljapurkar 1982; 1997 for further details).

\section{Short-term (transient) population dynamics}

To evaluate the short-term population dynamics, we calculated, for each pair of years, the three transient indices proposed by Stott et al. (2011): (1) the population density in the first time interval, (reactivity, when the population grows, or first-timestep attenuation, when the population decreases); (2) the maximal amplification / attenuation of the population relative to the population's stable growth rate; and (3) the long-term population density relative to 
the population's stable growth rate (inertia), an indication of how large or small a population with a non-stable size structure becomes compared to an equivalent stable population (complete biological definitions and formulas of transient indices can be consulted in Stott et al. 2011). Given that the case-specific calculation of the transient dynamics variables requires a known initial population size distribution $\left(n_{0}\right)$ and that size classes were absent in our continuous demographic model, we estimated $n_{0}$ as the relative density between each mesh point of the kernel-matrix for each evaluated period. We also built two scenarios in which the initial distribution of sizes was biased towards small individuals ( $\operatorname{size}<10 \mathrm{~cm}^{2}$ ) or large individuals (size $>100 \mathrm{~cm}^{2}$ ) to simulate the expected short-term dynamics under different population structures. To enable the projection of population dynamics in the absence of asymptotic dynamic effects, the standardisation term $\mathbf{K} / \lambda$ was applied, where $\mathbf{K}$ stands for the kernel-matrix built for each period and $\lambda$ represent its corresponding eigenvalue. This standardisation allows a meaningful comparison of the effect of different initial demographic distributions on the same demographic model. For each period, the population trajectory was projected along 30 time-steps.

\section{Non-linear simulations (transfer functions)}

To evaluate the expected effect of changes in the demographic parameters on the population under hypothetical management strategies, we used a non-linear approach based on the transfer function framework. For this, we evaluated the population inertia $\left(\mathrm{P}_{\infty}\right)$ and the asymptotic population growth rate $(\lambda)$ on a consistently perturbed kernel-matrix, $\mathbf{K}_{\delta}$, which was determined as follows: 
$K_{\delta}=K+\delta d e^{T}($ Eq. 4$)$

Here, the original kernel-matrix $\boldsymbol{K}$ was perturbed by a magnitude $\delta$ using an alteration structure determined by column vectors $\boldsymbol{d}$, and $\boldsymbol{e}$ (transposed, $T$ ), which when multiplied determine the elements of the kernel-matrix to be perturbed.

To define alteration structures, each kernel-matrix was divided in three categories: (i) small-sized orchids (individuals with size $<10 \mathrm{~cm}^{2}$ ), (ii) medium-sized orchids (size 10$100 \mathrm{~cm}^{2}$ ), and (iii) large-sized orchids (size $>100 \mathrm{~cm}^{2}$ ), and the alteration was iteratively applied to all the parameters of one section of the kernel matrix representing stasis, progression, retrogression, or fecundity, holding the other sections constant. The range of $\delta$ was conservatively fixed from 0 to 0.1 to explore the effect of small positive management strategies on different individual sizes (a maximum of $10 \%$ increase in each rate). All transient dynamics analyses were built using Popdemo ver. 0.1-4 (Stott et al. 2012), a free open-source package for R (R Core Team 2018).

\section{Spatial patterns}

To explore the effects of Hurricane Ivan on the spatial patterns of E. bocourtii populations, as well as possible interactions of $E$. bocourtii with other common epiphytes, we used the data gathered in the three plots $(20 \mathrm{~m} \times 20 \mathrm{~m})$ established on the study site in 2003 , and we calculated the pairwise-correlation function $g(r)$,

$g(r)=\frac{\frac{d K(r)}{d r}}{2 r} \quad($ Eq. 5) 
where $K(r)$ is the function of Ripley (Ripley 1976), and $r$ is the distance to be evaluated. This function is a distance-dependent function based on point-to-point distances that describes the spatial pattern (clumping or regularity) within a population (univariate function, $g 11(r)$ ), or the interaction (attraction or repulsion) between two different populations (bivariate function, $g 12(r)$ ) at the distance $r$ (Stoyan and Stoyan 1994; Illian et al. 2008; Wiegand and Moloney 2013).

In our study, the univariate statistic $g 11(r)$, was used to test for spatial differentiation between orchid host plants and non-host plants and to assess whether Hurricane Ivan had an effect on the spatial pattern of E. bocourtii. A $g 11(r)$ value of 1 indicates a random pattern, whereas $g 11(r)>1$ indicates aggregation and $g l 1(r)<1$ indicates regularity. In turn, the univariate quantity $\lambda g(r)$ estimates the expected density of neighbours in a ring of radius $r$ and ring width of $d r$ around an 'average' point of the pattern, where $\lambda$ is the intensity of the pattern (i.e., the number of points of the pattern divided by the area of the study plot). The pair-correlation function isolates specific distance classes, which makes it especially suitable for exploratory data analysis (Wiegand and Moloney 2004; Perry et al. 2006; Illian et al. 2008; Raventós et al. 2011). As proposed by Schiffers et al. (2008), we also calculated the K2-index (the first derivative of the $g(r)$ statistic) to deal with the virtual aggregation that can result from the actual variation in intensity across the study area). Using the K2-index together with the pair-correlation function provides a more accurate assessment of the aggregation and dispersion scales.

The bivariate $g 12(r)$ statistic was used to analyse the spatial pattern of E. bocourtii in relation to other common orchid species (Encyclia sp., Tolumnia sp. and Broughtonia cubensis) after a disturbance, by applying the random labelling null model. The bivariate 
statistic $K 2 g 12(r)$ corresponds to the expected density of species-2 neighbours in a ring of radius $r$ (and ring width $d r$ ) around an 'average' species- 1 individual, while $\lambda 2$ is the intensity of the pattern of species-2 points. If the test statistic $g 12$ is below the simulation envelopes, orchid plants of species 1 (E. bocourtii) and orchid plants of species-2 are segregated, whereas when $g 12$ is above the simulation envelopes, it indicates aggregation. In turn, if the test statistic $g 1,1+2 g 2,1+2$ is below the simulation envelopes, it indicates positive and density-dependent change (i.e., facilitation). Conversely, if the test statistic $g 1,1+2 g 2,1+2$ is above the simulation envelopes, this indicates negative dependent mortality (i.e., competition).

In all cases, we performed 999 simulations of null models and $95 \%$ confidence envelopes were calculated from the 25 highest and lowest values of $g 11(r)$ and $g 12(r)$. To assess the overall fit, we used the goodness of fit (Diggle 2003; Loosmore and Ford 2006). All spatial analyses were performed using Programita software (Wiegand and Moloney 2004).

\section{Results}

The population of E. bocourtii suffered severe physical damage during the passage of Hurricane Ivan, causing an immediate reduction of $63 \%$ in their numbers in our study plots. Significant variations in demographic rates (particularly in growth and survival) in the periods after the disturbance were recorded, affecting its whole population dynamics, as we describe below.

\section{Vital rate patterns}


Individual size growth

In all the evaluated periods, the small plants showed high values for growth in size, while the largest individuals showed a decrease in this vital rate, becoming smaller at the end of the life cycle, in eight of the 10 periods evaluated (Figure 1A). There was a sharp decrease in the individual growth rate after Hurricane Ivan (2004-2005), with positive values only for the smallest individuals, and with significant reductions in size for medium and large orchids.

Survival

The survival rate showed a sigmoid pattern, with the highest mortality values for small individuals and the highest survival values for medium and large plants (Figure 1B). The highest survival values (more than 95\% during the entire life cycle) were observed in the period before the hurricane, while the lowest survival (30\% for the smallest plants, reaching a maximum of $60 \%$ at the largest sizes) was observed in the period immediately after the disturbance. We did not find evidence of mortality from senescence in the large plants in any of the evaluated periods.

\section{Fecundity}

The probability of reproduction was zero for small plants, with a reproductive peak when they reach medium size, followed by a minor decrease among large plants. At its reproductive peak, an average individual had less than $20 \%$ probability of being reproductive (Figure 1C). When an individual reproduced, its fruit production increased with size, reaching a maximum of 2 fruits per individual for the largest individuals (Figure 
1D). The mean 'effective' germination rate, considering all the annual transitions, was computed at 2.78 seedlings per fruit, with wide variation across years (s.d. 2.66), but it did not show a clear recovery after Hurricane Ivan (the specific functions of the vital rates used for the construction of IPMs can be consulted in Table 2).

\section{Long-term population dynamics}

Based on the kernel-matrices constructed for each yearly period from 2003 to 2013 (Figure 2 ), we observed asymptotic population growth rates $(\lambda)$ below and above 1 (range 0.32 1.05; Table 3; Figure S2). The highest population growth rate was observed in the prehurricane period $\left(\lambda_{2003-2004}=1.05\right)$, and the lowest rate was observed immediately after Hurricane Ivan $\left(\lambda_{2004-2005}=0.32\right)$. The lower and upper $95 \%$ confidence limits revealed that, in five of the 10 studied periods, $\lambda$ decreased. In the other five periods, the population growth rate did not differ significantly from the demographic stable state, although the bootstrapped $\lambda$ value was below unity, suggesting that the population was still declining. Considering only post-hurricane yearly transitions (2004-2013), a geometric mean of the

population growth rate was estimated at $\lambda_{\text {mean }}=0.8$. Assuming equal probabilities of each observed annual condition into the future, the long-term stochastic growth rate was estimated at $\lambda_{\mathrm{s}}=0.86$.

\section{Short-term (transient) population dynamics}

Considering the actual population size structures for each pair of years, the projections predicted an increase in the population density relative to $\lambda$ in five of the 10 annual periods of study. For the other periods, the projections forecasted a relative attenuation (Table 3 , see Figure S3 for further details). The evolution of the actual transient indices throughout 
the study period shows that the years following the disturbance exhibited the most disruptive behaviour, which then stabilised around the stable size structure distribution (SSD) more recently (Figure 3, red lines and squares). When the transient indices are contrasted with the asymptotic population growth rates $(\lambda)$, in almost all cases $\lambda$ is buffered by the dynamics of the short-term population structure. This 'buffering effect' implies that when $\lambda$ indicates a decreasing population density $(\lambda<1)$, the transient dynamics promote an amplification of the population growth rate. In contrast, when $\lambda>1$, the actual population size structure promotes an attenuation of the growth rate. The most pronounced case of this 'buffering effect' was evident in the immediate period after Hurricane Ivan, which had the highest values for both reactivity and maximum amplification, predicting that the population growth rate would increase by $41 \%$ at 1 year and could double in 15 years (Table 3). In two periods (2004-2005 and 2005-2006), the transient dynamics exaggerated the $\lambda$ trend, which in both cases indicated an exacerbated decrease in the population size.

In the simulation scenario in which the population structures were composed only of small individuals (leaf area $<10 \mathrm{~cm}^{2}$ ), the transient indices consistently predicted a population density lower than that predicted for both the SSD and the actual size structure distribution (ASD) (Figure 3; blue lines and triangles). On the other hand, the first timestep attenuation indicated a greater decrease in density with respect to the SSD, but the maximum attenuation indicates that a population structure of this type could decrease by more than $50 \%$ compared to the density predicted for the SSD.

The opposite situation was found when the structure of the population was composed only of large individuals (leaf area $>100 \mathrm{~cm}^{2}$ ). In this scenario, the transient dynamics generated an impulse of population growth, with higher values than those 
predicted for the SSD and the ASD (Figure 3; red lines). The reactivity indicates that the population would reach twice the density predicted by the SS in the year following the disturbance, reaching a minimum in the period of 2005-2007, during which the dynamics are very similar to those of the SSD. The temporal trend of maximum amplification follows the same pattern as the reactivity but predicts a maximum amplification of five times the density predicted for the SS.

\section{Transfer functions}

The transfer function analyses suggested that most of the kernel alterations had a non-linear effect on the transient population dynamics. The response of inertia showed a complex pattern in which positive alterations in the kernel-matrix elements did not always lead to a positive effect on the population (Figure 4A, Figure S4). In contrast, when the stable population size structure was reached, the trajectories showed that a positive alteration in the matrix transitions always produced positive effects on the population growth rate (Figure 4B, Figure S5). Considering all the study years, it seems that in the short term, population growth can be stimulated by increasing fecundity (i.e., the generation of new small-sized individuals by medium and large reproductive orchids) and, in some cases, by increasing individual growth.

\section{Spatial patterns}

The univariate pair-correlation function $g 11$ showed that trees with orchids were significantly aggregated compared to all trees within short distances (0.2-1.0 m; Figure $5 \mathrm{~A}$ ), indicating a difference in spatial distribution between trees with and without epiphytic orchid species. We also detected a significant aggregation of the epiphytic orchid $E$. 
bocourtii in phorophytes at short distances $(<1.2 \mathrm{~m}$; Figure $5 \mathrm{~B}$ upper panel), suggesting a spatial aggregation of $E$. bocourtii among phorophytes. This aggregation was confirmed by the negative values of the K2-index statistic in the range of $0.2-1.2 \mathrm{~m}$ (Figure 5B lower panel). Hurricane Ivan essentially did not change this pattern; it only increased the aggregation among individuals (Figure 5B upper). On the other hand, the bivariate paircorrelation function $\mathrm{g} 12 \mathrm{did}$ not detect a spatial association between E. bocourtii and Encyclia sp. (Figure S6A upper), but a separation pattern with Broughtonia cubensis (Fig. S6B upper) and Tolumnia sp. at distances of $<1 \mathrm{~m}$ (Figure S6C upper panel) was found. We did not detect any density-dependent interaction between E. bocourtii and the other orchid species (Figure S6A-C lower panel).

\section{Discussion}

Our analyses revealed that Hurricane Ivan had a significant impact on the E. bocourtii; there was a critical negative population response in the period immediately following the disturbance (2004-2005), causing a reduction in the number of plants and alterations in vital rates. Individual growth was severely affected, with a consistent pattern of retrogression across all size classes in the period immediately following the disturbance (Figure 1A). Survivorship also significantly decreased after the disturbance, from a sustained value near unity in the pre-hurricane period to 0.3 for the smallest individuals and ca. 0.6 for the largest orchids in the post-hurricane period (2004-2005) (Figure 1B). All these changes were even more remarkable when we built the kernel (Figure 2), integrating the survival probability, the individual growth, and the fecundity production (as a combination of the probability of reproduction, fruit production, and establishment index). In this comprehensive evaluation, we also noted that reproductive activity was wholly suppressed 
in the four years following the disturbance and it only recovered in the 2007-2008 period (discussed below).

These changes in the vital rates translated into a rapid decline in the projected asymptotic population growth rate (considering a stable size structure for the population), from $\lambda_{2003-2004}=1.05(95 \%$ CI $0.97-1.08)$ to $\lambda_{2004-2005}=0.32(95 \%$ CI $0.26-0.46)$. Considering only this figure, it would be expected that the population would rapidly become extinct, but other factors played an important role to avoid this effect in the short term, particularly the transient dynamics of the population and its size structure after the disturbance. Considering the whole picture after 10 years of follow-up, it is evident that the population is still far from a stable growth rate, with a value of $\lambda_{\mathrm{s}}=0.86$, indicating an annual decrease of $14 \%$.

During the years following the disturbance, the vital rates have shown some recovery, but there have been both good and bad years. The best years in our assessment, i.e., those with positive population growth (pre-hurricane period 2003-2004, and posthurricane periods 2007-2008, 2010-2011 and 2011-2012), also had higher survival rates along the entire life cycle (Figure 1B), which could result from microclimatic factors and the associated physiological responses. This individual behaviour, and the persistence of the population over 10 years after the disturbance, are indicators of resilience. This idea was confirmed by our transient dynamic analyses showing that the period immediately following Hurricane Ivan (the one with the lowest survival, size growth and fecundity rates) had the highest reactivity value $\left(\rho_{1}=1.41\right)$, with a projected maximum amplification of $\rho_{\max }=1.98$ reachable 15 years after the disturbance (Figure 3, Table 3). This result, however, does not imply an absolute boom in population density, but rather a buffer on the expected 
asymptotic population growth rate $(\lambda)$. In this sense, our transient dynamics results are consistent with the 'buffering' hypothesis proposed by McDonald et al. (2016), who suggested that life histories might be selected to maximise the opportunity of populations to boom in response to environmental disturbances. In our case, however, this buffer was not sufficient to alleviate the effects of the disturbance, even without considering the maximum amplification or the inertia figures.

The pervasive immediate effect of Hurricane Ivan on the E. bocourtii population, the immediate reduction of its vital rates and asymptotic population growth rate, the transient response compared to the actual size structure, and the progression over the 10 years of evaluation all suggest that $E$. bocourtii is not safe from extinction, especially in a context of restricted spatial distribution and active hurricane dynamics.

\section{Exploring the causal factors}

Previous post-hurricane assessments for other epiphytic species in our study area have revealed both positive and negative responses at individual and population levels, depending mainly on the morphology of the studied species. Raventós et al. (2015) have assessed the population dynamics of two orchids with contrasting life histories, Dendrophylax lindenii (Lindl.) Bentham \& Rolfe and Broughtonia cubensis (Lindl.) Cogniaux two years after Hurricane Ivan, projecting asymptotic population growth rates $\left(\lambda_{\max }\right)$ of 0.94 and 1.03 , respectively. They suggested that the differences in the recovery rate for these species were highly related to their microhabitat and their photosynthetic capacity. Although E. bocourtii exhibits well-developed leaves and potentially great photosynthetic capacity, our expectation for population recovery after Hurricane Ivan was not reached. In a previous study, we found that the biomass of the E. bocourtii population 
declined significantly after Hurricane Ivan (ca. 50\%) and the mean leaf area per individual decreased by $80 \%$, showing a quasi-steady state over the years (Mújica and González 2007). On the other hand, at their reproductive peak, individuals have a low probability of being reproductive (ca. 20\%; Figure 1C), and we observed a considerable variation in the germination probability across study periods (Table 2), which can also be driven by pollination rate. In many orchid species, a low insect pollination rate is typical and is integrated into their complex reproduction system (Robbirt et al. 2014).

A previous comparison showed a lower rate of pollination only in the first year after Hurricane Ivan (Mújica and Raventós 2010). Interactions with other factors such as the presence of mycorrhizal fungi as a carbon source (Wiegand et al. 2013), or altered abiotic factors (light or humidity) likely contribute to the limited reproductive behaviour of the population.

\section{Effects on spatial configuration}

Epiphytic orchids depend upon several host characteristics such as bark substrate, light levels or height location in the tree canopy (Trapnell and Hamrick 2006). Previous studies (Mújica 2008) showed host specificity of E. bocourtii for nine tree species, but the most aggregated, dense and abundant populations grew on two native host tree species: Erythroxylum areolatum and Chrysobalanus icaco. The former has semi-rugose bark and the latter has smooth bark (49.4\% of individuals). Overall, $80 \%$ of $E$. bocourtii individuals colonise host trees with a DBH of 10-20 cm, and microsites situated less than $1 \mathrm{~m}$ above the ground. In terms of light intensity, sites with attenuated radiation by dense canopies were preferred ( $66 \%$ of individuals), although the plants can also withstand high radiation. Spatial differentiation was observed between phorophytes with and without epiphytic 
orchid species (Figure 5A). We detected intraspecific spatial aggregation of E. bocourtii with the other species on occupied phorophytes and segregation (repulsion) between $E$. bocourtii and B. cubensis. The spatial clustering of E. bocourtii with its phorophytes indicates a clear choice of habitat that would minimise the lack of moisture and nutrient availability of epiphytic growth, especially in a dry tropical forest (Trapnell et al. 2004). The non-random pattern of host plants could be caused by two different mechanisms. First, dispersal limitation may lead to clustering of orchids over potential host plants. Second, suitability of resources provided by host plants (i.e., the right mycorrhiza species) may vary spatially and impose a spatial pattern on the orchids. Nieder et al. (2000) have found a nonrandom highly clustered distribution of holoepiphytes (epiphytes that complete their entire life cycle on a host plant) due to the lack of suitable phorophytes. Raventós et al. (2011) have analysed orchid-host plant communities of a co-occurring orchid species $B$. cubensis in the Guanahacabibes National Park and found a hierarchical spatial structure with aggregation and repulsion at different levels. In our case, for the three different orchid species analysed, we did not find any evidence of positive or negative density dependence. We can hypothesise a coexistence of these tropical epiphytic orchid communities by niche differentiation that should be examined in future studies.

\section{Proposed management strategies}

Management strategies should be applied to help in the recovery of declining populations, especially in frequently perturbed habitats. Implementation of management strategies and conservation actions are commonly developed to protect endangered epiphytic orchid populations that are affected by human disturbances such as illegal harvesting (Wraith and Pickering 2018) as well as natural disturbances such as hurricanes (Tremblay 2008). In situ 
conservation management strategies including phorophyte selection, relocation, and reintroduction of medium and large orchids appear to be feasible to ensure the survival of local populations (Swarts and Dixon 2009). Tremblay (2008) has examined the relocation of the protected orchid Lepanthes eltoroensis Stimson from trees affected by Hurricane George to non-affected trees, finding that $73 \%$ of relocated individuals survived the first year and that survival was not influenced by the presence of other orchids on new host trees or their species. For E. bocourtii, we found that a significant number of individuals were immediately affected because Hurricane Ivan caused the collapse of their phorophyte trees or, at least, of some of their branches; the orchids died in the first few years after the hurricane (Mújica 2008). Recently, Yang et al. (2017) have shown that ex situ propagation is a useful technique for the reintroduction of epiphytic orchids, resulting in significantly higher germination rates. Similarly, Segovia-Rivas et al. (2018) have assessed the success of artificial reintroduction of Barkeria whartoniana (C. Schweinf.) Soto Arenas, an epiphytic microendemic orchid of southern Mexico, through in vitro cultivation. Reintroduction of $E$. bocourtii orchids reproduced in vitro into their habitat may be efficient as it can skip two critical phases in the life cycles, seed dispersal and establishment. On the other hand, population reinforcement of host tree species through the establishment of new plantations, and special protection of medium and old individuals in nearby E. bocourtii sites can also restore the habitat affected by hurricanes and provide more available microsites for relocated, artificial reintroduced, and naturally dispersed orchid individuals (Vergara-Torres et al. 2010; Adhikari et al. 2012; Wagner et al. 2015).

The findings of our transfer function analysis were consistent across all years. We found that inertia, the persistence of the increase or decrease in population density when the 
population has not reached the stable-stage equilibrium, suggested that if we induce a small positive alteration on individual growth, the population density will have a small positive response. Nonetheless, if we favour a small increase in fecundity rate, especially in medium- and large-sized orchids (leaf area $>10 \mathrm{~cm}^{2}$ ), the population will quickly recover. As expected, if we induce positive changes in the stasis of size, leaving all the other vital rates static, the population tends to decline. Once the population reaches the stable-stage equilibrium, positive changes in vital rates will always produce a positive effect on the population growth rate. The importance of the largest individuals was also confirmed by the analysis of transient dynamics, which showed that a population composed of large orchids is more resilient to environmental disturbances as it is able to buffer negative effects on the population density (Figure 3, purple lines and squares).

\section{Conclusions}

Our findings, in the context of a frequently perturbed habitat and a very restricted distribution of the population, point to the possibility of extinction for E. bocourtii if no management policies are implemented. Hurricane Ivan immediately affected the density of the studied population and its vital rates. After 10 years of evaluation, we observed that transient dynamics, i.e. the population responses in the short-term, are playing an important role in the maintenance of the population after environmental disturbances. We suggest that an effective conservation scheme for E. bocourtii must include strategies aiming to enhance fecundity, especially for medium- and large-sized orchids and to stimulate the individual growth of all individuals. Such interventions may include the following: i) ex situ propagation (propagation and cultivation of E. bocourtii individuals, including in vitro cultivation in order to ensure an adequate stock) in botanical gardens and nurseries to 
produce reproductive propagules with an intermediate size $\left(10-100 \mathrm{~cm}^{2}\right)$ for reintroductions; ii) the cautious propagation of pollinators (at least in an experimental phase); iii) the reallocation of reproductive individuals from affected trees after hurricane events on to a suitable host tree to minimise the impact of the perturbation on population size; iv) the reallocation of orchids from hostile to suitable micro-habitats in xeromorphic forests in karstic limestone areas along the coast, where they can grow on the main phorophytes for this orchid: Chysobalanus icaco (Chrysobalanaceae), Erythroxylum areolatum (Erythroxylaceae), Gymnanthes lucida (Euphorbiaceae), Plumeria tuberculata (Apocynaceae), Metopium brownii (Anacardiaceae) and Thrinax radiata (Arecaceae); and iv) the plantation of host tree species in the areas most affected by hurricanes.

\section{Acknowledgements}

This work was supported by the Inter-ministerial Commission for Science and Technology under Grant [CICYT-Spain, Project CGL2015-69985-R]; and the Havana Project of the University of Alicante. We sincerely thank the anonymous reviewers for their insightful comments on previous versions of the manuscript.

\section{Authors' contributions}

J.R., E.M., and E.G. conceived and designed study, coordinated its design and gathered data in the field; I.A.O-R. and J.R. analysed data and wrote the paper; E.V.P., P.O.L., A.B., and C.M. gave feedback on the writing of the paper. 


\section{Notes on contributors}

Iván A. Ortiz-Rodríguez is an environmental scientist interested in the population and community dynamics of tropical plants for their conservation and sustainable use. He is also interested in the use of Big Data for planning conservation and management strategies in protected areas.

José Raventós has a particular interest in the composition, function and restoration of ecosystems, and plant population ecology.

Ernesto Mújica is interested in ecology, demography and orchid taxonomy.

Elaine González-Hernández has a particular interest in the impacts of hurricanes on orchids and in the study of invasive plants.

Ernesto Vega-Peña is a plant ecologist with experience in arid and tropical areas. He is interested in developing numerical simulation models related to the links between ecological and social processes.

Pilar Ortega-Larrocea is a geobiologist interested in soil rehabilitation using microorganisms.

Andreu Bonet focuses on Landscape Ecology and Conservation Biology. His main research is on land use change and disturbance effects on ecosystems, with an emphasis on spatiotemporal analysis of vegetation dynamics.

Cory Merow is a quantitative ecologist interested in building mechanistic models to forecast population and community responses to environmental change. 


\section{References}

Acevedo-González M. 1999. Geografía física de Cuba. Tomo II. La Habana, Cuba: Editorial Pueblo y Educación.

Adhikari YP, Fischer A, Fischer HS. 2012. Micro-site conditions of epiphytic orchids in a human impact gradient in Kathmandu valley, Nepal. J Mt Sci. 9:331-342.

Caswell H. 2001. Matrix population models: Construction, analysis and interpretation. 2nd edition. Massachusetts, USA: Sinauer Associates.

Crain BJ, Tremblay RL. 2014. Do richness and rarity hotspots really matter for orchid conservation in light of anticipated habitat loss? Divers Distrib. 20(6):652-662.

Crone EE, Menges ES, Ellis MM, Bell T, Bierzychudek P, Ehrlén J, Kaye TN, Knight TM, Lesica P, Morris WF, et al. 2011. How do plant ecologists use matrix population models? Ecol Lett. 14(1):1-8.

Coulson, T. 2012. Integral projections models, their construction and use in posing hypotheses in ecology. Oikos, 121(9), 1337-1350.

Diggle PJ. 2003. Statistical analysis of spatial point patterns. Boca Raton (FL): CRC Press.

Easterling M, Ellner S, Dixon P. 2000. Size-specific sensitivity: applying a new structured population model. Ecology. 81(3):694-708.

Ellner SP, Rees M. 2006. Integral projection models for species with complex demography. The American Naturalist, 167(3), 410-428. 
Ezard THG, Bullock JM, Dalgleish HJ, Millon A, Pelletier F, Ozgul A, Koons DN. 2010. Matrix models for a changeable world: The importance of transient dynamics in population management. J Appl Ecol. 47(3):515-523.

Gregg KB, Kéry M. 2006. Comparison of size vs. life-state classification in demographic models for the terrestrial orchid Cleistes bifaria. Biol Conserv. 129(1):50-58.

Hernández R, Ramírez R, López-Portilla M, González P, Antigüedad I, Díaz S. 2013.

Seawater intrusion in the coastal aquifer of Guanahacabibes, Pinar del Río, Cuba. In: Farfán González H, Corvea Porras J, de Bustamente Gutiérrez I, LaMoreaux J, editors. Management of Water Resources in Protected Areas. New York, USA: Springer-Verlag; $p$. $301-308$.

Hodgson DJ, Townley S. 2004. Linking management changes to population dynamic responses: the transfer function of a projection matrix. J Appl Ecol. 41:1155-1161.

Illian J, Penttinen A, Stoyan H, Stoyan D. 2008. Statistical Analysis and Modelling of Spatial Point Patterns. Chichester, West Sussex: John Wiley \& Sons Ltd.

[IPCC] Intergovernmental Panel on Climate Change. 2012. Managing the risks of extreme events and disasters to advance climate change adaptation: special report of the Intergovernmental Panel on Climate Change. Cambridge, United Kingdom and New York: Cambridge University Press.

Işik K. 2011. Rare and endemic species: why are they prone to extinction? Turk J Botany. $35: 411-417$. 
Jacquemyn H, Brys R, Vandepitte K, Honnay O, Roldán-Ruiz I, Wiegand T. 2007. A spatially explicit analysis of seedling recruitment in the terrestrial orchid Orchis purpurea. New Phytol. 176(2):448-459.

Jacquemyn H, Wiegand T, Vandepitte K, Brys R, Roldán-Ruiz I, Honnay O. 2009. Multigenerational analysis of spatial structure in the terrestrial, food-deceptive orchid Orchis mascula. J Ecol. 97(2):206-216.

Koons DN, Grand JB, Zinner B, Rockwell RF. 2005. Transient population dynamics: Relations to life history and initial population state. Ecol Modell. 185(2-4):283-297. Landsea CW, Pielke RA, Mestas-Nuñez AM, Knaff JA. 1999. Atlantic basin hurricanes: Indices of climatic changes. Clim Change. 42(1):89-129.

Loosmore NB, Ford ED. 2006. Statistical inference using the G or K point pattern spatial statistics. Ecology. 87(8):1925-1931.

Mcdonald JL, Stott I, Townley S, Hodgson DJ. 2016. Transients drive the demographic dynamics of plant populations in variable environments. J Ecol. 104(2):306-314.

Merow C, Dahlgren JP, Metcalf CJE, Childs DZ, Evans MEK, Jongejans E, Record S, Rees M, Salguero-Gómez R, Mcmahon SM. 2014. Advancing population ecology with integral projection models: A practical guide. Methods Ecol Evol. 5(2):99-110.

Metcalf CJE, McMahon SM, Salguero-Gómez R, Jongejans E. 2013. IPMpack: an R package for integral projection models. Methods Ecol Evol. 4(2):195-200.

Migenis LE, Ackerman JD. 1993. Orchid-phorophyte relationships in a forest watershed in 
Puerto Rico. J Trop Ecol. 9(2):231-240.

Mújica E, González E. 2007. Dynamics of changes in biomass in the population of Encyclia bocourtii Mújica \& Pupulin ( Orchidaceae ) and its relation with hurricane Ivan impacts in Guanahacabibes peninsula, CUBA.. Ecovida. 1(2).

Mújica E, Raventós J. 2010. Ecología de poblaciones de orquídeas en Cabo San Antonio, Península de Guanahacabibes, Cuba. Análisis espacio- temporal e implicaciones del impacto de un fenómeno atmosférico severo. Rev del Jardín Botánico Nac. 30-31:51-52.

Mújica EB. 2008. Ecología de las orquídeas epífitas Broughtonia cubensis (Lindley) Cogniaux, Dendrophylax lindenii (Lindley) Cogniaux, Dendrophylax lindenii (Lindley) Bentham et Rolfe y Encyclia bocourtii Mújica et Pupulin en el Cabo San Antonio, Peninsula de Guanahacabibes, Cuba. Análisis espacio-temporal e implicaciones del impacto de un fenómeno atmosférico severo [PhD thesis]. Alicante: University of Alicante.

Nieder J, Engwald S, Klawun M, Barthlott W. 2000. Spatial distribution of vascular epiphytes (including hemiepiphytes) in a lowland Amazonian rain forest (Surumoni crane plot) of Southern Venezuela. Biotropica. 32(3):385-396.

[NOAA] National Oceanic and Atmospheric Administration, Historical Hurricane Tracks, 2016. Charleston, SC: NOAA Office for Coastal Management; [accessed 2016 July 23]. http://coast.noaa.gov/hurricanes/.

Oberbauer SF, von Kleist IIIK, Whelan KRT, Koptur S. 1996. Effects of hurricane Andrew on epiphyte communities within cypress domes of Everglades National Park. Ecology. 77(3):964-967. 
Perry GLW, Miller BP, Enright NJ. 2006. A comparison of methods for the statistical analysis of spatial point patterns in plant ecology. Plant Ecol. 187(1):59-82.

Pfeifer M, Wiegand K, Heinrich W, Jetschke G. 2006. Long-term demographic fluctuations in an orchid species driven by weather: Implications for conservation planning. J Appl Ecol. 43(2):313-324.

Pupulin F, Mújica E. 2005. Another new species of Encyclia (Orchidaceae: Laeliinae) from Cuba. Harvard Pap Bot. 10(2):277-230.

R Core Team. 2018. R: a language and environment for statistical computing. Vienna, Austria.

Rasmussen HN, Dixon KW, Jersáková J, Těšitelová T. 2015. Germination and seedling establishment in orchids: A complex of requirements. Ann Bot. 116(3):391-402.

Raventós J, González E, Mújica E, Bonet A. 2015. transient population dynamics of two epiphytic orchid species after Hurricane Ivan: implications for management. Biotropica. 47(4):441-448.

Raventós J, González E, Mújica E, Doak DF. 2015. Population viability analysis of the epiphytic ghost orchid (Dendrophylax lindenii) in Cuba. Biotropica. 47(2):179-189.

Raventós J, Mujica E, Wiegand T, Bonet A. 2011. Analyzing the spatial structure of Broughtonia cubensis (Orchidaceae) populations in the dry forests of Guanahacabibes, Cuba. Biotropica. 43(2):173-182.

Ripley BD. 1976. The Second-Order Analysis of Stationary Point Processes. J Appl 
Probab. 13(2):255-266.

Robbirt KM, Roberts DL, Hutchings MJ, Davy AJ. 2014. Potential disruption of pollination in a sexually deceptive orchid by climatic change. Curr Biol. 24(23):2845-2849.

Rodríguez-Robles J, Ackerman J, Meléndez-Ackerman E, Rodriguez-Robles JA, Melendez-Ackerman E. 1990. Host distribution and hurricane damage to an orchid population at Toro Negro forest, Puerto Rico. Caribb J Sci. 26(3-4):163-164.

Salguero Gómez R, Plotkin JB. 2010. Matrix dimensions bias demographic inferences: implications for comparative plant demography. Am Nat. 176(6):710-722.

Schiffers K, Schurr FM, Tielbörger K, Urbach C, Moloney K, Jeltsch F. 2008. Dealing with virtual aggregation -a new index for analyzing heterogeneous point patterns. Ecography 31(5):545-555.

Schödelbauerová I, Tremblay RL, Kindlmann P. 2010. Prediction vs. reality: Can a PVA model predict population persistence 13 years later? Biodivers Conserv. 19(3):637-650.

Segovia-Rivas A, Meave JA, González EJ, Pérez-García EA. 2018. Experimental reintroduction and host preference of the microendemic and endangered orchid Barkeria whartoniana in a mexican tropical dry forest. J Nat Conserv. 43:156-164.

Stott I, Hodgson DJ, Townley S. 2012. Popdemo: An R package for population demography using projection matrix analysis. Methods Ecol Evol. 3(5):797-802.

Stott I, Townley S, Hodgson DJ. 2011. A framework for studying transient dynamics of population projection matrix models. Ecol Lett. 14(9):959-970. 
Stott I. 2016. Perturbation analysis of transient population dynamics using matrix projection models. Methods Ecol Evol. 7:666-678.

Stoyan D, Stoyan H. 1994. Fractals, random shapes, and point fields: methods of geometrical statistics. Chichester, West Sussex: John Wiley \& Sons.

Swarts ND, Dixon KW. 2009. Terrestrial orchid conservation in the age of extinction. Ann Bot. 104(9): 543-556.

Tanner EVJ, Rodriguez-Sanchez F, Healey JR, Holdaway RJ, Bellingham PJ. 2014. Longterm hurricane damage effects on tropical forest tree growth and mortality. Ecology. 95(10):2974-2983.

Trapnell DW, Hamrick JL, Nason JD. 2004. Three-dimensional fine-scale genetic structure of the neotropical epiphytic orchid, Laelia rubescens. Mol Ecol. 13(5):1111-1118.

Trapnell D, Hamrick J. 2006. Variety of phorophyte species colonized by the neotropical epiphyte, Laelia rubescens (Orchidaceae). Selbyana. 27:60-64.

Tremblay RL. 2008. Ecological correlates and short-term effects of relocation of a rare epiphytic orchid after Hurricane Georges. Endanger Species Res. 5(1):83-90.

Tremblay RL, Hutchings MJ. 2003. Population dynamics in orchid conservation: a review of analytical methods, based on the rare species Lepanthes eltoroensis. In: Dixon KW, Kell SP, Barrett RL, Cribb PJ, editors. Orchid Conservation. Kota Kinabalu, Sabah: Natural History Publications; p. 163-183.

Tremblay RL, Raventós J, Ackerman JD. 2015. When stable-stage equilibrium is unlikely: 
integrating transient population dynamics improves asymptotic methods. Ann Bot. 116(3):381-390.

Tuljapurkar S. 1997. Stochastic matrix models. In: Tuljapurkar S, Caswell H, editors. Structured-population models in marine, terrestrial and freshwater systems. New York, USA: Chapman \& Hall; p. 59-82.

Tuljapurkar SD. 1982. Population dynamics in variable environments. II. Correlated environments, sensitivity analysis and dynamics. Theor Popul Biol. 21(1):114-140.

Vergara-Torres CA, Pacheco-Álvarez MC, Flores-Palacios A. 2010. Host preference and host limitation of vascular epiphytes in a tropical dry forest of central Mexico. J Trop Ecol. 26(6):563-570.

Wagner K, Mendieta-Leiva G, Zotz G. 2015. Host specificity in vascular epiphytes: A review of methodology, empirical evidence and potential mechanisms. AoB Plants. 7(1):125.

Walker LR, Lodge DJ, Brokaw NVL, Waide RB. 1991. An introduction to hurricanes in the Caribbean. Biotropica. 23(2):313-316.

Wiegand T, Moloney KA. 2004. Rings, circles, and null-models for point pattern analysis in ecology. Oikos. 104(2):209-229.

Wiegand T, Moloney KA. 2013. Handbook of spatial point pattern analysis in Ecology. New York, USA: CRC Press.

Wiegand T, Raventós J, Mújica E, González E, Bonet A. 2013. Spatio-temporal analysis of 
the effects of Hurricane Ivan on two contrasting epiphytic orchid species in Guanahacabibes, Cuba. Biotropica. 45(4):441-449.

Wraith, J, Pickering, C. 2018. Quantifying anthropogenic threats to orchids using the IUCN Red List. Ambio. 47: 307-317

Yang FS, Sun AH, Zhu J, Downing J, Song XQ, Liu H. 2017. Impacts of host trees and sowing conditions on germination success and a simple ex Situ approach to generate symbiotic seedlings of a rare epiphytic orchid endemic to Hainan Island, China. Bot Rev. $83: 74-86$.

Zotz G, Schmidt G. 2006. Population decline in the epiphytic orchid Aspasia principissa.

Biol Conserv. 129(1):82-90. 


\section{FIGURE LEGENDS}

\section{Figure 1. Demographic patterns of Encyclia bocourtii in Guanahacabibes, Cuba.}

Statistical models describing the vital rates for each year during the 2003-2013 period. (A) Size growth rate, (B) Survival as a function of size (leaf area), (C) Probability of reproduction, (D) Number of fruits produced by reproductive orchids. The colour legend is the same for panels A and B.

Figure 2. Kernels describing survival, growth and fecundity for Encyclia bocourtii over a 10-year study period. (A) Pre-hurricane period (2003-2004); (B) post-hurricane periods (2004-2013). In each plot, the darkest areas represent the more likelihood of transition.

Figure 3. Trends in the transient indices of the Encyclia bocourtii population in Guanahacabibes, Cuba, over a 10-year monitoring period. Transient indices were computed for three different initial size structure scenarios: (i) The actual size structure distribution (ASD), (ii) a population structure biased towards individuals with a small leaf area $\left(<10 \mathrm{~cm}^{2}\right)$, and (iii) a population structure biased towards individuals with a large leaf area $\left(>100 \mathrm{~cm}^{2}\right)$. The black line indicates the stable size structure distribution (SSD). Firsttime attenuation (FTSA; when the population attenuates) or reactivity (React; when the population amplifies) correspond to the expected changes in density in a single time-step relative to the asymptotic population growth rate $(\lambda)$. Maximum amplification (Max amp) or attenuation (Max att) indicate the largest or smallest possible future density for a given population structure, relative to a population with stable growth rate.

Figure 4. Transfer functions for the Encyclia bocourtii population (2012-2013).

Multiplot of transfer functions for inertia (A) and asymptotic population growth rate (B) for 
the period of 2012-2013 (see Fig. S4 and S5 for the other periods). The layout of the multiplot mirrors the layout of each section on the kernel-matrix. Each graph represents the effect of a change in lambda as a general function of a change in the demographic parameters of one section while holding the other parameters constant.

\section{Figure 5. Spatial patterns of Encyclia bocourtii and its host trees in Guanahacabibes,}

Cuba. (A) Univariate pair-correlation function $(g 11(r))$. Points above the upper envelope indicate a positive association between host trees (aggregated pattern), points between the envelopes indicate no spatial association (random pattern), and points below the lower envelope indicate a negative association between host trees. (B) Univariate pair-correlation function $(g 11(r))$. Points above the upper envelope indicate a positive association between individuals of the same orchid species (aggregated pattern), points between the envelopes indicate no spatial association (random pattern), and points below the lower envelope indicate a negative association between individuals of the same orchid species (overdispersed pattern). The K2-index (Schiffers et al. 2008) is an extension of the paircorrelation function that can identify hyperdispersion and aggregation in univariate patterns. A negative $K 2$ value indicates clustering, whereas a positive value indicates hyperdispersion. In all the cases, grey lines show the 25 th smallest and largest values of the 999 simulations of the null random model. The expectation of the null model is indicated with the continuous grey line. The red lines with diamonds indicate the spatial patterns of orchids not perturbed by Hurricane Ivan whereas black lines with points indicate the spatial patterns of orchids affected by Hurricane Ivan. 


\section{Notes on contributors}

Iván A. Ortiz-Rodríguez is an environmental scientist interested in the population and community dynamics of tropical plants for their conservation and sustainable use. He is also interested in the use of Big Data for planning conservation and management strategies in protected areas.

José Raventós has a particular interest in the composition, function and restoration of ecosystems, and plant population ecology.

Ernesto Mújica is interested in ecology, demography and orchid taxonomy.

Elaine González-Hernández has a particular interest in the impacts of hurricanes on orchids and in the study of invasive plants.

Ernesto Vega-Peña is a plant ecologist with experience in arid and tropical areas. He is interested in developing numerical simulation models related to the links between ecological and social processes.

Pilar Ortega-Larrocea is a geobiologist interested in soil rehabilitation using microorganisms.

Andreu Bonet focuses on Landscape Ecology and Conservation Biology. His main research is on land use change and disturbance effects on ecosystems, with an emphasis on spatio-temporal analysis of vegetation dynamics.

Cory Merow is a quantitative ecologist interested in building mechanistic models to forecast population and community responses to environmental change. 
Table 1. The density of the main phorophyte species associated with Encyclia bocourtii before and after Hurricane Ivan

\begin{tabular}{|c|c|c|c|c|c|c|}
\hline \multirow[t]{2}{*}{ Phorophyte species } & \multirow[t]{2}{*}{ Plot 1} & \multirow[t]{2}{*}{ Plot 2} & \multirow[t]{2}{*}{ Plot 3} & \multicolumn{2}{|c|}{ Host trees density } & \\
\hline & & & & $\begin{array}{l}\text { Before } \\
\text { hurricane }\end{array}$ & $\begin{array}{c}\text { After } \\
\text { hurricane }\end{array}$ & \\
\hline Chrysobalanus icaco & & & 16 & 16 & 0 & 100 \\
\hline $\begin{array}{l}\text { Erythroxylum } \\
\text { areolatum }\end{array}$ & 5 & 7 & & 12 & 2 & 83.3 \\
\hline Gymnanthes lucida & 4 & & & 4 & 1 & 75 \\
\hline
\end{tabular}

Table 2. Statistical models describing the vital rates of the Encyclia bocourtii population in Guanahacabibes, Cuba, from 2003 to 2013. These functions were used for the building of the Integral Projection Models. For each vital rate we fitted a series of polynomial functions (linear, quadratic and cubic) using appropriate error distributions (Gaussian for growth, binomial for survival and probability of reproduction, and Poisson for the number of fruits) considering the size of the individuals as a factor $(z)$, and the best model was selected based on the Akaike Information Criterion (AIC). When corresponds, the mean model and the year random effects in the intercept are showed. When the vital rate was not related to size, the mean was used as a constant.

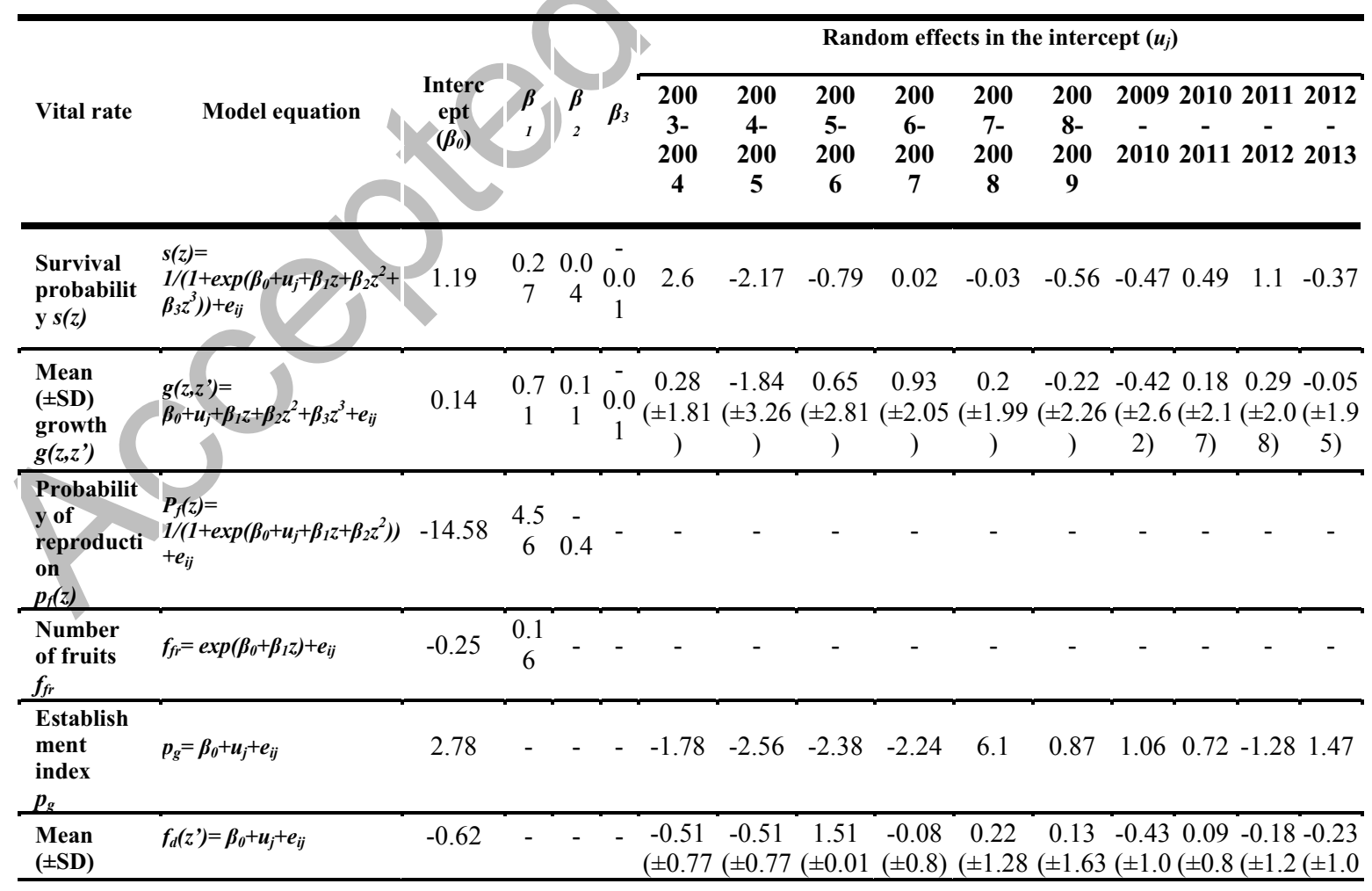




\begin{tabular}{|c|c|c|c|c|c|c|c|c|c|}
\hline $\begin{array}{l}\text { offspring } \\
\text { size } \\
f_{d}\left(z^{\prime}\right) \\
\end{array}$ & ) & ) & ) & ) & ) & 2) & 6) & ) & 7) \\
\hline
\end{tabular}

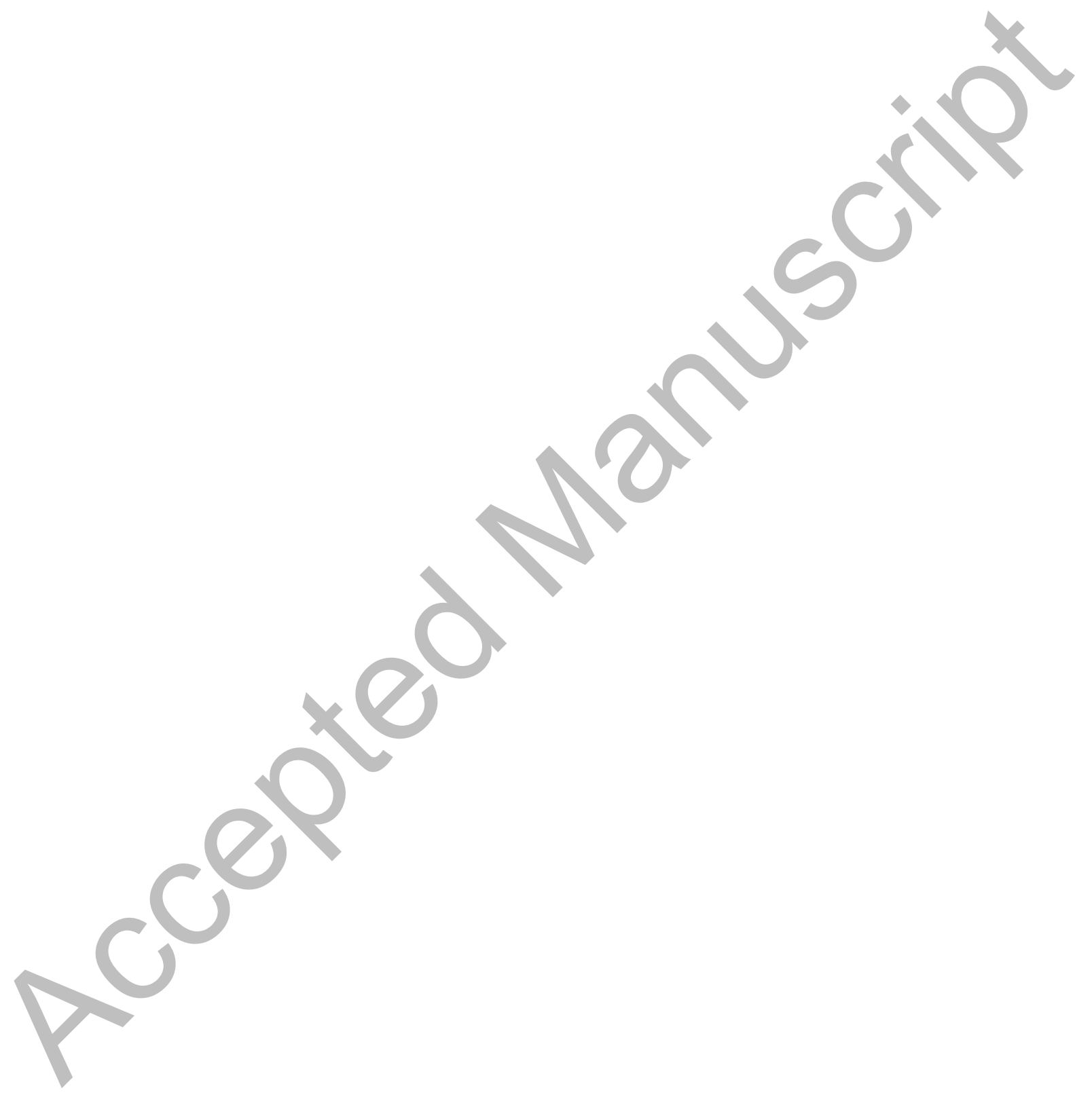


Table 3. Annual asymptotic population growth rates $(\lambda)$ and transient indices for the endemic epiphytic orchid Encyclia bocourtii, Guanahacabibes, Cuba. The asymptotic population growth rate $\lambda$ was obtained as the eigenvalue of the kernel-matrix for each period; the $95 \%$ confidence interval was calculated using a parametric bootstrap procedure. Transient indices are given considering three scenarios with different initial size-structure distribution conditions: (i) The actual distribution observed for each period, (ii) a biased distribution composed only for small individuals (foliar area $<10 \mathrm{~cm}^{2}$ ), and (iii) a biased distribution composed only for big individuals (foliar area $>100 \mathrm{~cm}^{2}$ ).

\begin{tabular}{|c|c|c|c|c|}
\hline Period & $\begin{array}{c}\text { Asymptotic population } \\
\text { growth rate }(\lambda) \\
{[95 \% \mathrm{CI}]}\end{array}$ & Initial conditions & $\begin{array}{cc}\text { First time step } & \\
\text { attenuation }(-) / & \text { Maximum attenuation }(-) / \\
\text { Reactivity }(+) & \text { Maximum amplification }(+)\end{array}$ & Inertia \\
\hline \multirow{3}{*}{$\begin{array}{l}\text { 2003-2004 } \\
\text { (Pre-hurricane) }\end{array}$} & \multirow{3}{*}{$\begin{array}{c}1.053 \\
{[0.974-1.08]}\end{array}$} & Actual distribution & {$[-] 0.95(t=20)$} & 0.95 \\
\hline & & $\left(<10 \mathrm{~cm}^{2}\right)$ & {$[-] 0.58(\mathrm{t}=16)$} & 0.59 \\
\hline & & $\left(>100 \mathrm{~cm}^{2}\right)$ & {$[+] 1.75(\mathrm{t}=11)$} & 1.71 \\
\hline \multirow{3}{*}{ 2004-2005 } & \multirow{3}{*}{$\begin{array}{c}0.321 \\
{[0.261-0.462]}\end{array}$} & Actual distribution & {$[+] 1.41 \longrightarrow[+] 1.98(t=15)$} & 1.98 \\
\hline & & $\left(<10 \mathrm{~cm}^{2}\right)$ & {$[-] 0.25(\mathrm{t}=17)$} & 0.25 \\
\hline & & $\left(>100 \mathrm{~cm}^{2}\right)$ & {$[+] 5.06(\mathrm{t}=16)$} & 5.06 \\
\hline \multirow{3}{*}{ 2005-2006 } & \multirow{3}{*}{$\begin{array}{c}0.800 \\
{[0.693-0.888]}\end{array}$} & Actual distribution & {$[-] 0.74(t=18)$} & 0.74 \\
\hline & & $\left(<10 \mathrm{~cm}^{2}\right)$ & {$[-] 0.52(t=19)$} & 0.52 \\
\hline & & $\left(>100 \mathrm{~cm}^{2}\right)$ & {$[+] 1.20(\mathrm{t}=9)$} & 1.20 \\
\hline \multirow{3}{*}{ 2006-2007 } & \multirow{3}{*}{$\begin{array}{c}0.957 \\
{[0.884-1.006]}\end{array}$} & Actual distribution & {$[-] 0.82(t=7)$} & 0.82 \\
\hline & & $\left(<10 \mathrm{~cm}^{2}\right)$ & {$[-] 0.59(\mathrm{t}=8)$} & 0.59 \\
\hline & & $\left(>100 \mathrm{~cm}^{2}\right)$ & {$[+] 1.07(\mathrm{t}=4)$} & 1.07 \\
\hline \multirow{3}{*}{ 2007-2008 } & \multirow{6}{*}{$\begin{array}{c}1.029 \\
{[0.948-1.111]} \\
0.795 \\
{[0.752-0.86]}\end{array}$} & Actual distribution & {$[+] 1.19(t=9)$} & 1.19 \\
\hline & & $\left(<10 \mathrm{~cm}^{2}\right)$ & {$[-] 0.37(\mathrm{t}=7)$} & 0.39 \\
\hline & & $\left(>100 \mathrm{~cm}^{2}\right)$ & {$[+] 4.74(\mathrm{t}=4)$} & 4.36 \\
\hline \multirow{6}{*}{$2008-2009$} & & Actual distribution & {$[+] 1.32(t=28)$} & 1.32 \\
\hline & & $\left(<10 \mathrm{~cm}^{2}\right)$ & {$[-] 0.41(\mathrm{t}=32)$} & 0.41 \\
\hline & & $\left(>100 \mathrm{~cm}^{2}\right)$ & {$[+] 4.45(\mathrm{t}=30)$} & 4.45 \\
\hline & \multirow{3}{*}{$\begin{array}{c}0.763 \\
{[0.712-0.870]}\end{array}$} & Actual distribution & {$[+] 1.38(t=22)$} & 1.38 \\
\hline & & $\left(<10 \mathrm{~cm}^{2}\right)$ & {$[-] 0.63(\mathrm{t}=24)$} & 0.63 \\
\hline & & $\left(>100 \mathrm{~cm}^{2}\right)$ & {$[+] 3.8(\mathrm{t}=23)$} & 3.80 \\
\hline \multirow{3}{*}{ 2010-2011 } & \multirow{3}{*}{$\begin{array}{c}1.004 \\
{[0.952-1.067]}\end{array}$} & Actual distribution & {$[-] 0.98(t=1)$} & 0.99 \\
\hline & & $\left(<10 \mathrm{~cm}^{2}\right)$ & {$[-] 0.50(\mathrm{t}=10)$} & 0.51 \\
\hline & & $\left(>100 \mathrm{~cm}^{2}\right)$ & {$[+] 2.54(\mathrm{t}=6)$} & 2.49 \\
\hline 2011-2012 & 1.031 & Actual distribution & {$[-] 0.86(t=12)$} & 0.86 \\
\hline
\end{tabular}




\begin{tabular}{cclccc}
\hline \multirow{4}{*}{$\mathbf{2 0 1 2 - 2 0 1 3}$} & {$[0.974-1.086]$} & $\left(<10 \mathrm{~cm}^{2}\right)$ & {$[-] 0.88$} & {$[-] 0.55(\mathrm{t}=13)$} & 0.55 \\
\cline { 3 - 6 } & & $\left(>100 \mathrm{~cm}^{2}\right)$ & {$[+] 1.34$} & {$[+] 2.38(\mathrm{t}=13)$} & 2.42 \\
\cline { 3 - 5 } & 0.86 & Actual distribution & {$[+] \mathbf{1 . 1}$} & {$[+] \mathbf{1 . 3 9}(\mathbf{t}=\mathbf{1 7})$} & $\mathbf{1 . 3 9}$ \\
\cline { 3 - 6 } & {$[0.770-0.933]$} & $\left(<10 \mathrm{~cm}^{2}\right)$ & {$[-] 0.8$} & {$[-] 0.33(\mathrm{t}=18)$} & 0.33 \\
\cline { 3 - 5 } & & $\left(>100 \mathrm{~cm}^{2}\right)$ & {$[+] 2.47$} & {$[+] 4.65(\mathrm{t}=11)$} & 4.62 \\
\hline
\end{tabular}


A

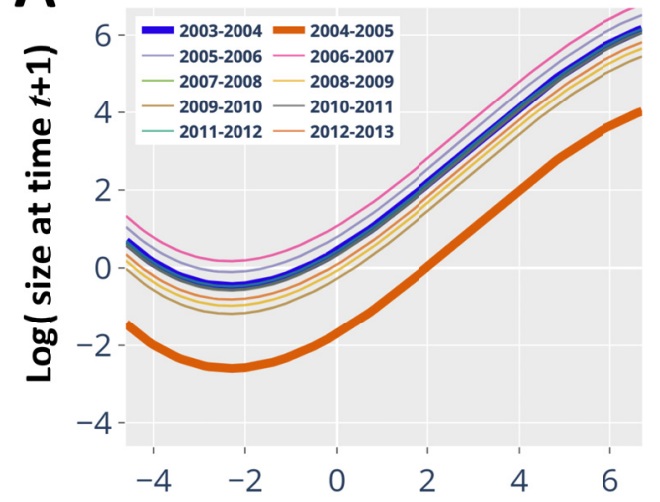

C

흠

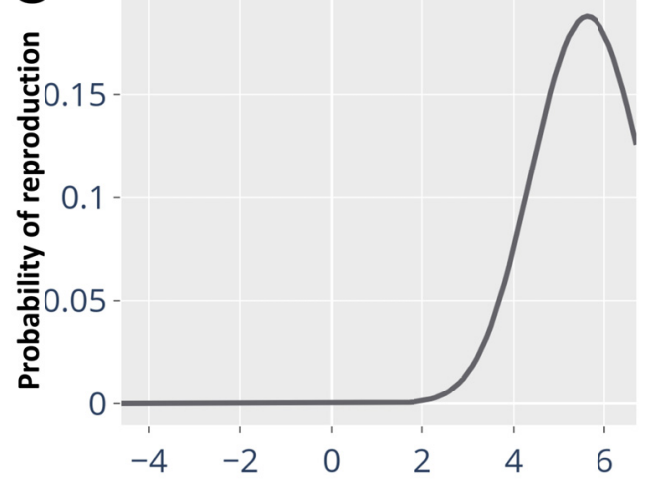

B

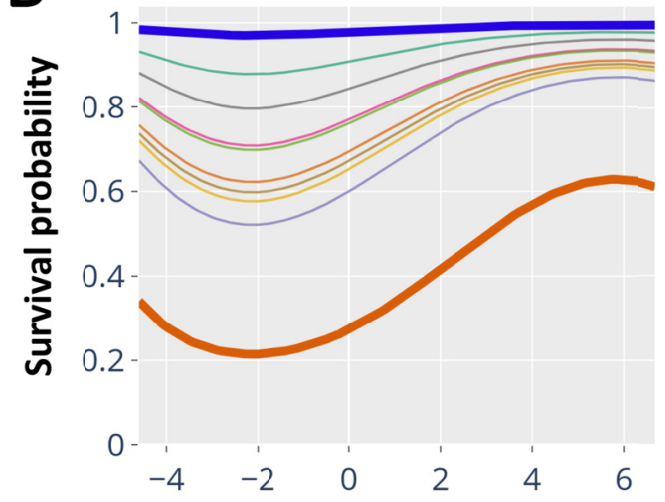

D

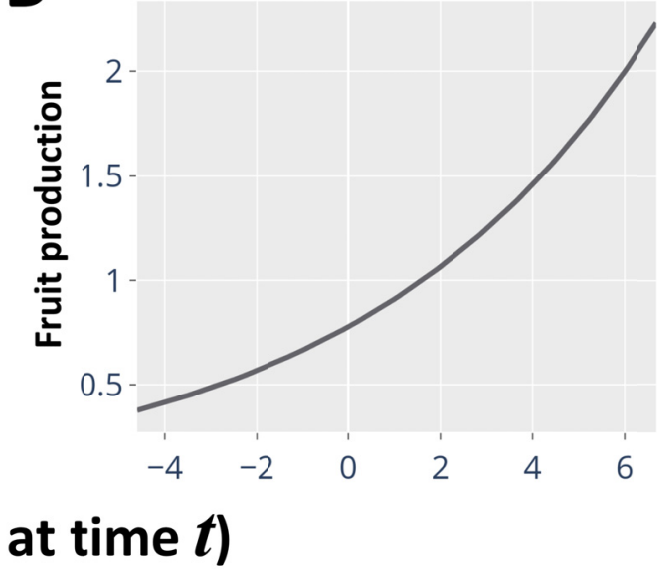

Fig 1

\section{$\log$ (size at time $t$ )}


B
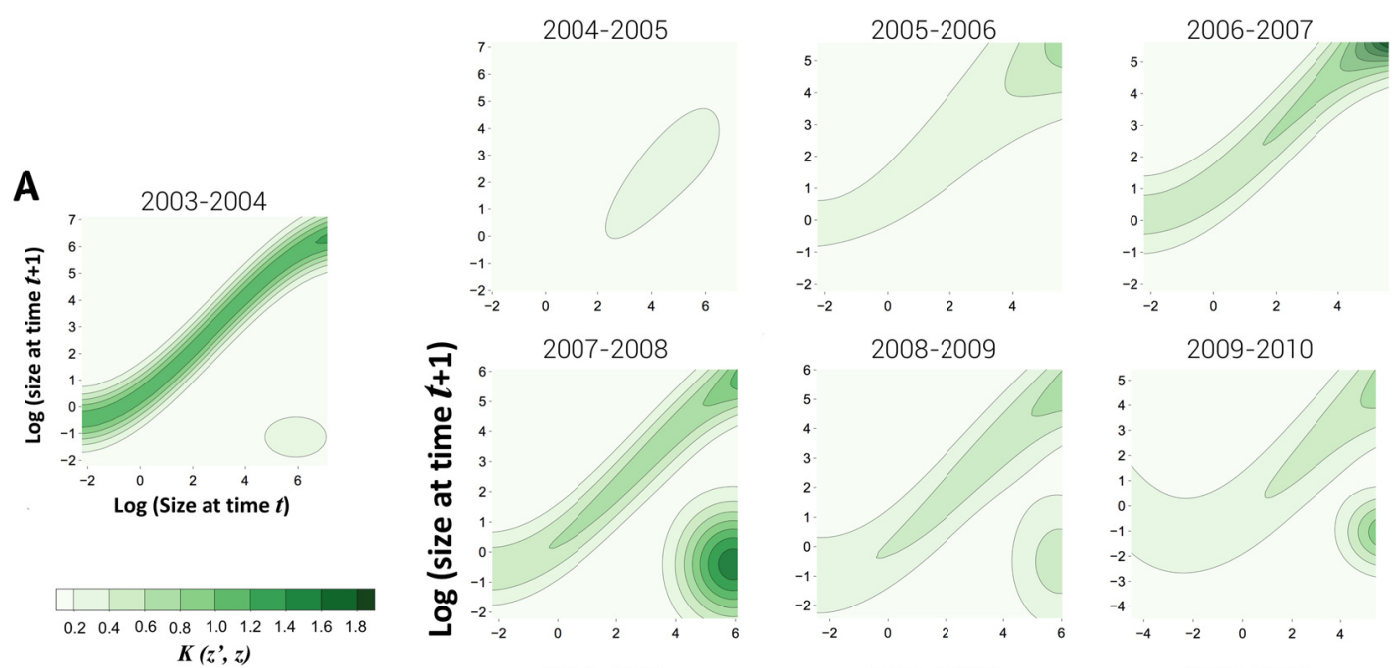

2009-2010

20า0-2011

2011-2012

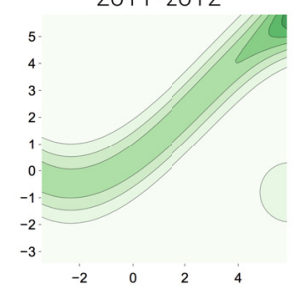

$2012-2013$

Log (size at time $t$ )

Fig 2

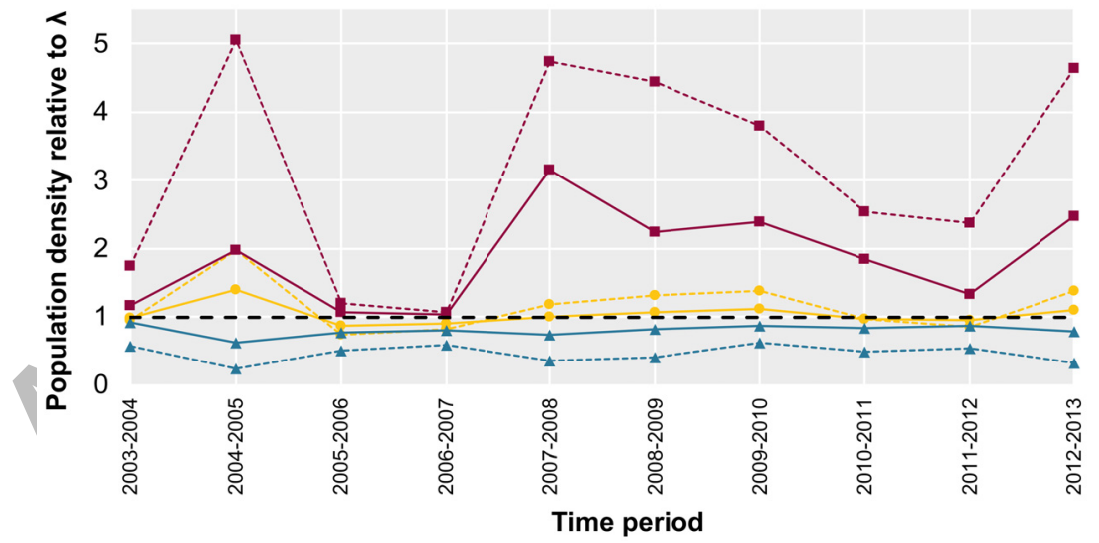

- Biased initial distribution $\left(>100 \mathrm{~cm}^{2}\right)$ React of FTSA

- Biased initial distribution (>100 cm²)Max att or Max amp

Actual distributionReact of FTSA

Actual distributionMax att or Max amp

- Biased initial distribution ( $\left.<10 \mathrm{~cm}^{2}\right)$ React of FTSA

-. Biased initial distribution ( $\left.<10 \mathrm{~cm}^{2}\right)$ Max att or Max amp

- Stable distribution

Fig 3 

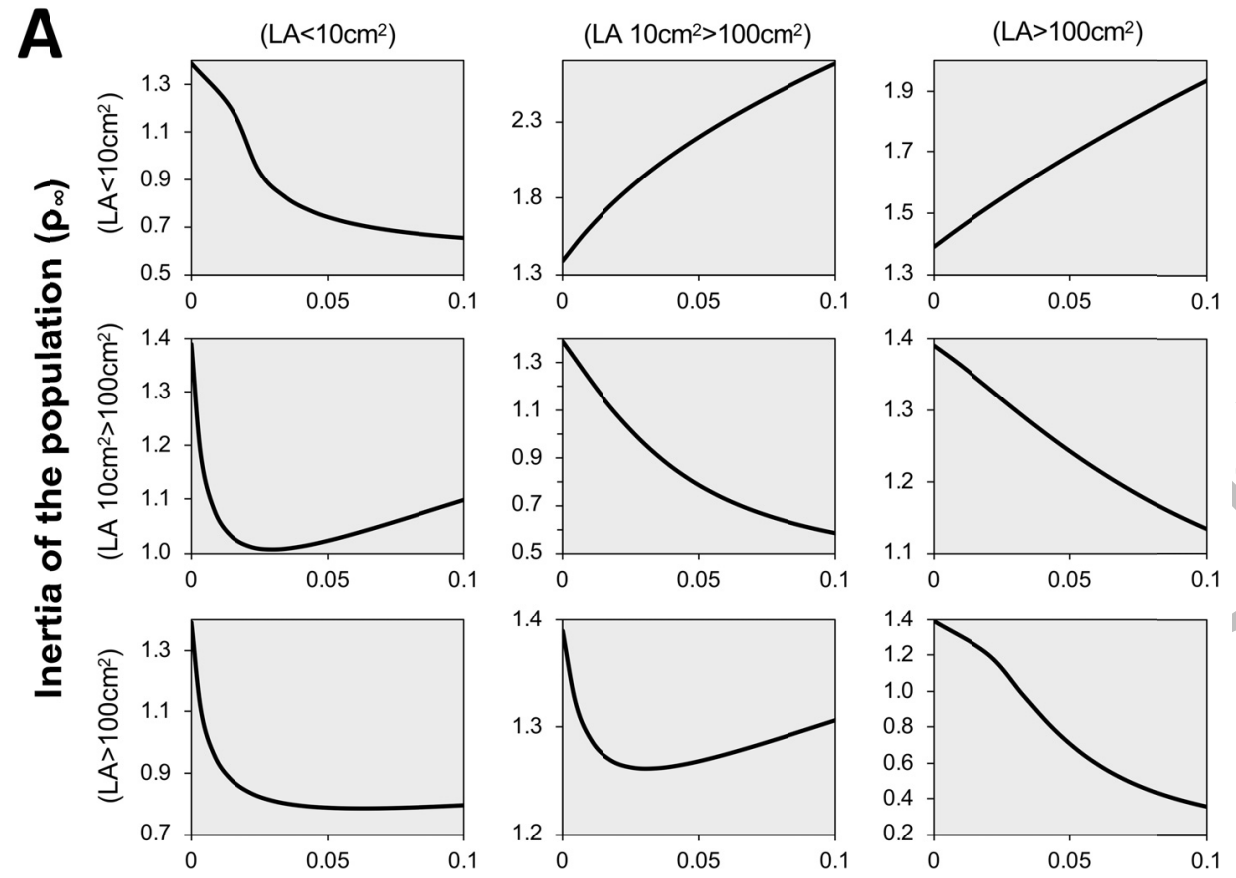

Perturbation magnitude (p)
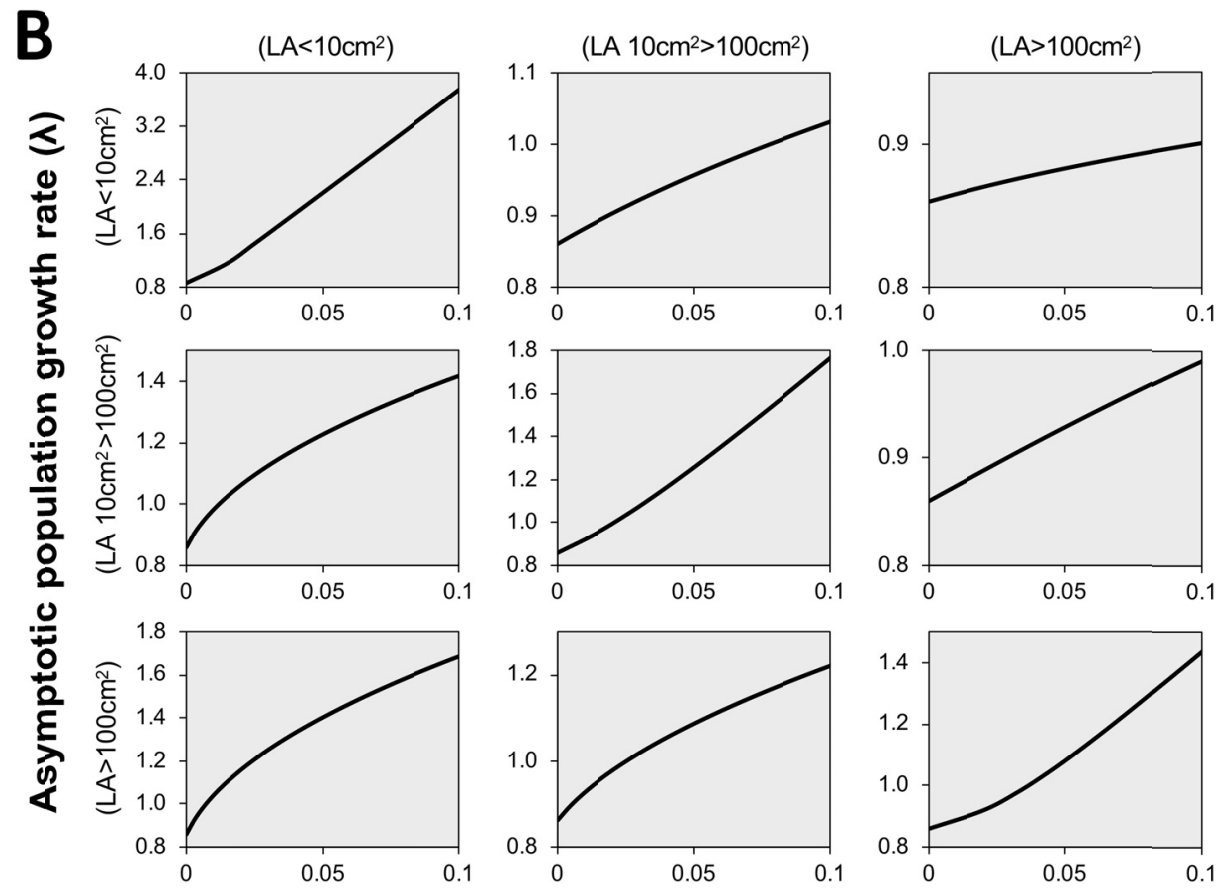

Perturbation magnitude (p)

Fig 4 
A Phorophyte-Phorophyte

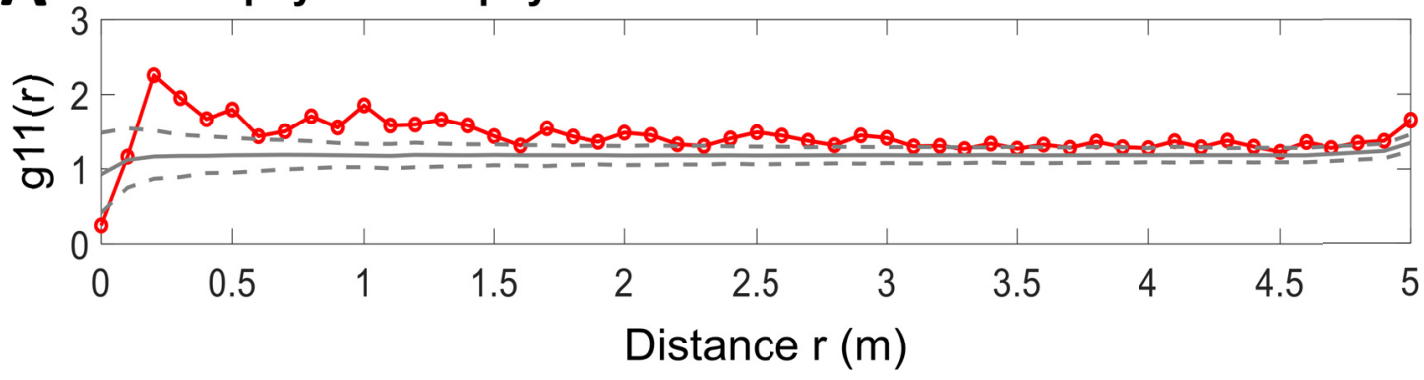

B Encyclia bocourtii - Encyclia bocourtii
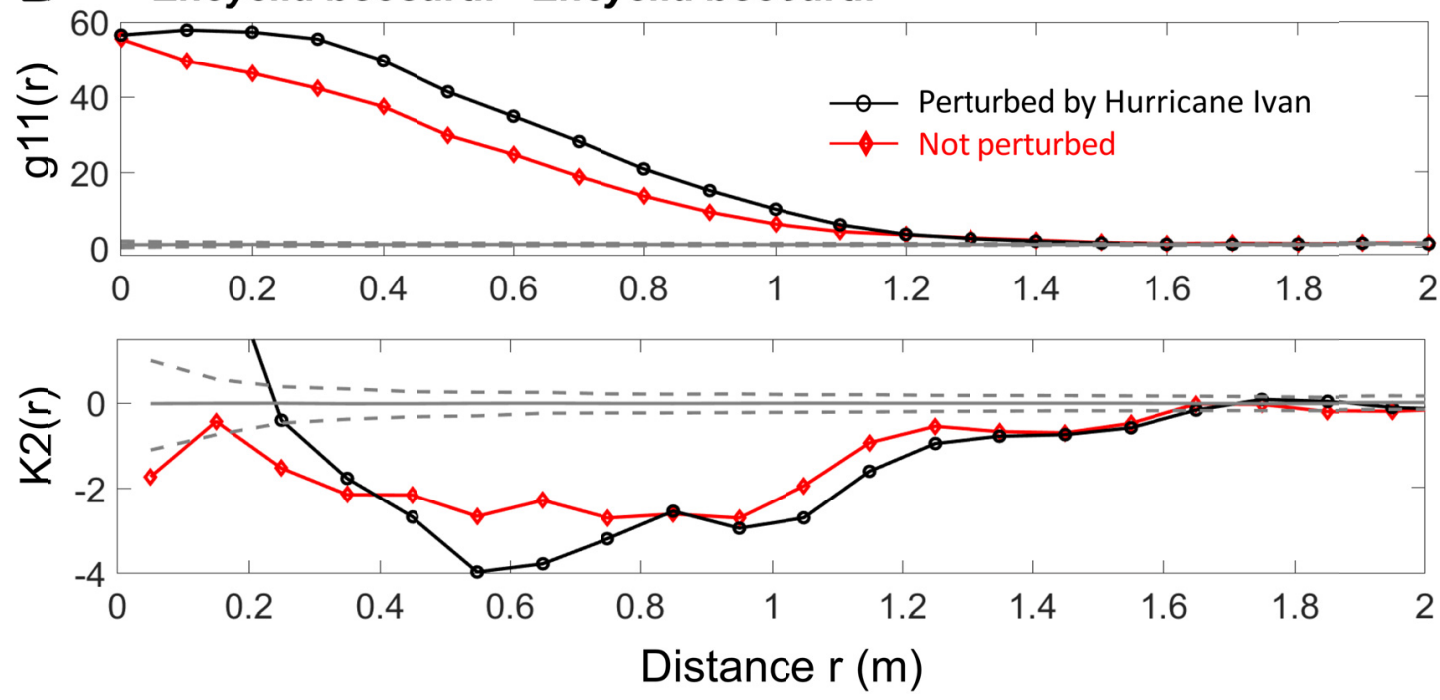

Fig 5 
Supporting information to the paper

\section{Spatiotemporal effects of Hurricane Ivan on an endemic epiphytic orchid: ten years of follow-up}

Ortiz-Rodríguez, et al.

\section{SUPPLEMENTARY TABLES}

Table S1. Hurricanes that have affected the Guanahacabibes peninsula, Cuba since 1975.

\begin{tabular}{cccc}
\hline No. & Hurricane name & Year & Windspeed (max) \\
& & & \\
\hline 1 & Caroline & 1975 & 200 \\
\hline 2 & Eloise & 1975 & 220 \\
\hline 3 & Claudette & 1979 & 90 \\
\hline 4 & Jeanne & 1980 & 170 \\
\hline 5 & Allison & 1995 & 130 \\
\hline 6 & Isidore & 2002 & 130 \\
\hline 7 & Lily & 2002 & 134 \\
\hline 8 & Iván & 2004 & 270 \\
\hline 9 & Katrina & 2005 & 140 \\
\hline 10 & Wilma & 2005 & 214 \\
\hline 11 & Dean & 2007 & 100 \\
\hline 12 & Barry & 2007 & 78 \\
\hline 13 & Paula & 2010 & 97 \\
\hline 14 & Michael & 2019 & 171 \\
\hline
\end{tabular}




\section{SUPPLEMENTARY FIGURES}

Figure S1. Location of study area in Guanahacabibes Peninsula, Cuba, and location of the permanent study plots for assessing the population dynamics of Encyclia bocourtii. The three study plots $(20 \times 20 \mathrm{~m})$ were established in July 2003, 14 months prior to hurricane Ivan, we established three plots in the study site. In 2006, after the passage of hurricane Ivan, the number of E. bocourtii individuals in these three plots was very low. In 2007, in order to follow up on the postIvan demographic dynamics of $E$. bocourtii, we enlarged our sample and established a permanent monitoring system in five permanent plots $(100 \mathrm{~m}$ long $\times$ variable width from 10 to $20 \mathrm{~m}$; black lines). These five permanent plots were located in the same area, near our previous three plots, with no apparent differences in vegetation composition or topographic attributes. Plots were close enough together $(2-3 \mathrm{~km})$ that we assume that the intensity of hurricane Ivan $(270 \mathrm{~km} / \mathrm{h}) \mathrm{did}$ not greatly vary among them.

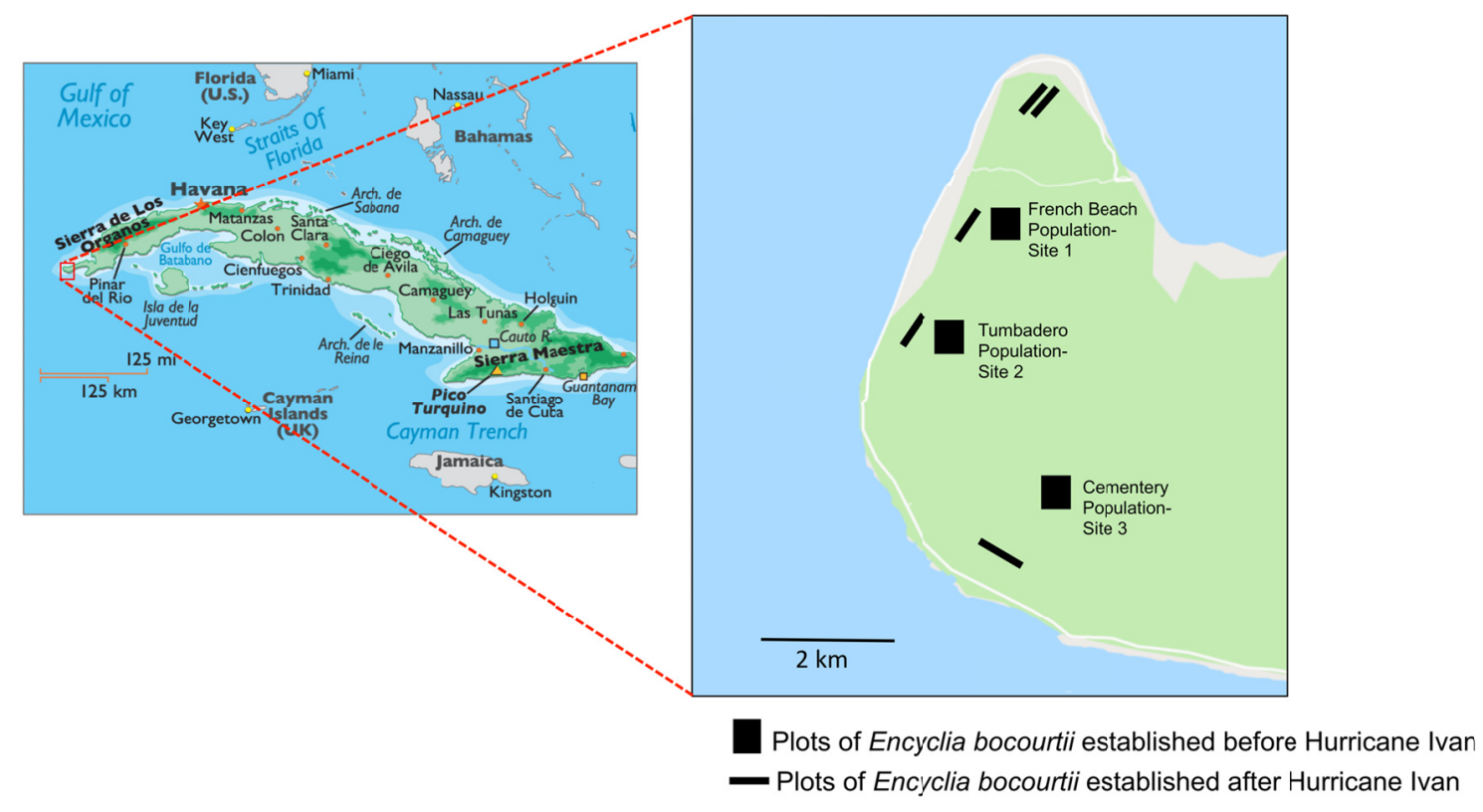


Figure S2. Annual population growth rates for Encyclia bocourtii during 2003-2013. Error bars indicate $95 \%$ confidence intervals for each year according to 1000 bootstrap simulations. Discontinuous line indicates the equilibrium state $(\lambda=1)$, and continuous line indicates the stochastic population growth rate considering all post-hurricane years $\left(\lambda_{\mathrm{s}}=0.861\right)$.

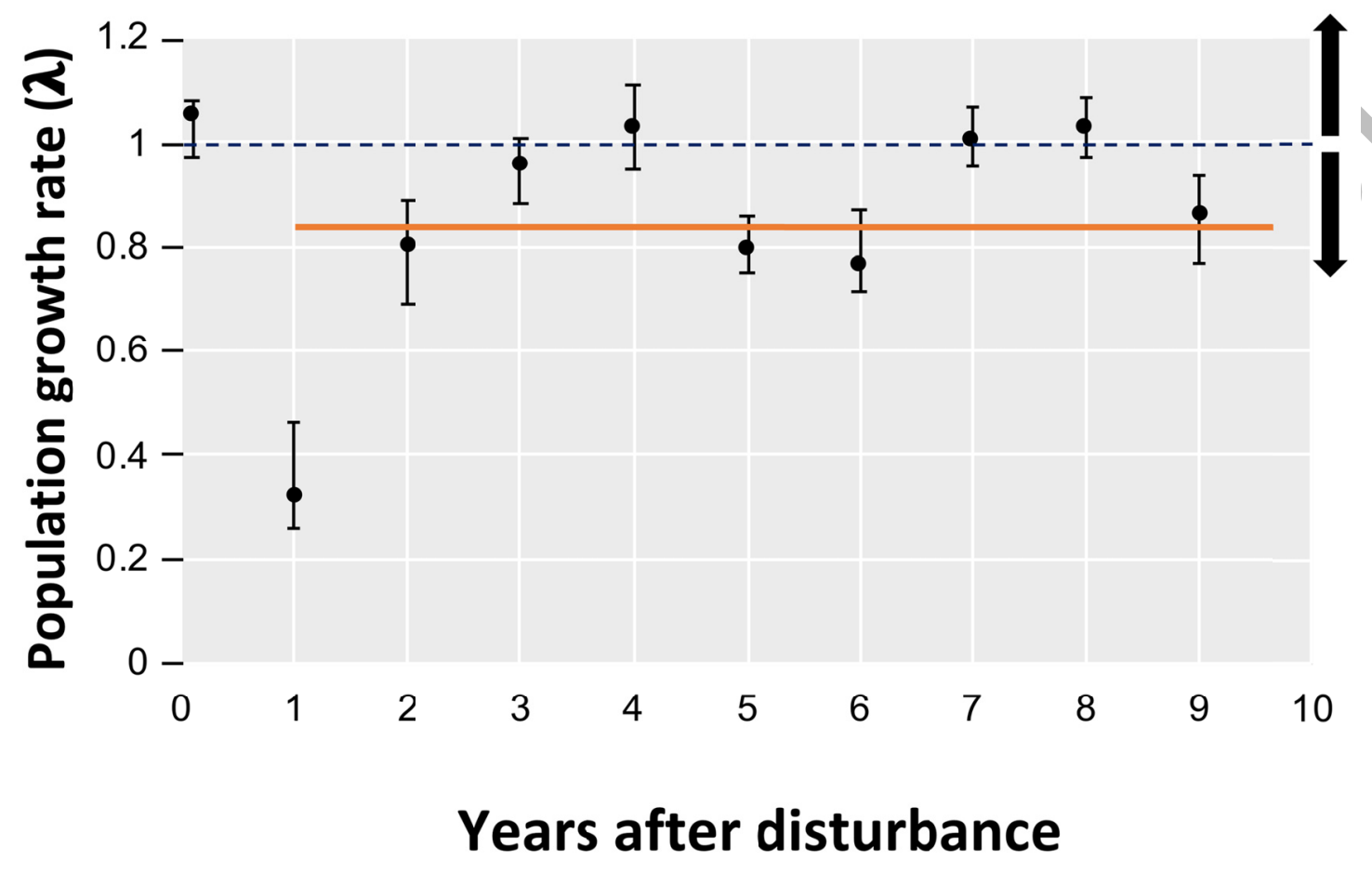


Figure S3. Transient dynamics for Encyclia bocourtii population in 10-years of monitoring. For each period the upper panel shows the absolute population dynamics for E. bocourtii, including both transient and asymptotic influences, and the lower panel presents the standardized transient dynamics, excluding the influence of asymptotic growth for $E$. bocourtii. The orange lines represent the yearly trajectories initiated with the actual size-structure at a total density of 1 , the black lines represent the trajectories initiated with the stable size-structure, and the blue and red lines represent the trajectories initiated with a biased size-structure with only small plants (foliar area $<10 \mathrm{~cm}^{2}$ ) and big plants (foliar area $>100 \mathrm{~cm}^{2}$ ) respectively.

Period 2003-2004 

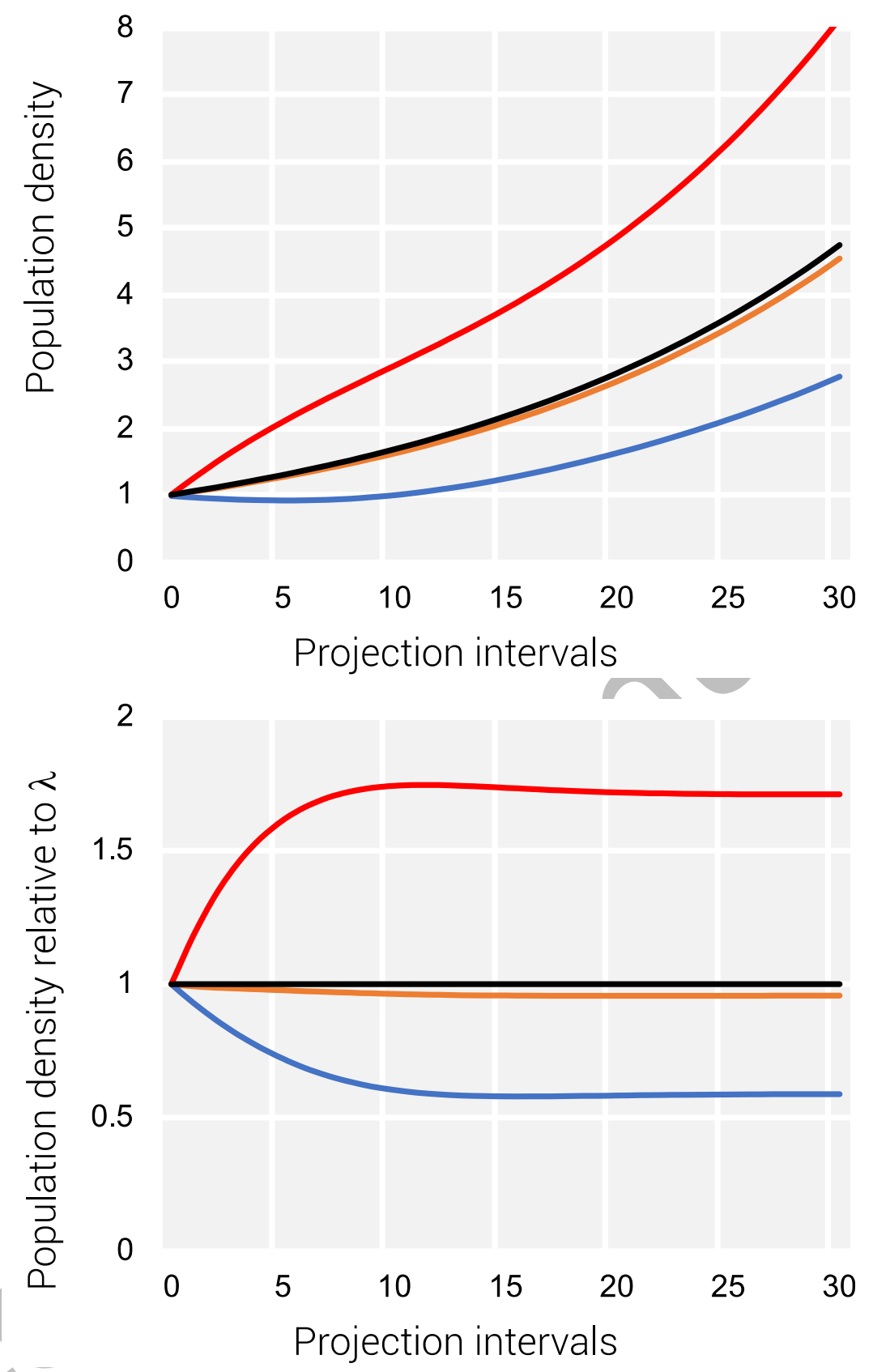
Figure S3 (cont.) Period 2004-2005
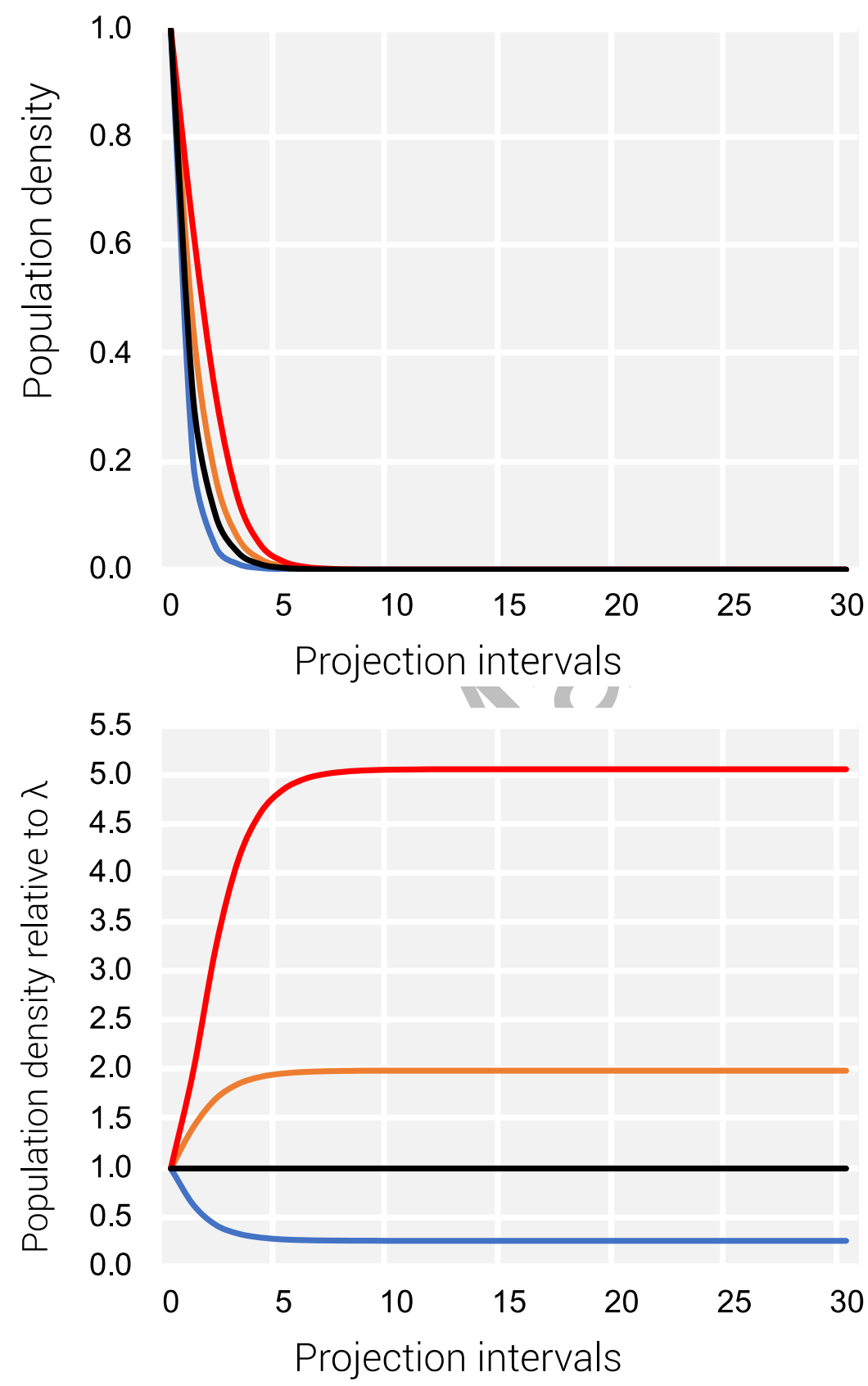
Figure S4 (cont.) Period 2005-2006
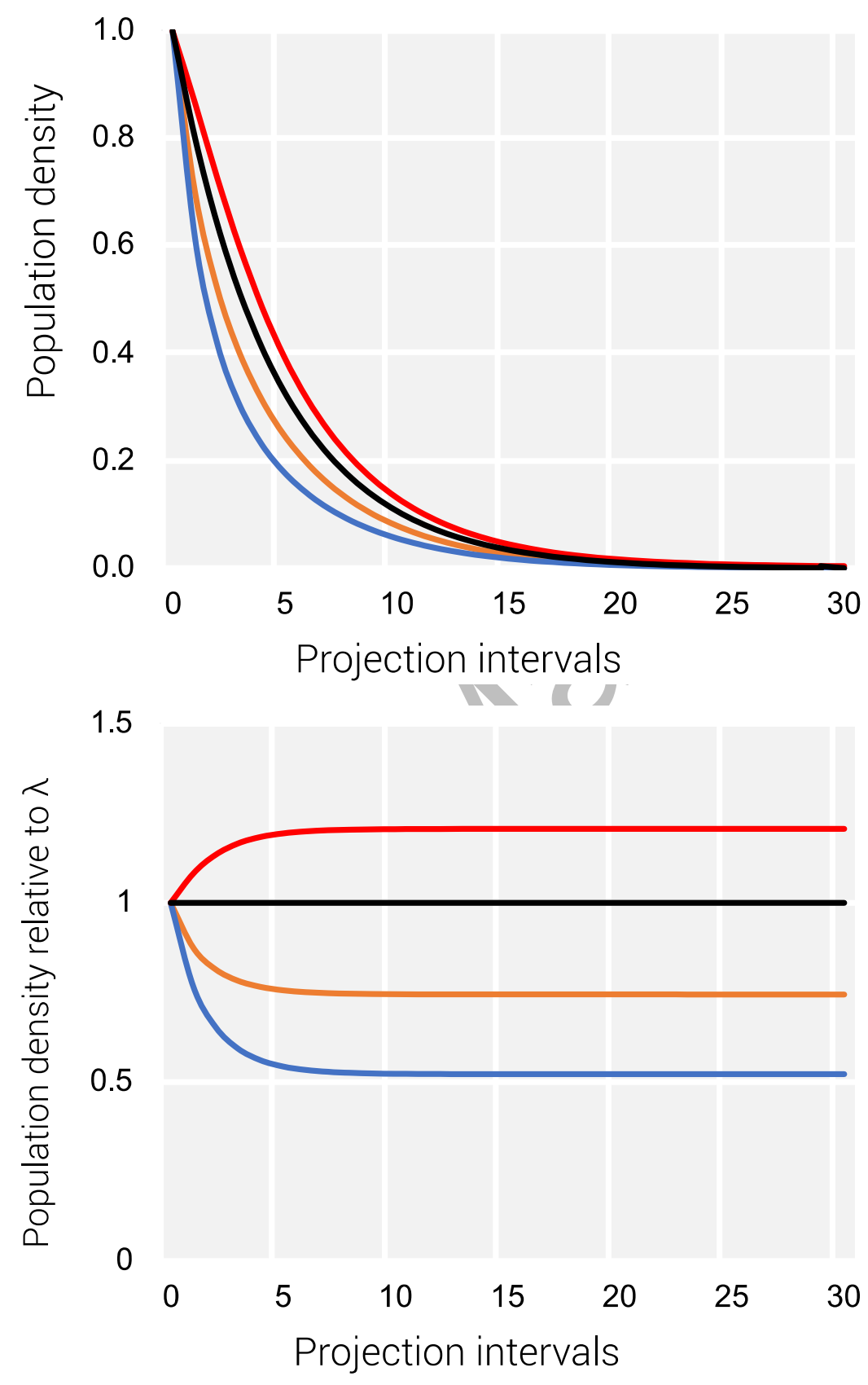
Figure S3 (cont.) Period 2006-2007
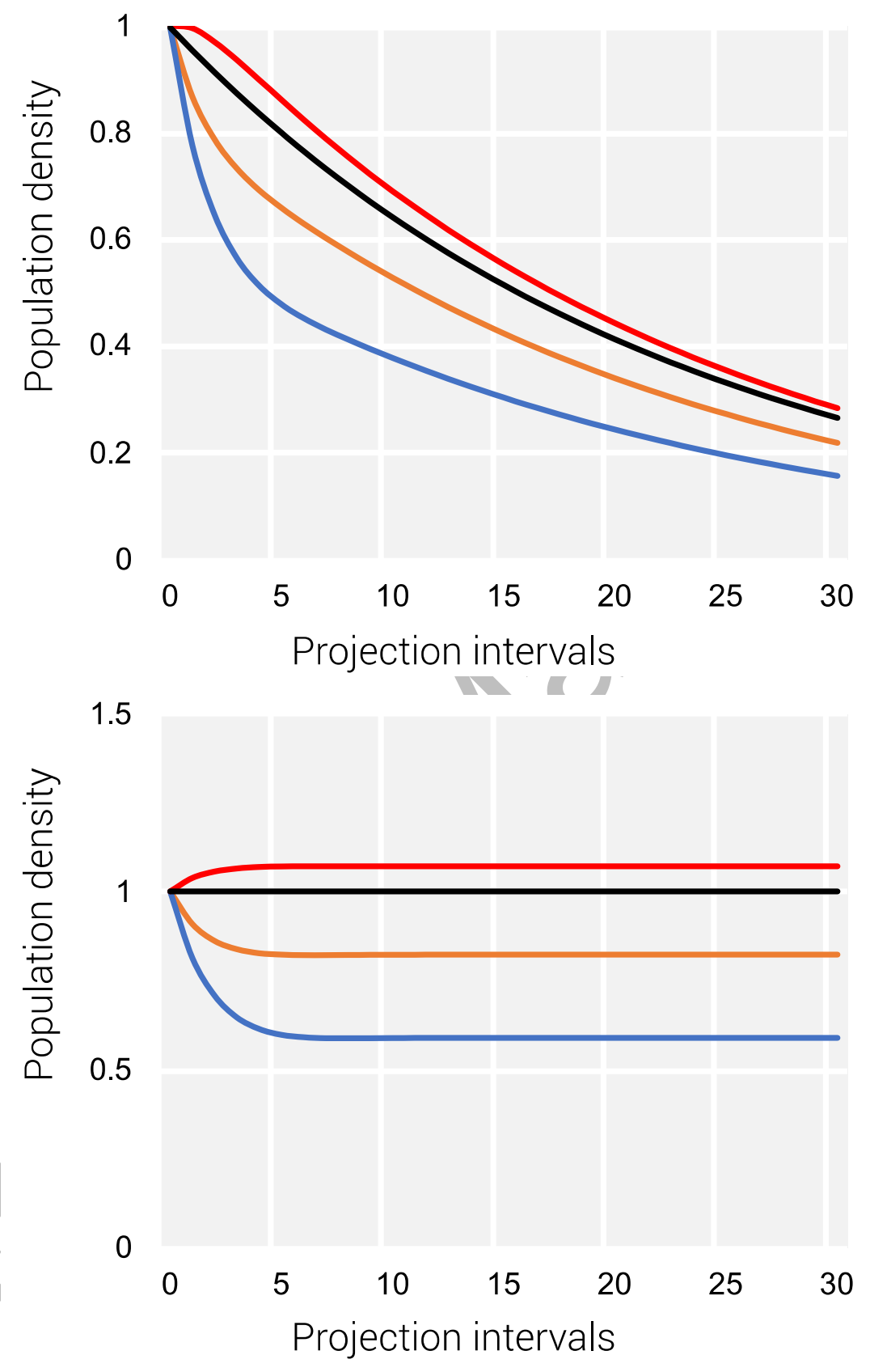
Figure S3 (cont.) Period 2007-2008
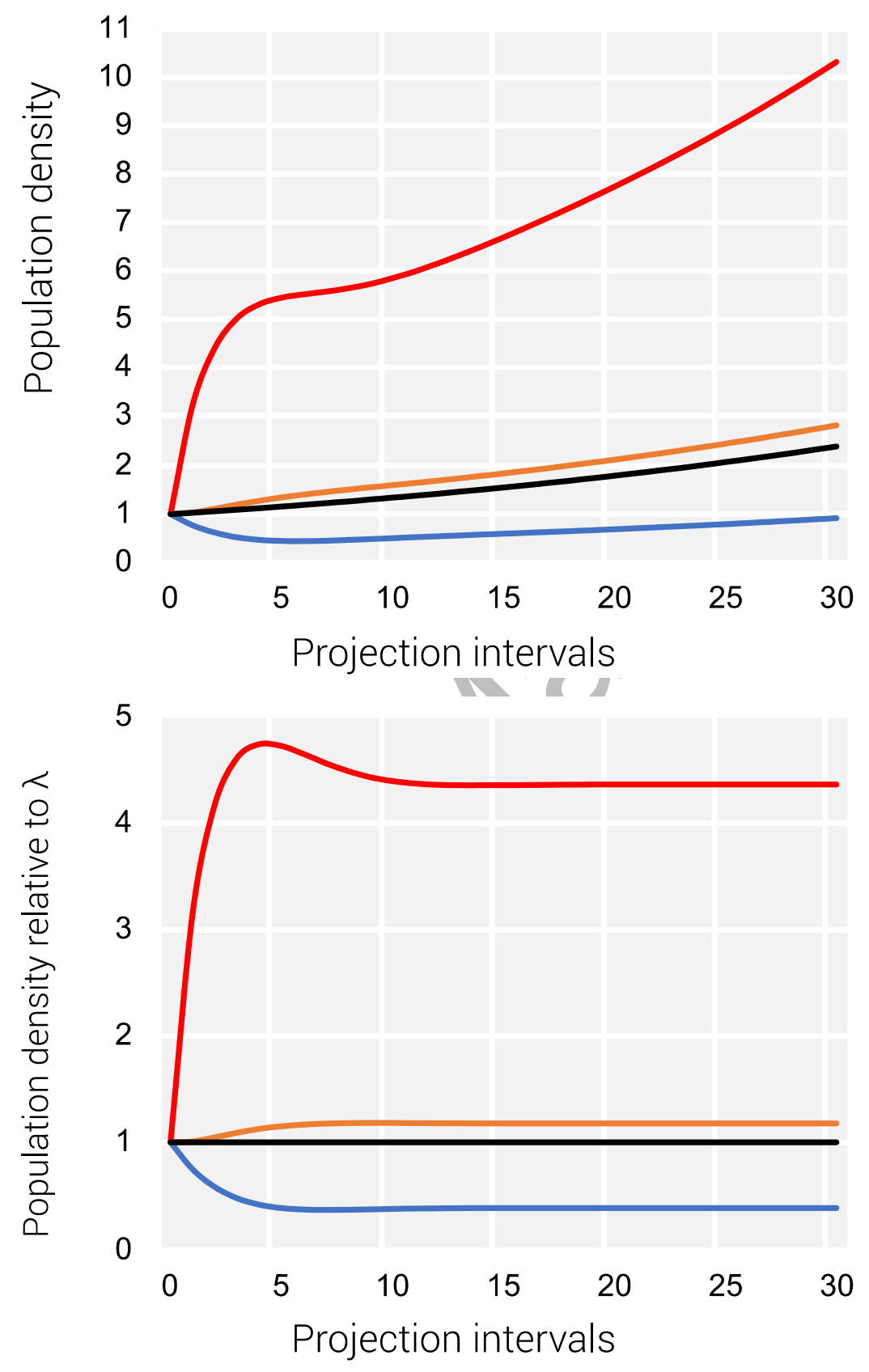
Figure S3 (cont.) Period 2008-2009
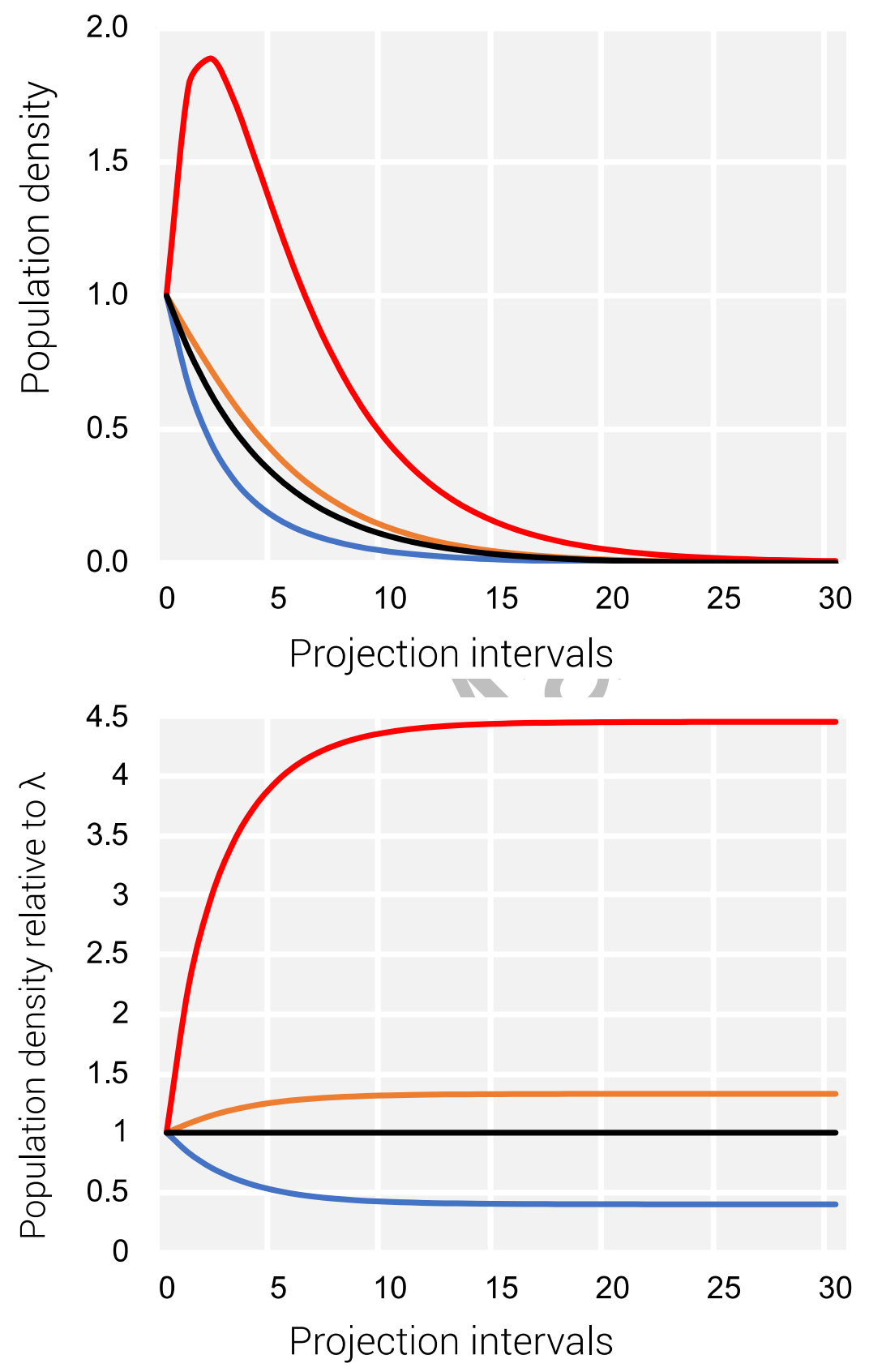
Figure S3 (cont.) Period 2009-2010
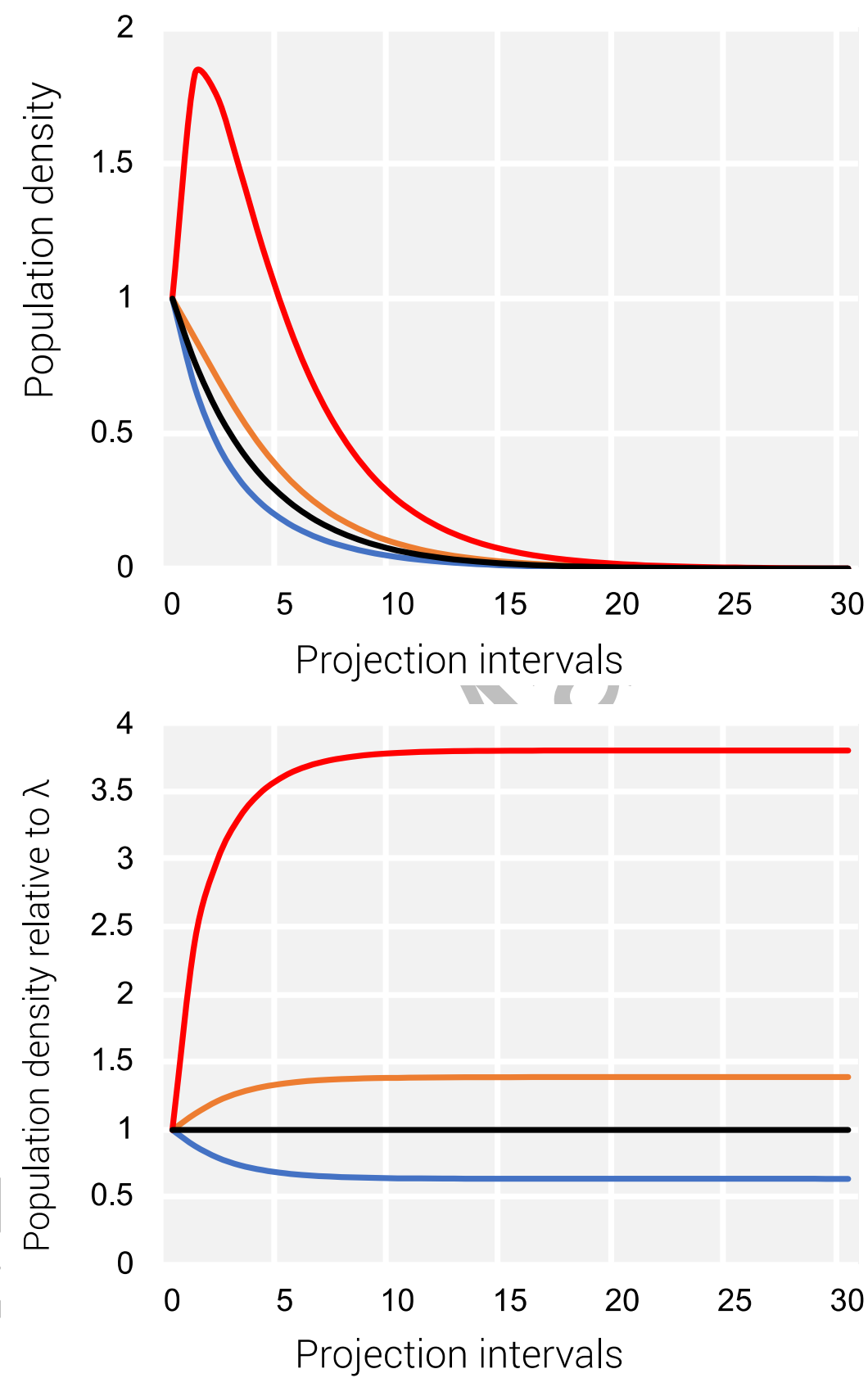
Figure S3 (cont.) Period 2010-2011
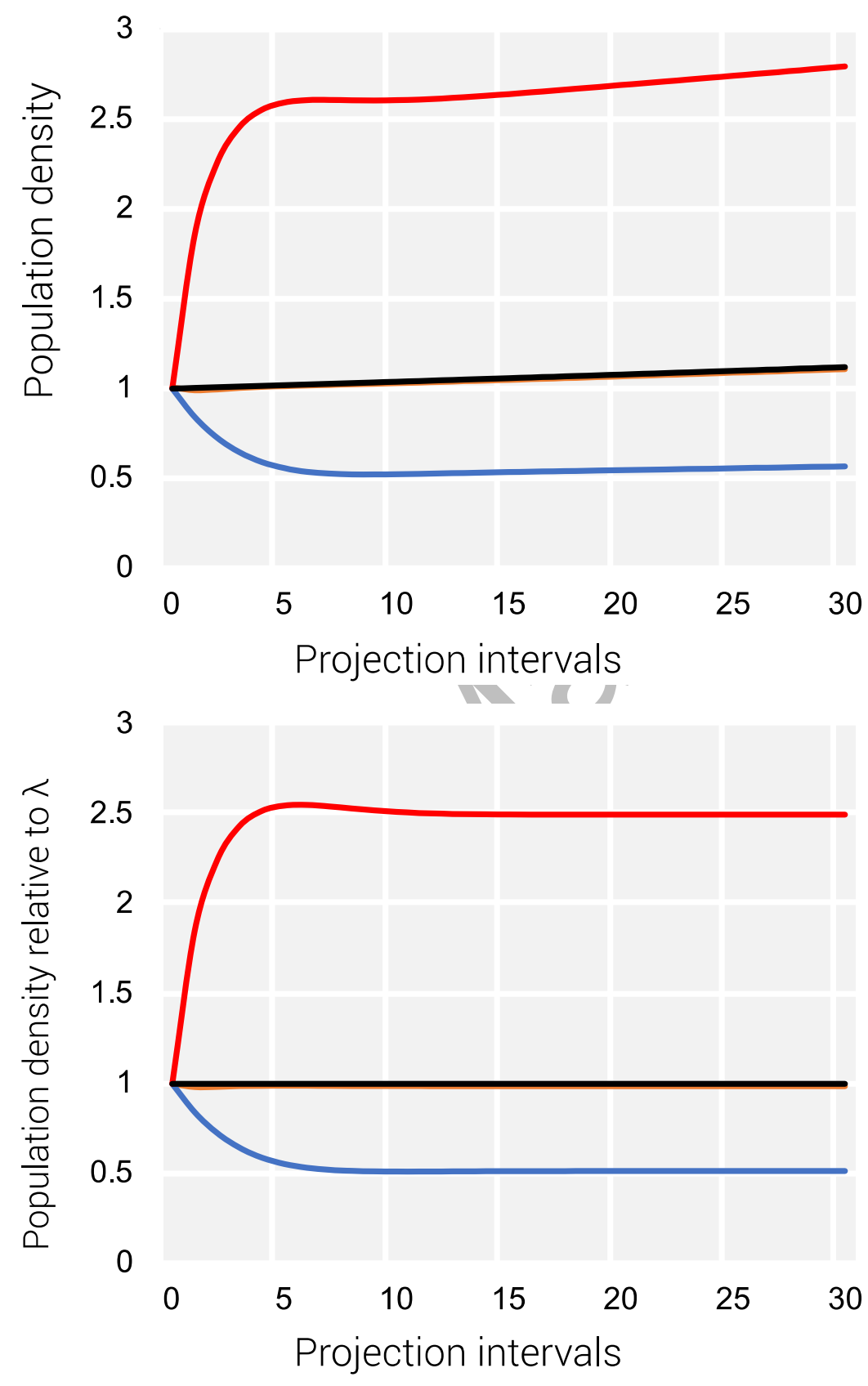
Figure S3 (cont.) Period 2011-2012
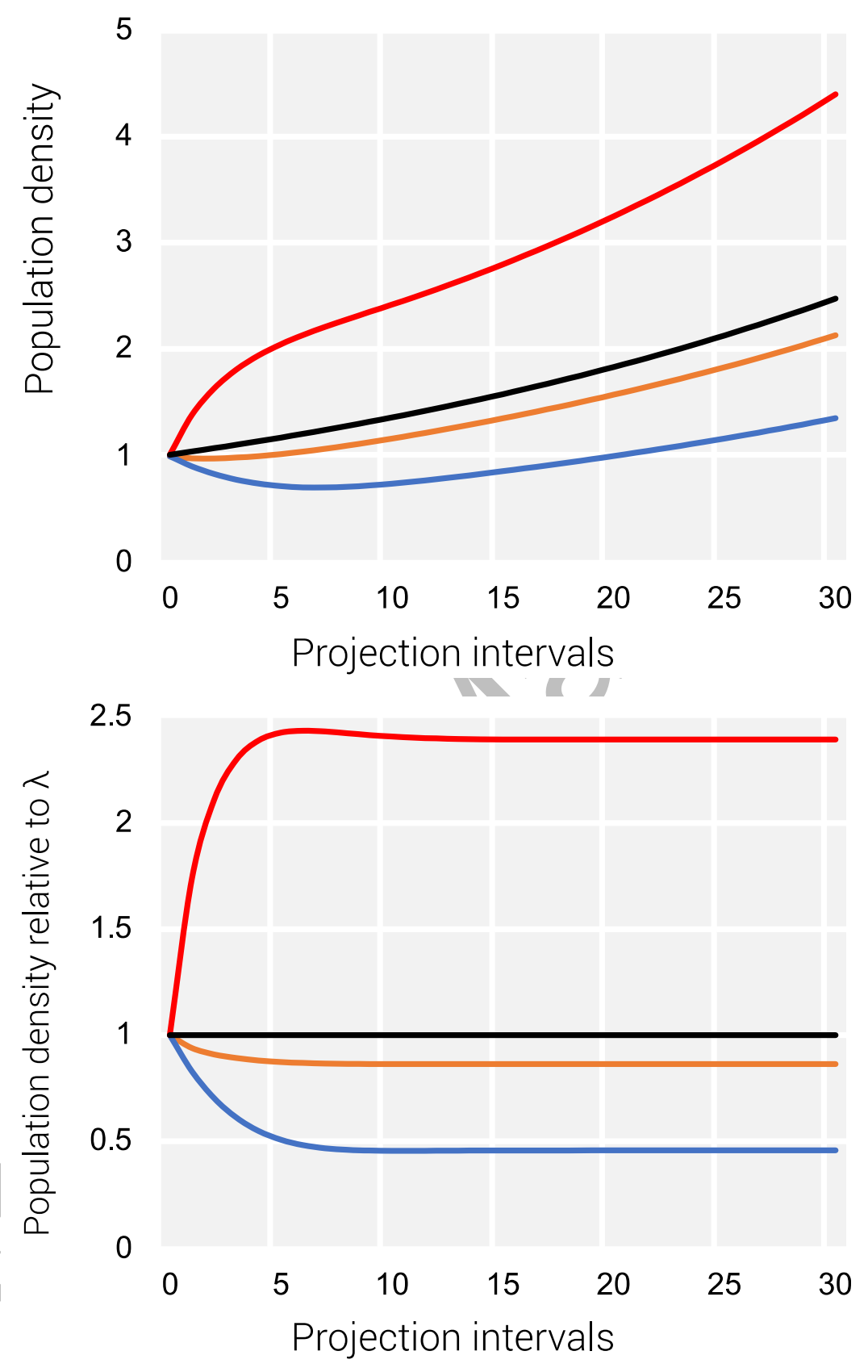
Figure S3 (cont.) Period 2012-2013
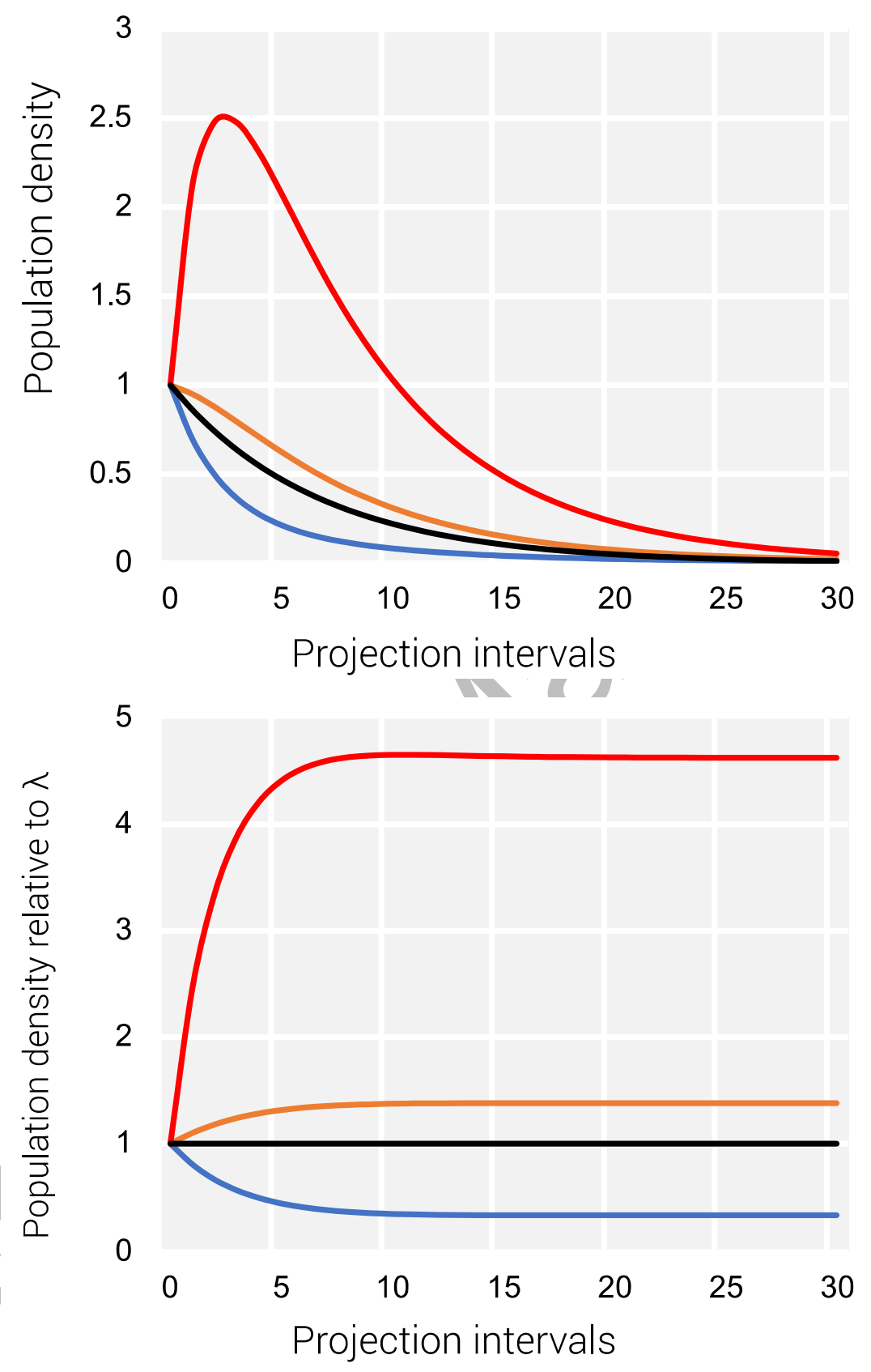
Figure S4. Multiplot of transfer functions for inertia for the annual periods between 2007-2012. The layout of the multiplot corresponds with the layout of each section on the kernel-matrix. Each graph represents the effect of change in inertia $\left(\rho_{\infty}\right)$ as a general function of change in demographic parameters of one section while holding the other parameters constant. Period 2012-2013 can be consulted in the main text of the paper.

\section{Period 2003-2004}
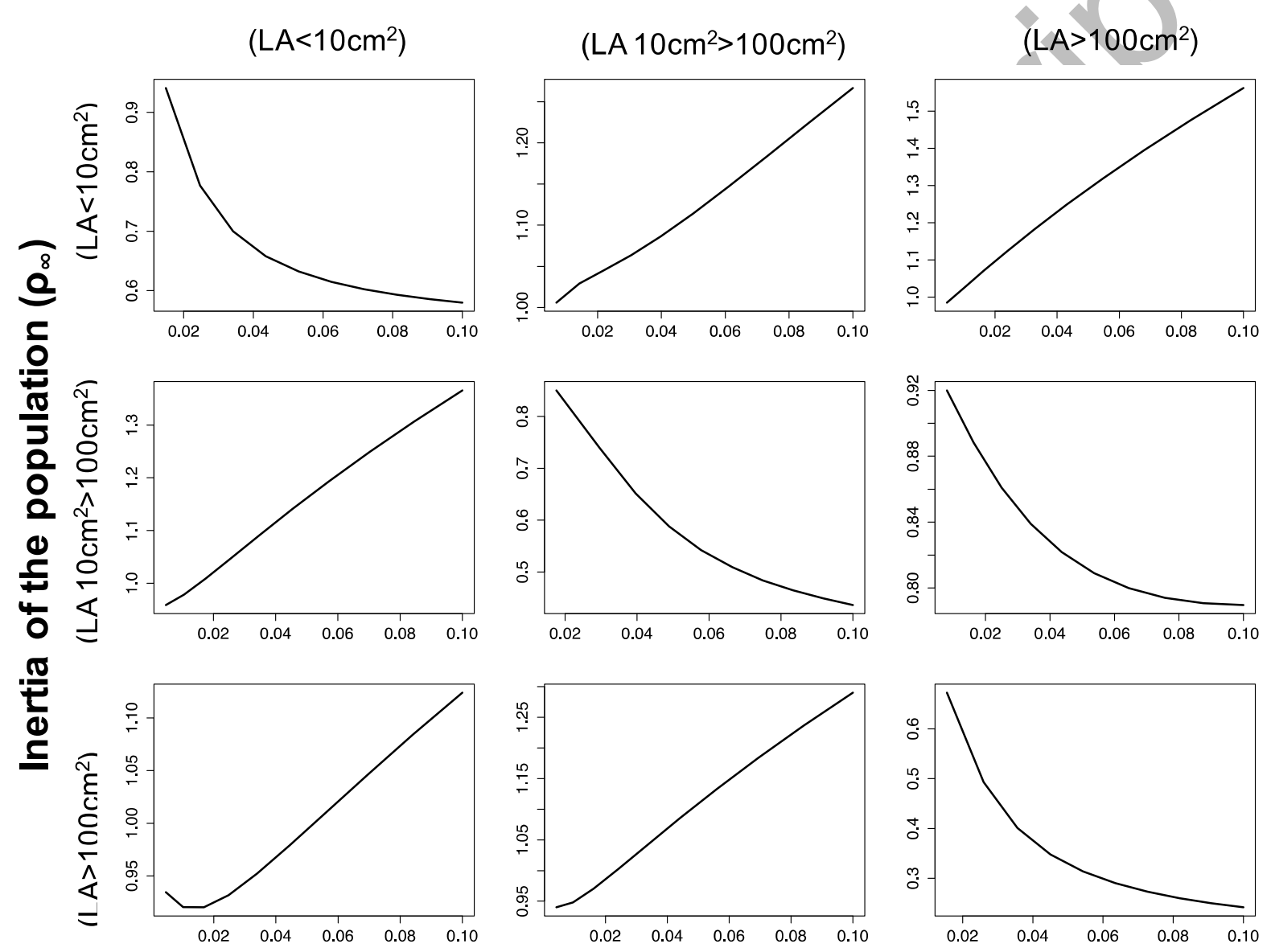

Perturbation magnitude (p) 
Figure S4 (cont.) Period 2004-2005
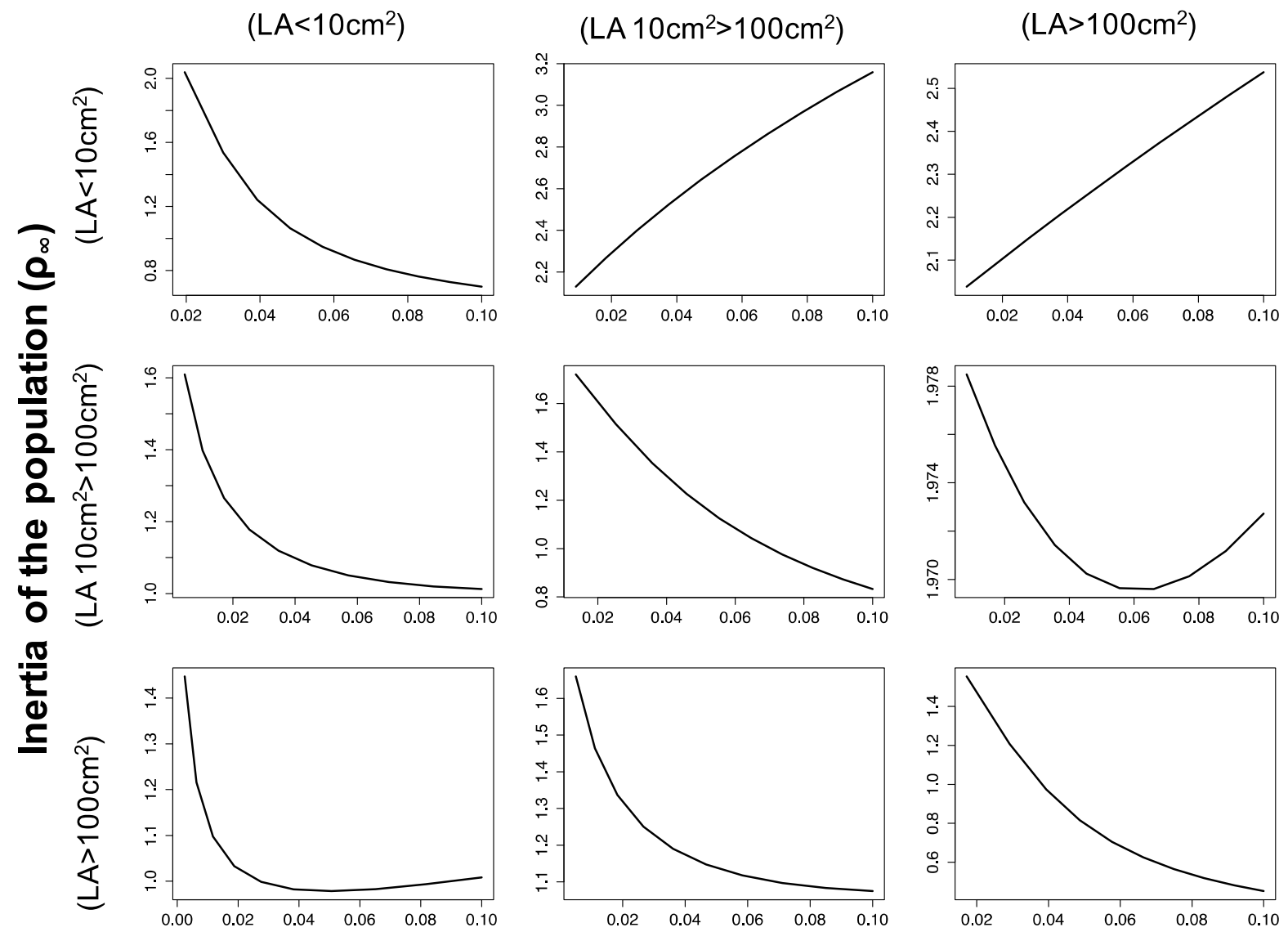

\section{Perturbation magnitude (p)}


Figure S4 (cont.) Period 2005-2006
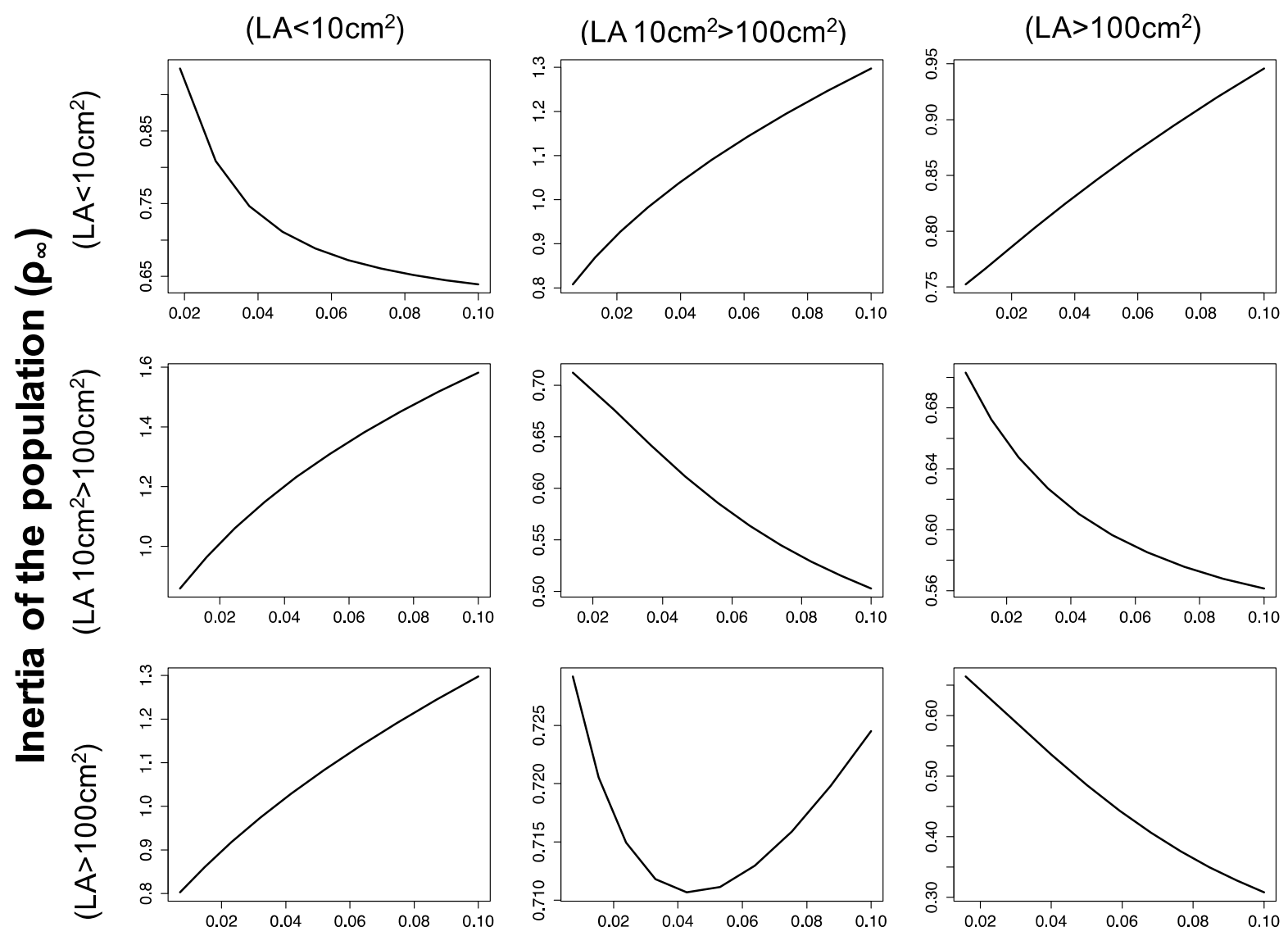

Perturbation magnitude (p) 
Figure S4 (cont.) Period 2006-2007
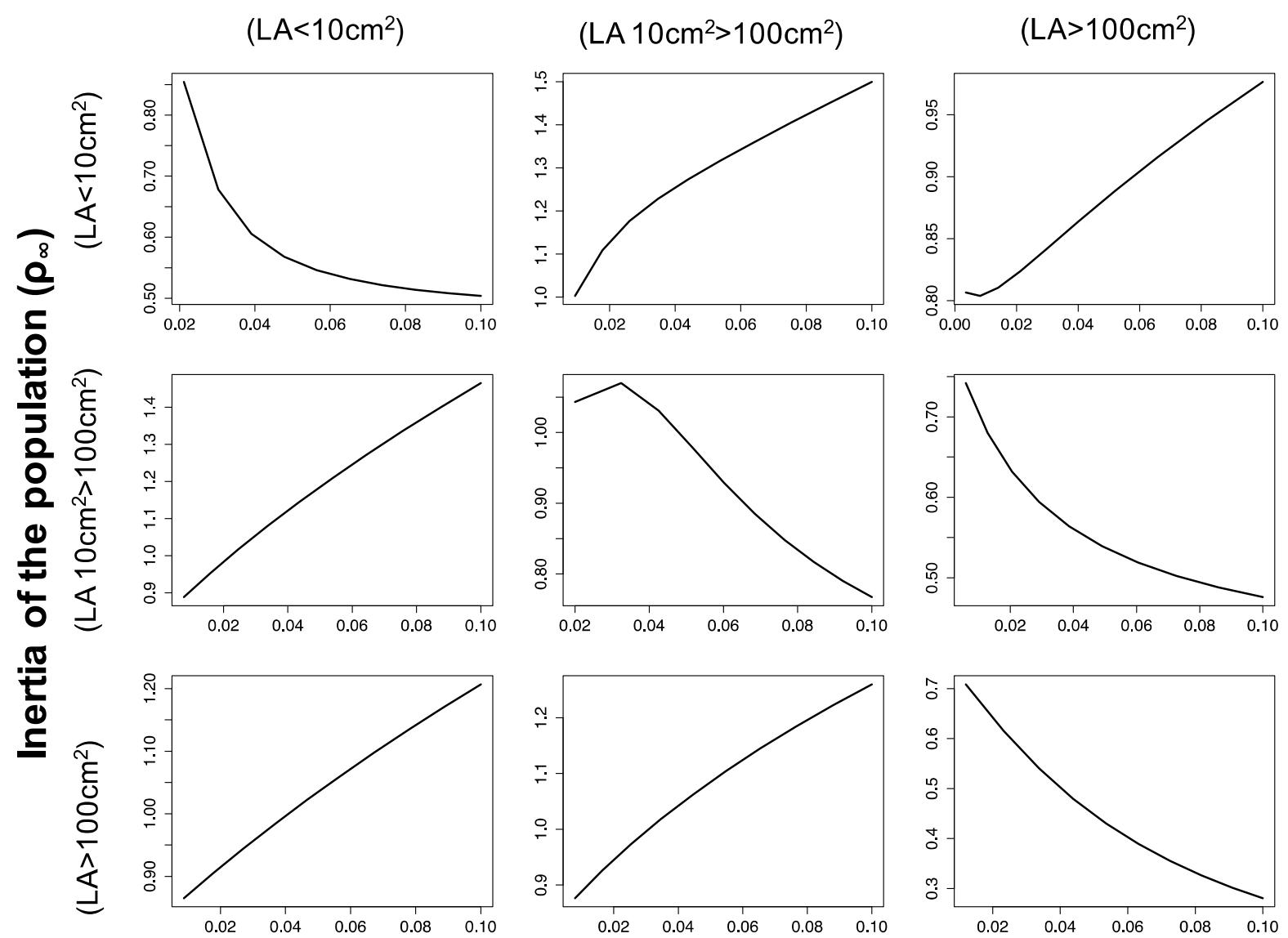

Perturbation magnitude (p) 
Figure S4 (cont.) Period 2007-2008
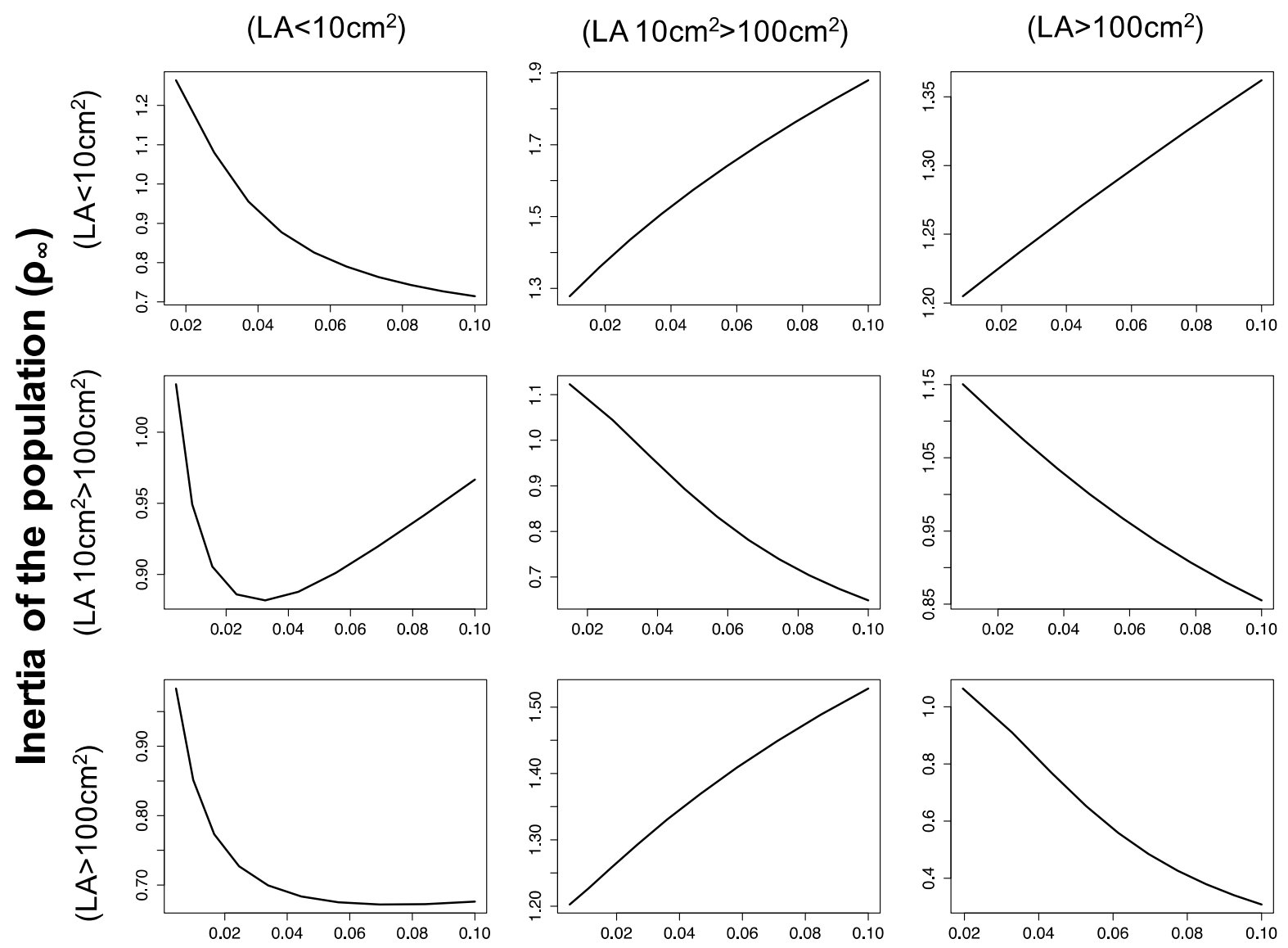

Perturbation magnitude (p) 
Figure S4 (cont.) Period 2008-2009
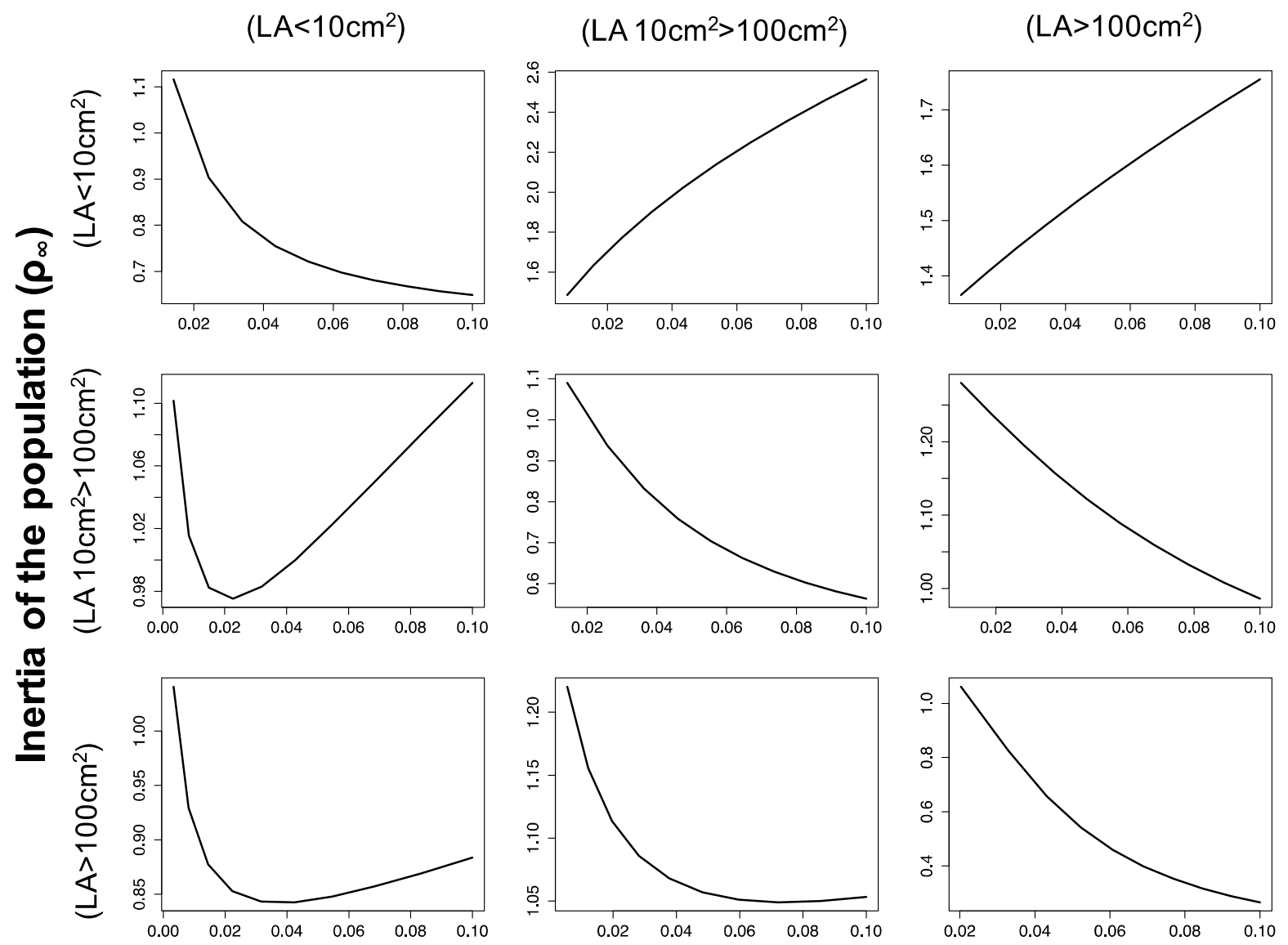

Perturbation magnitude (p) 
Figure S4 (cont.) Period 2009-2010
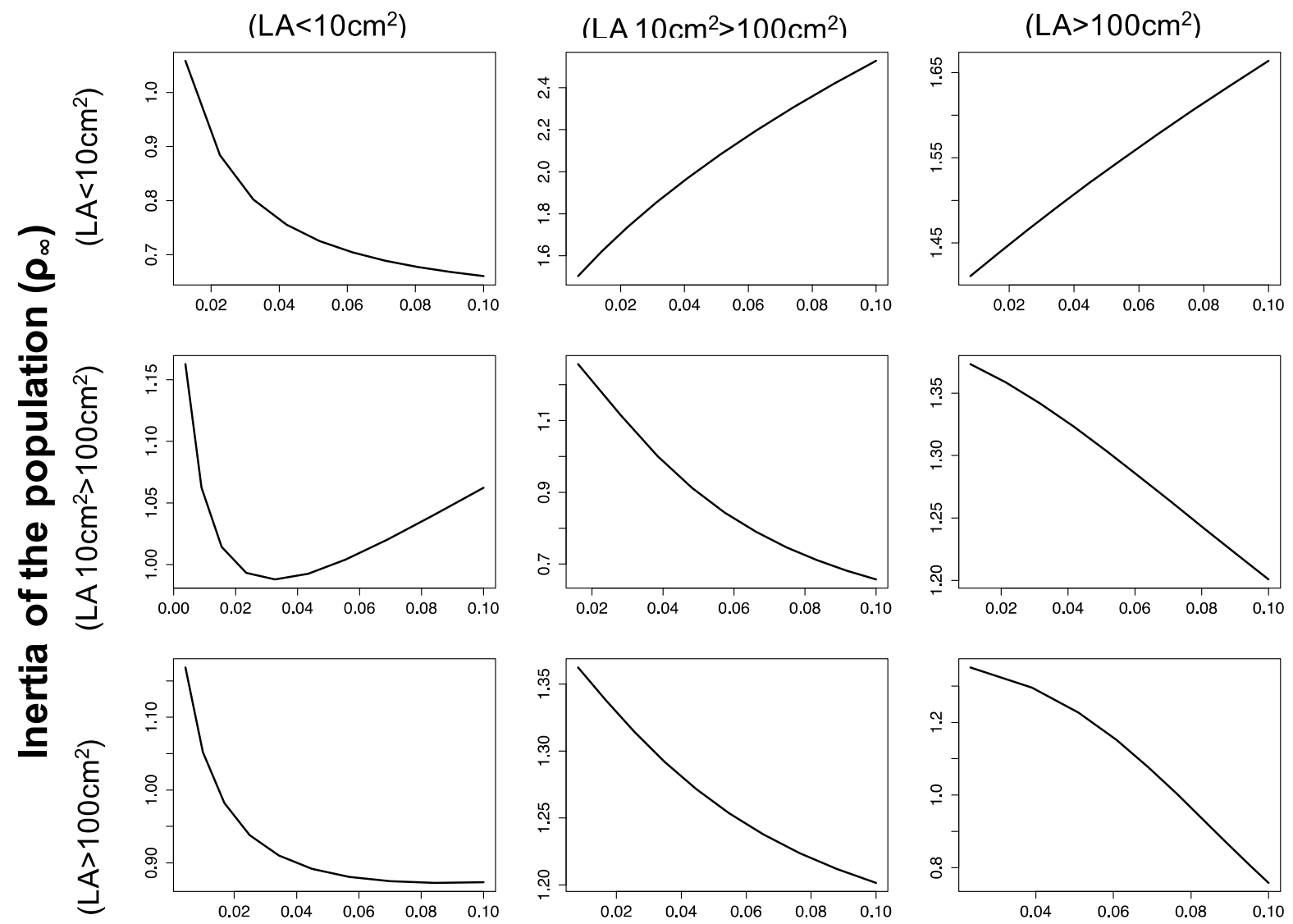

Perturbation magnitude (p) 
Figure S4 (cont.) Period 2010-2011
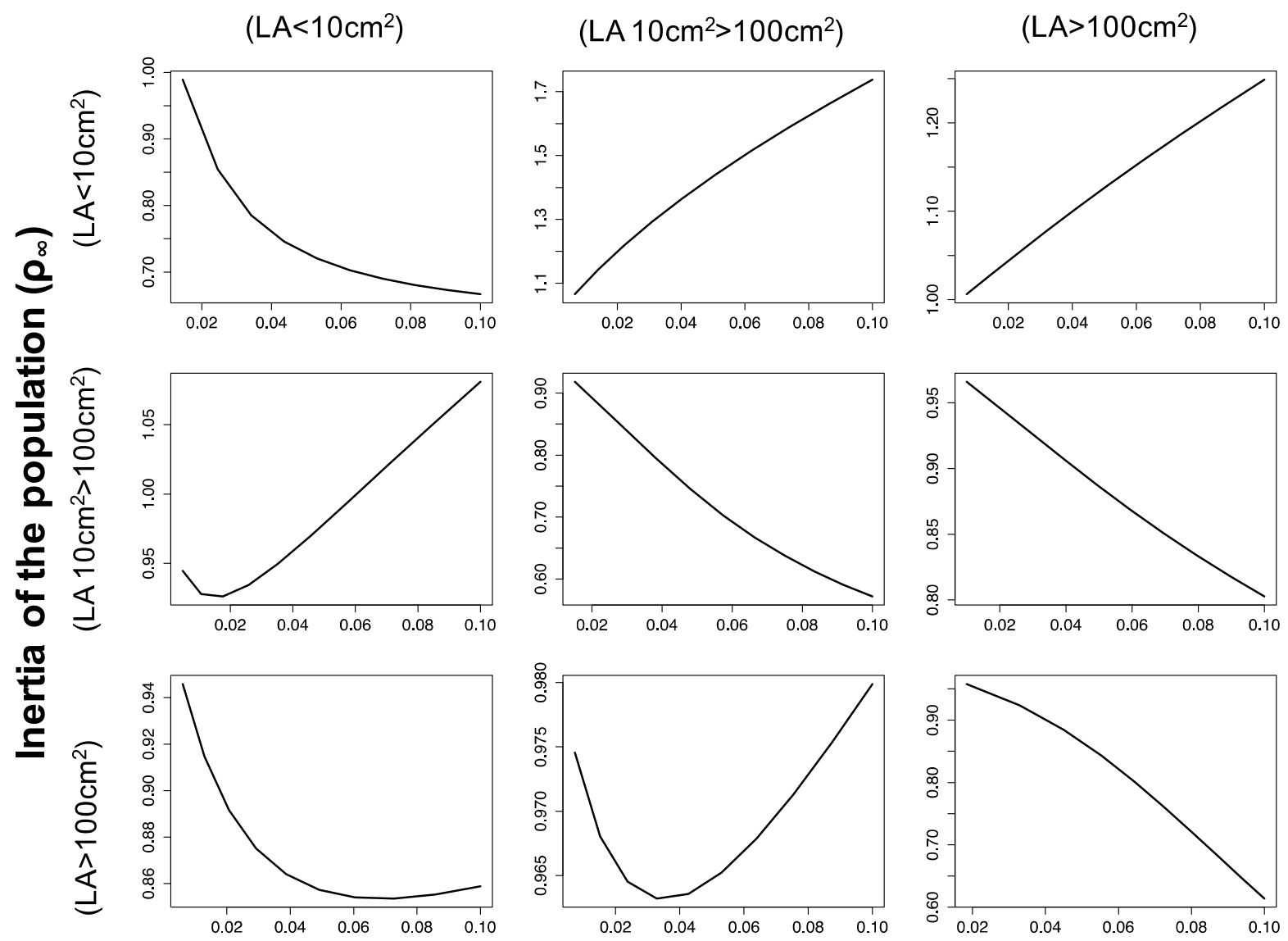

\section{Perturbation magnitude (p)}


Figure S4 (cont.) Period 2011-2012
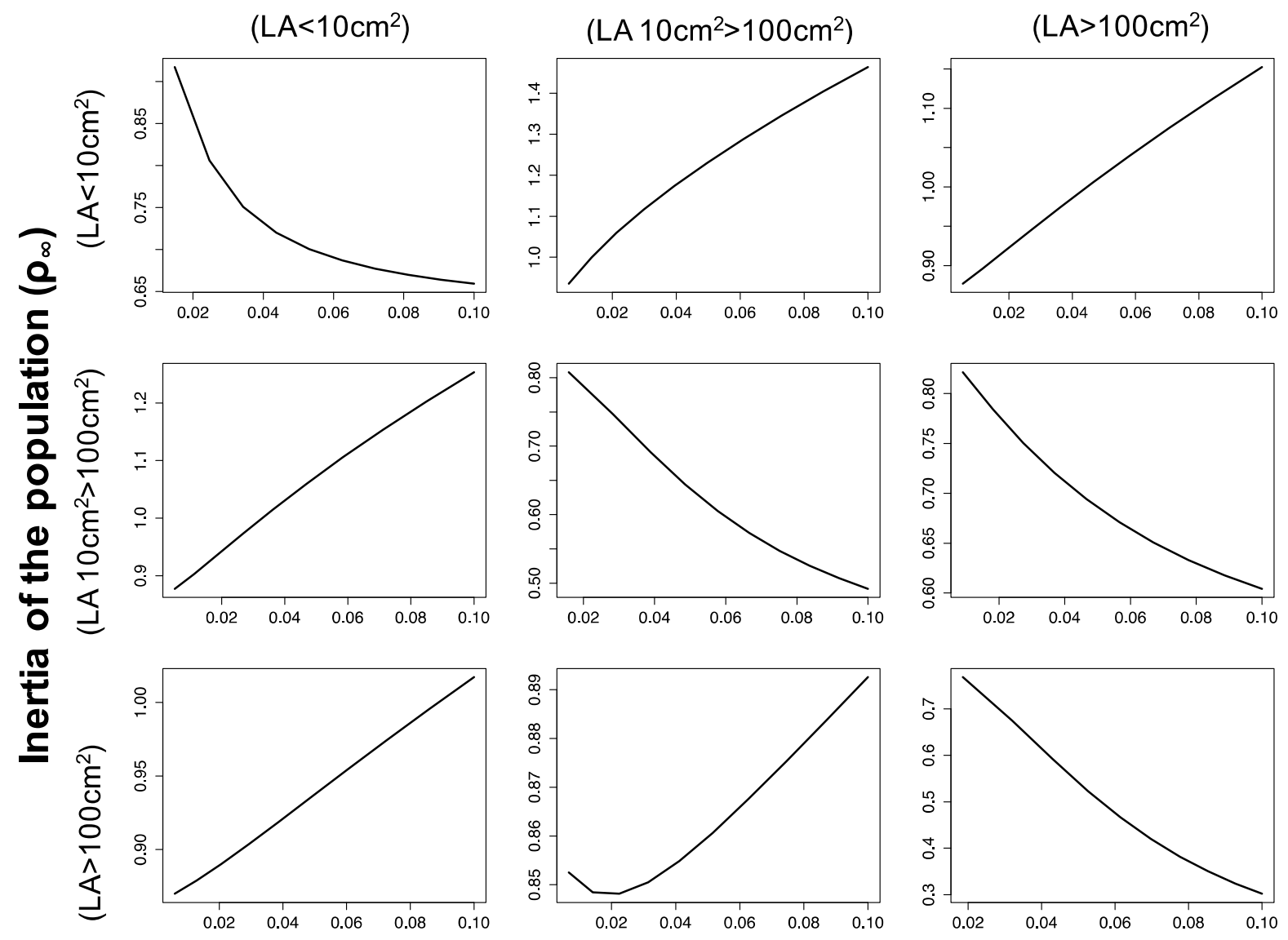

Perturbation magnitude (p) 
Fig S5. Multiplot of transfer functions for population growth rate $(\lambda)$ for the annual periods between 2003-2013. The layout of the multiplot corresponds with the layout of each section on the kernelmatrix. Each graph represents the effect of change in $\lambda$ as a general function of change in demographic parameters of one section while holding the other parameters constant. Period 20122013 can be consulted in the main text of the paper.

\section{Period 2003-2004}

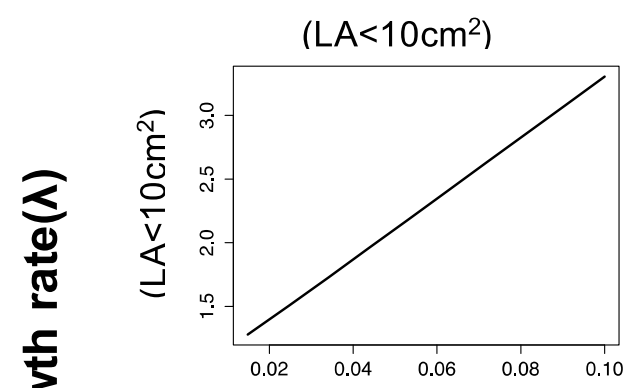

\section{$\left(\mathrm{LA} 10 \mathrm{~cm}^{2}>100 \mathrm{~cm}^{2}\right)$}
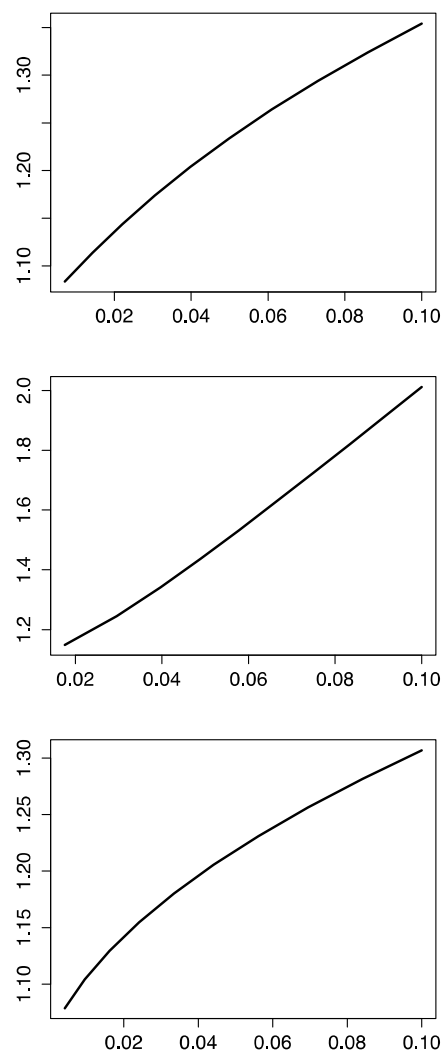

$\left(\mathrm{LA}>100 \mathrm{~cm}^{2}\right)$
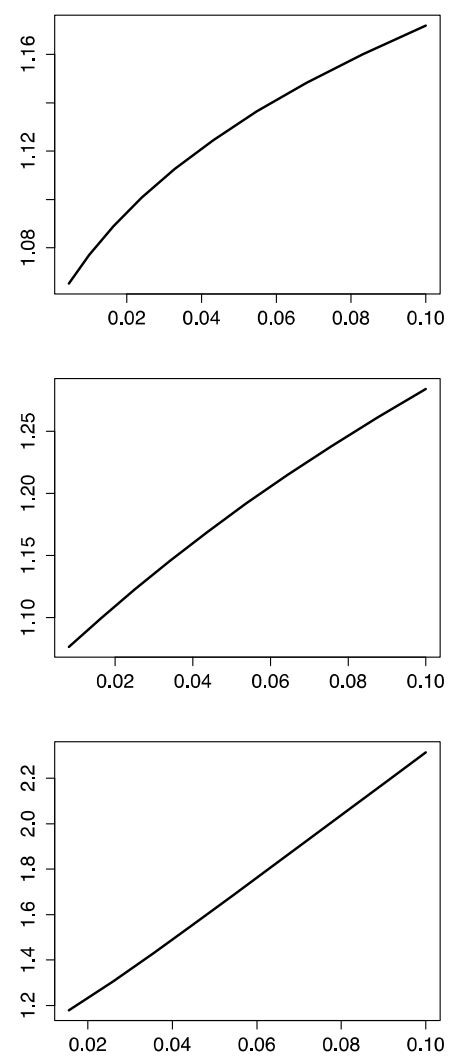

Perturbation magnitude (p) 
Figure S5 (cont.) Period 2004-2005
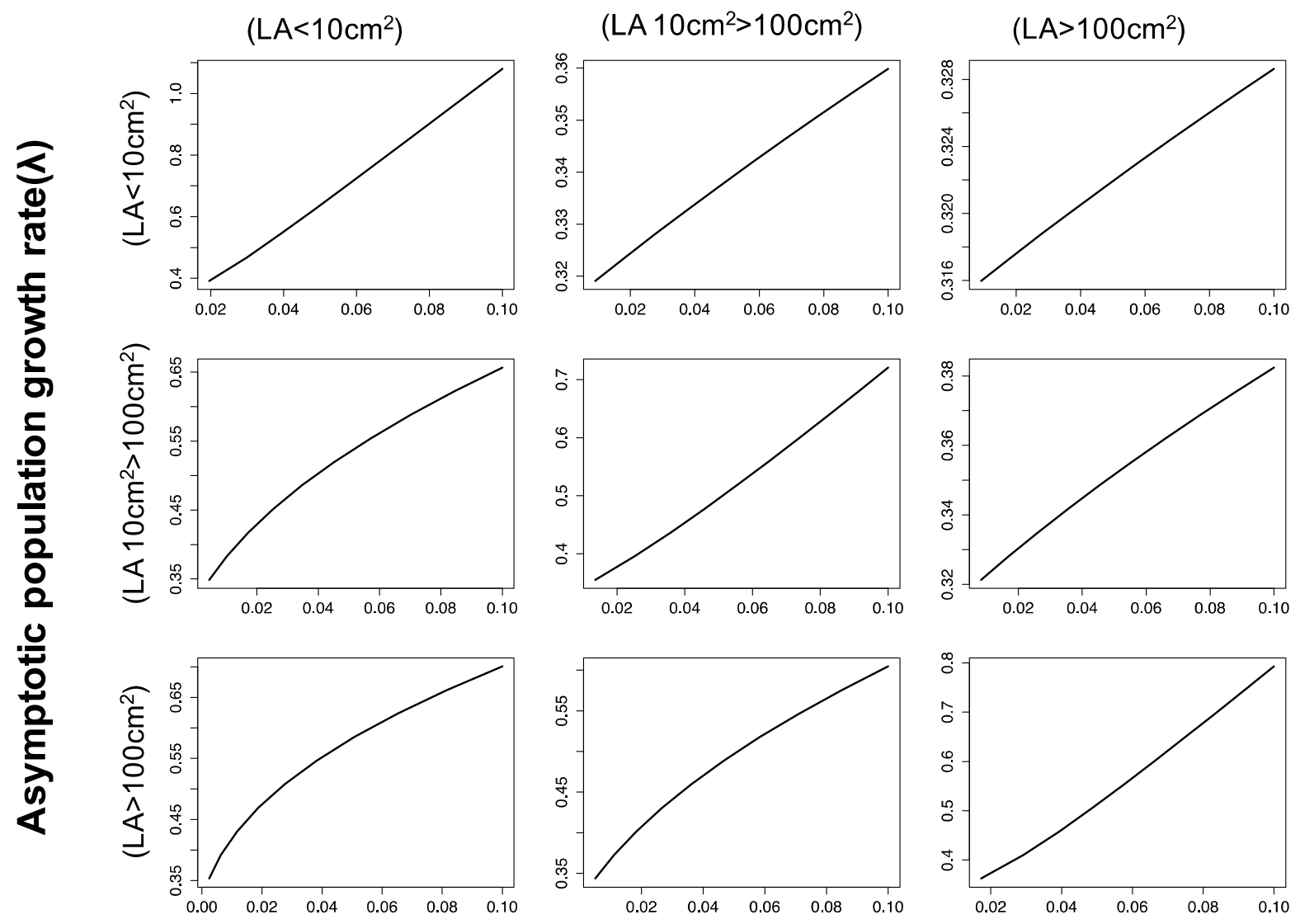

Perturbation magnitude (p) 
Figure S5 (cont.) Period 2005-2006
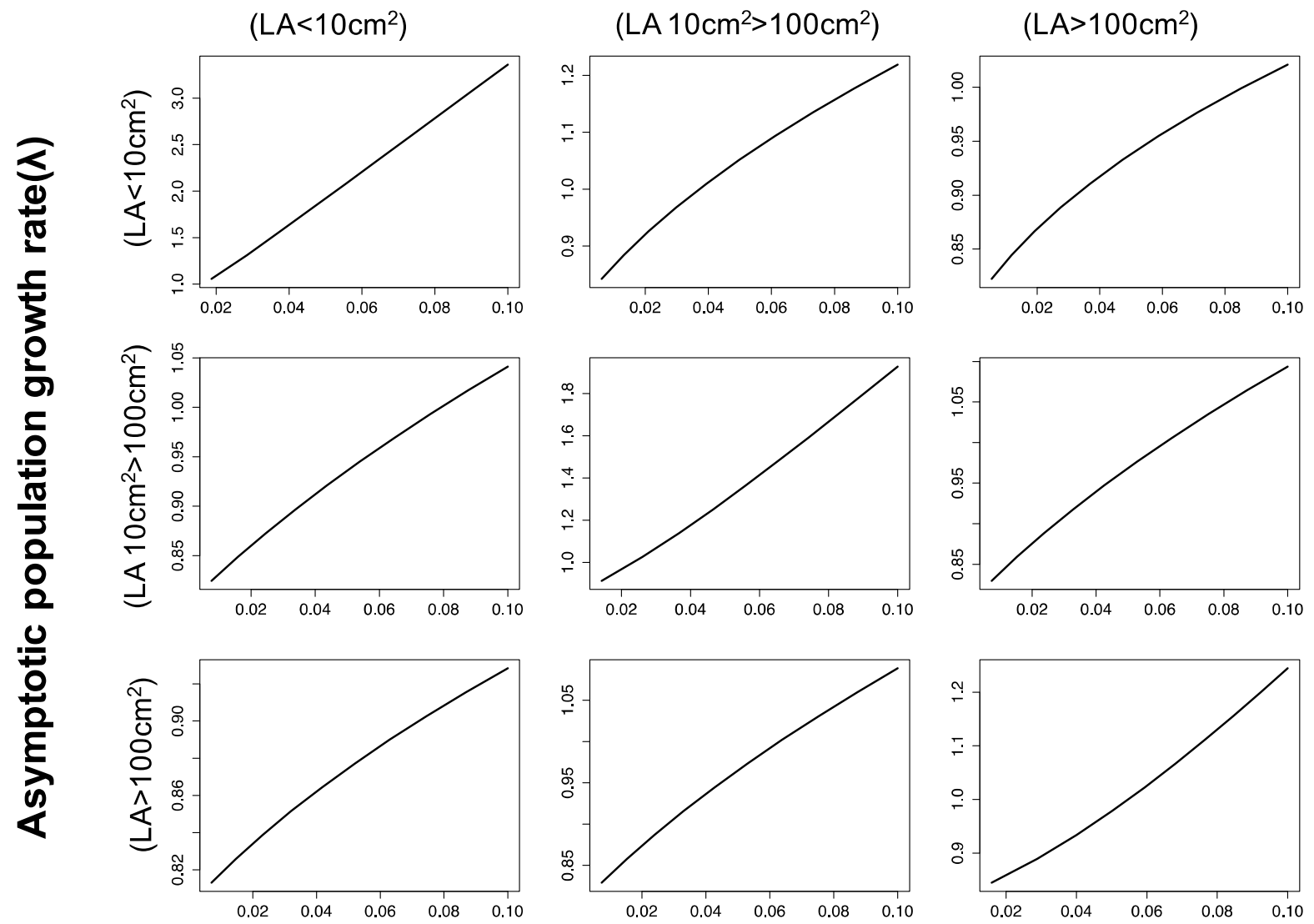

Perturbation magnitude (p) 
Figure S5 (cont.) Period 2006-2007
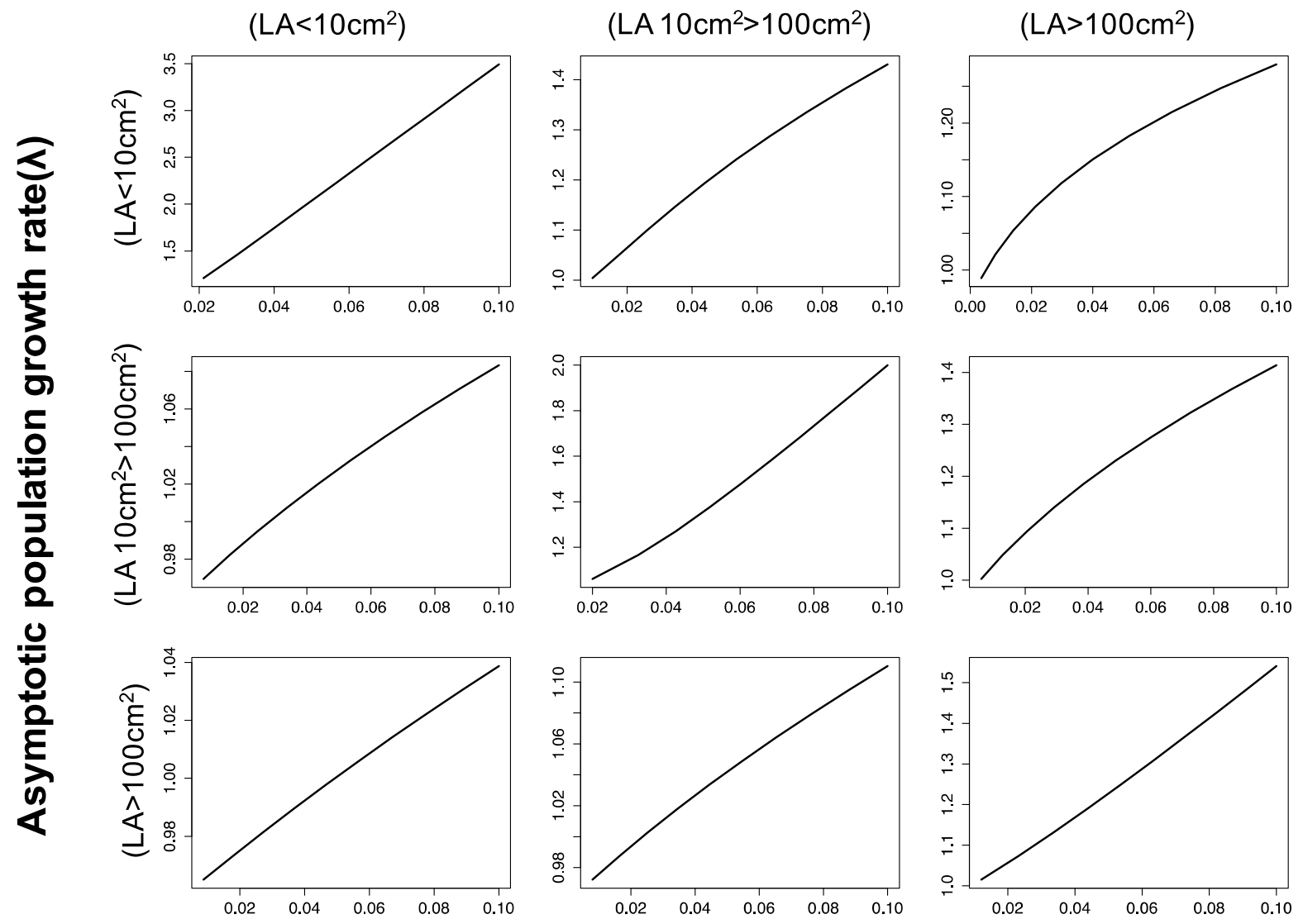

Perturbation magnitude (p) 
Figure S5 (cont.) Period 2007-2008
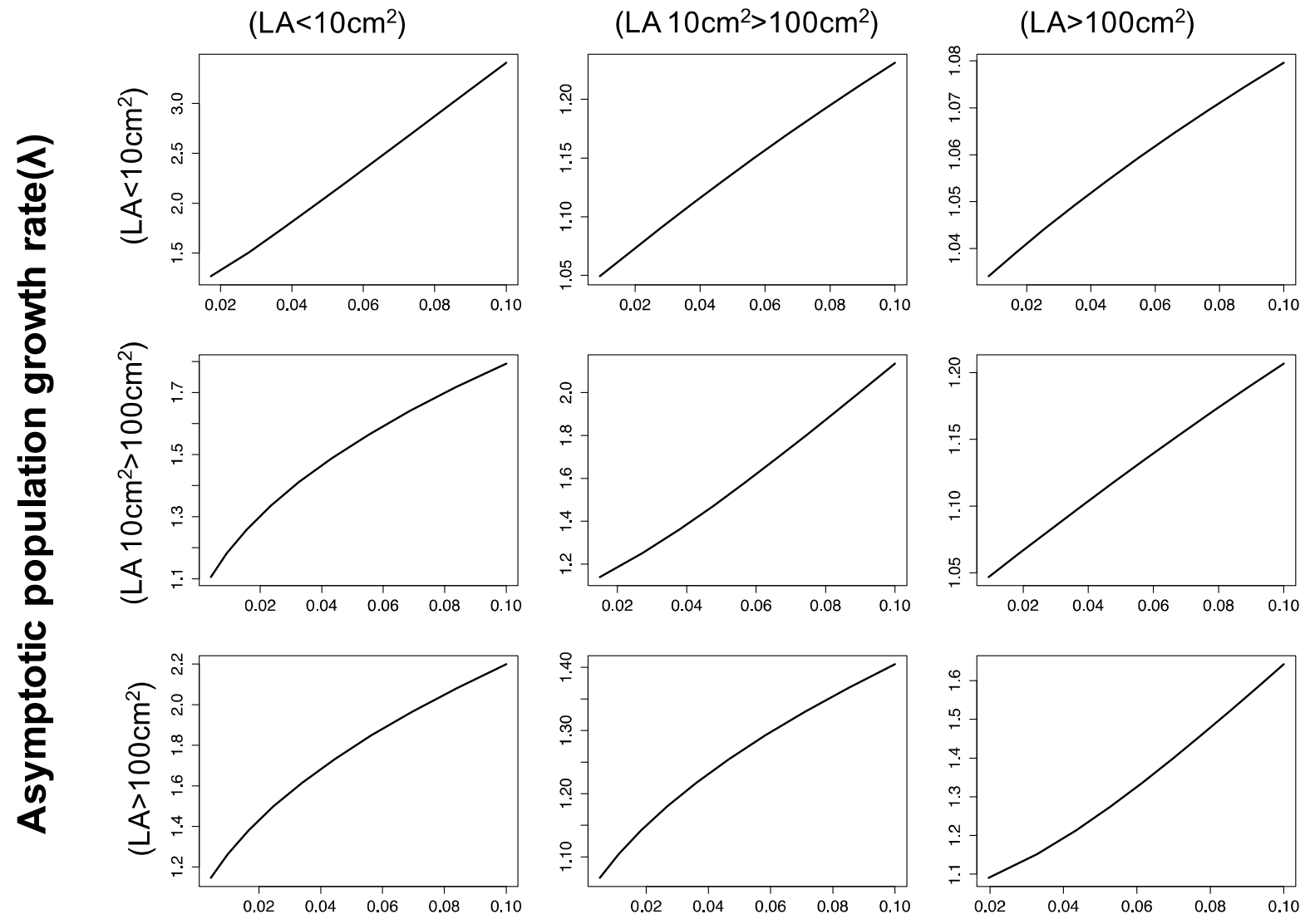

Perturbation magnitude (p) 
Figure S5 (cont.) Period 2008-2009
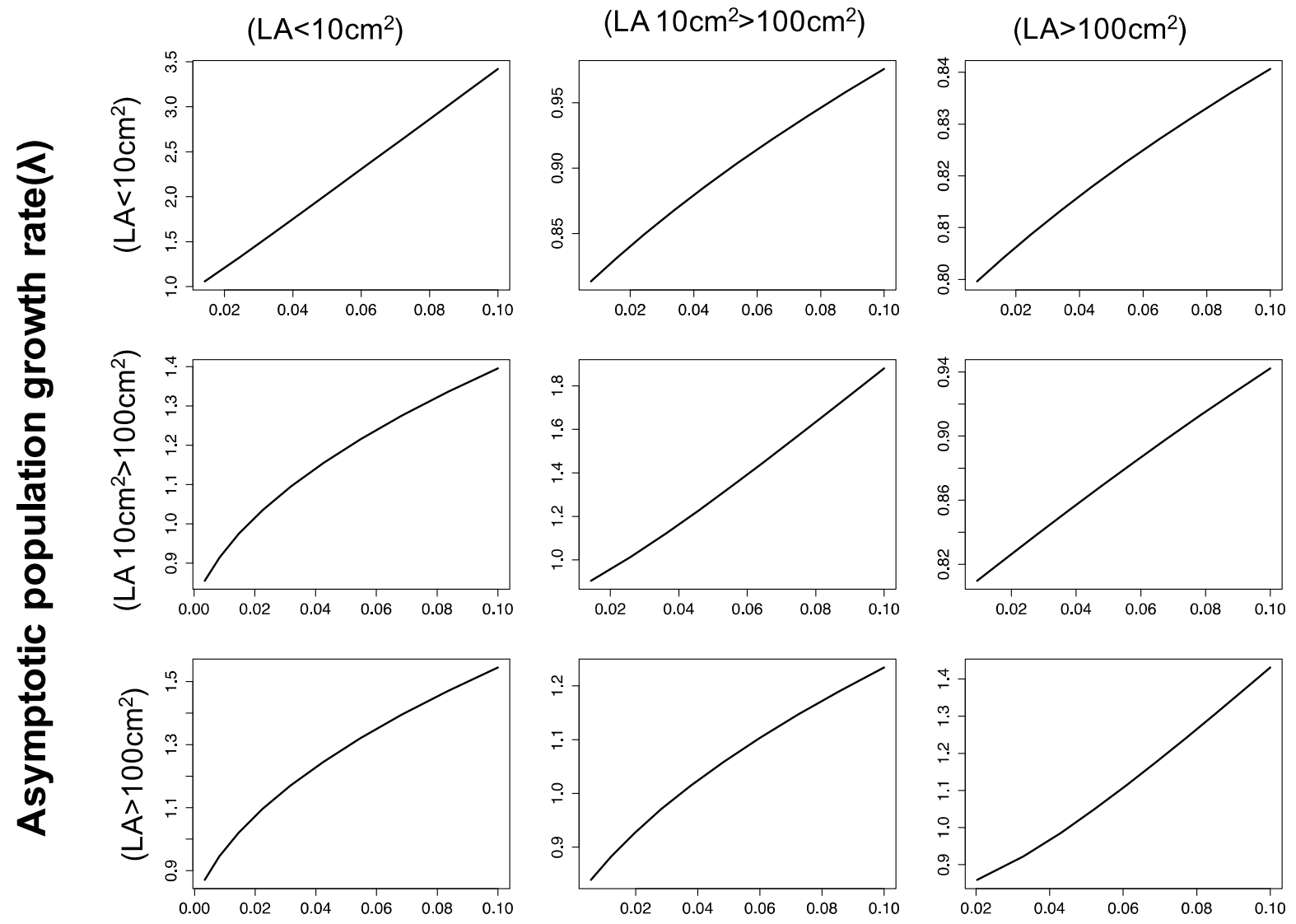

Perturbation magnitude (p) 
Figure S5 (cont.) Period 2009-2010
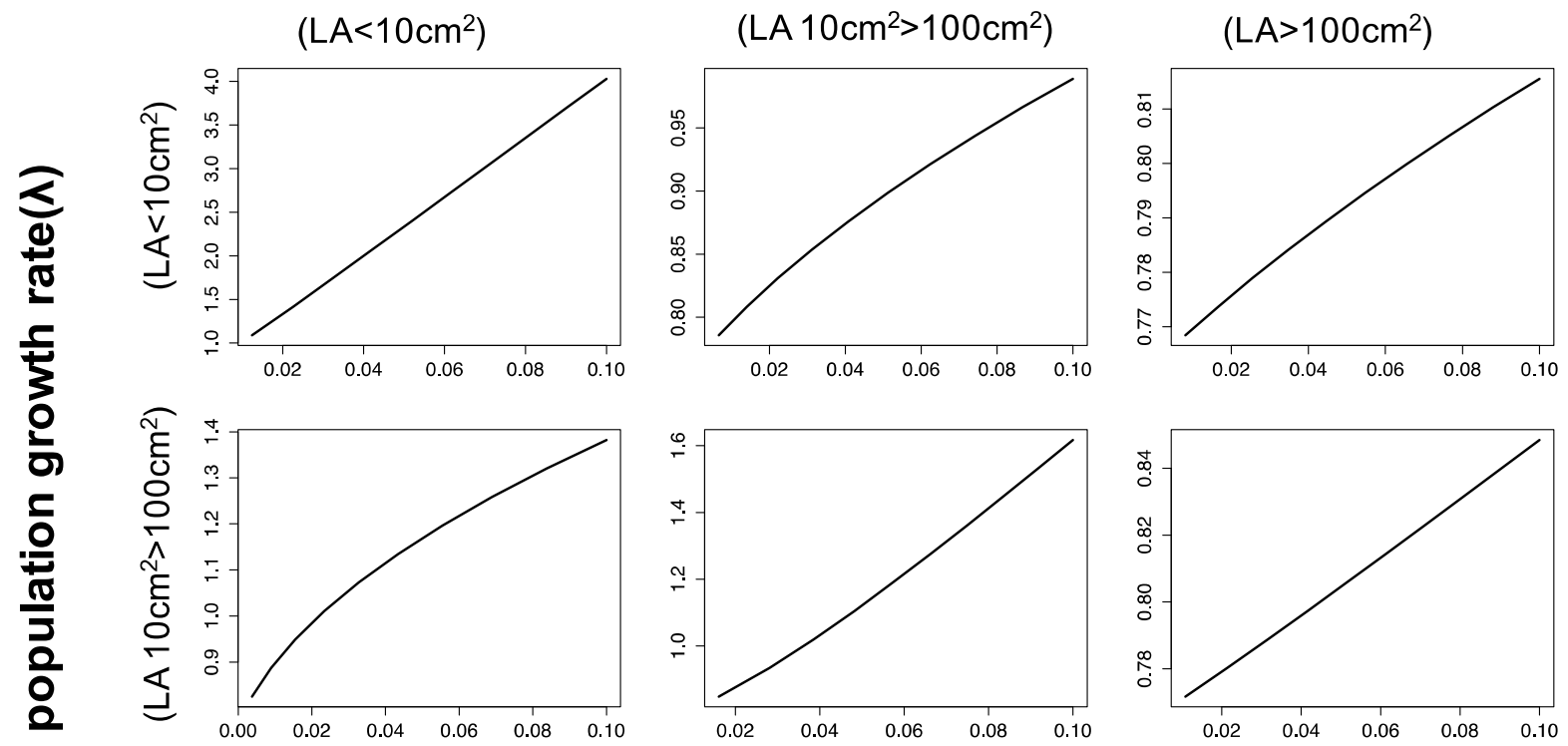

ํㅜㄹ
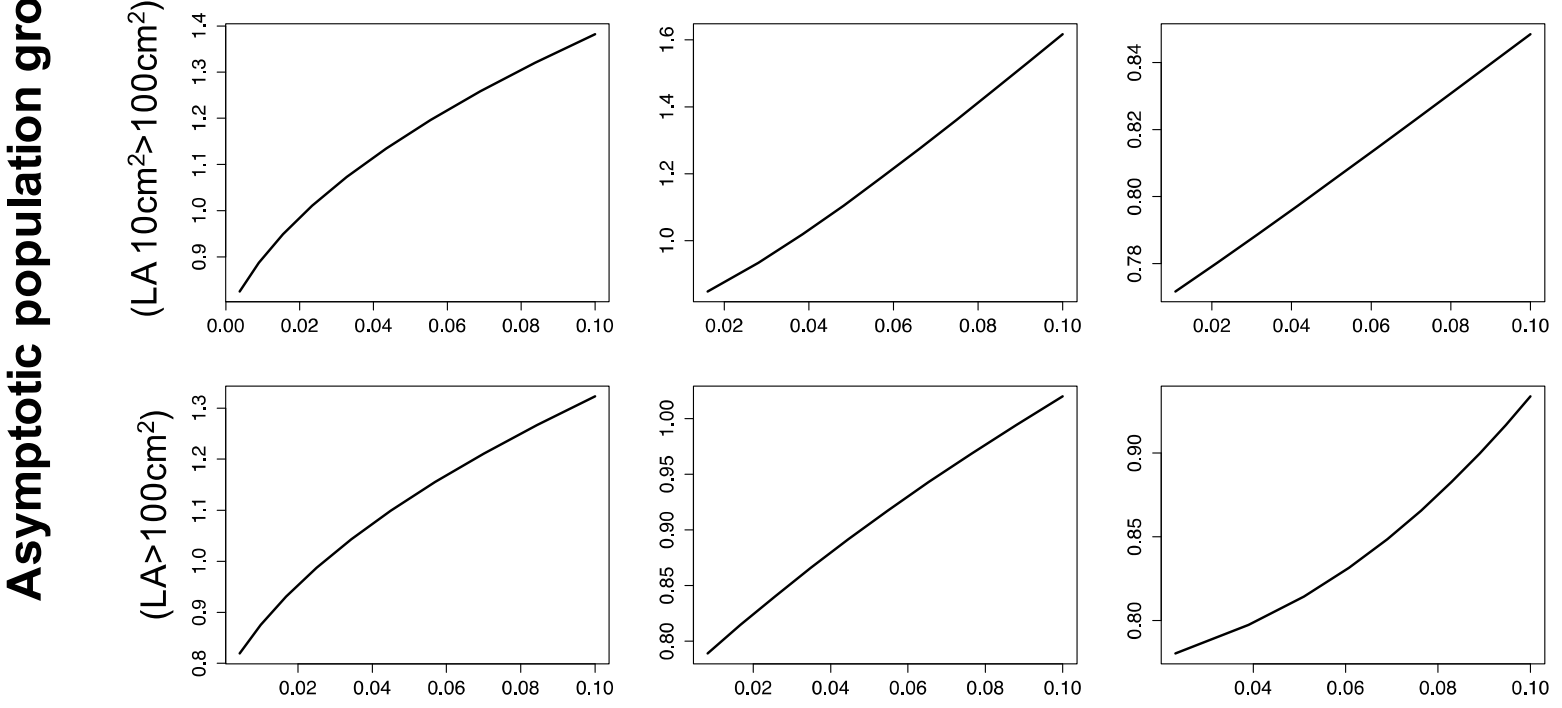

Perturbation magnitude (p) 
Figure S5 (cont.) Period 2010-2011
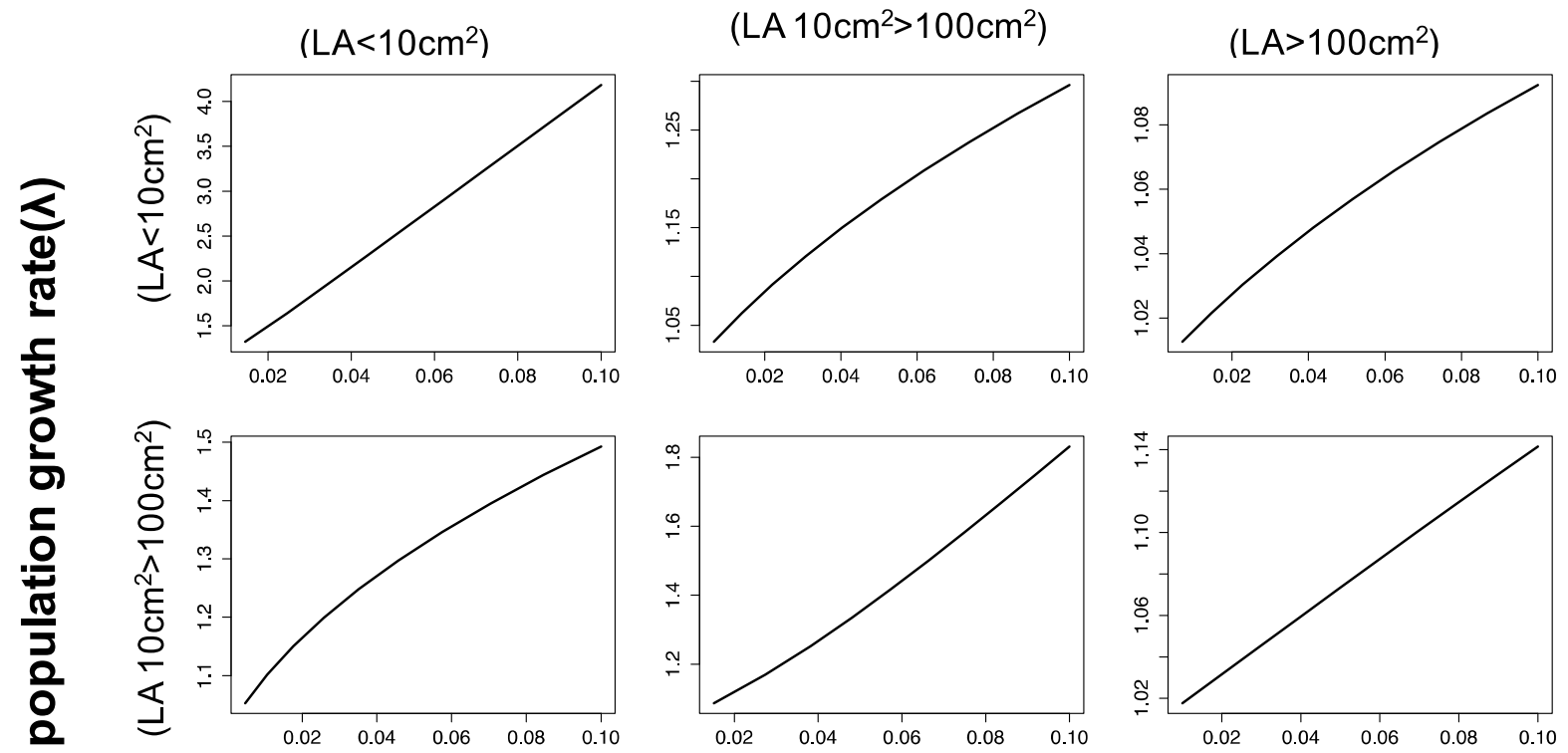

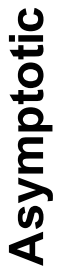
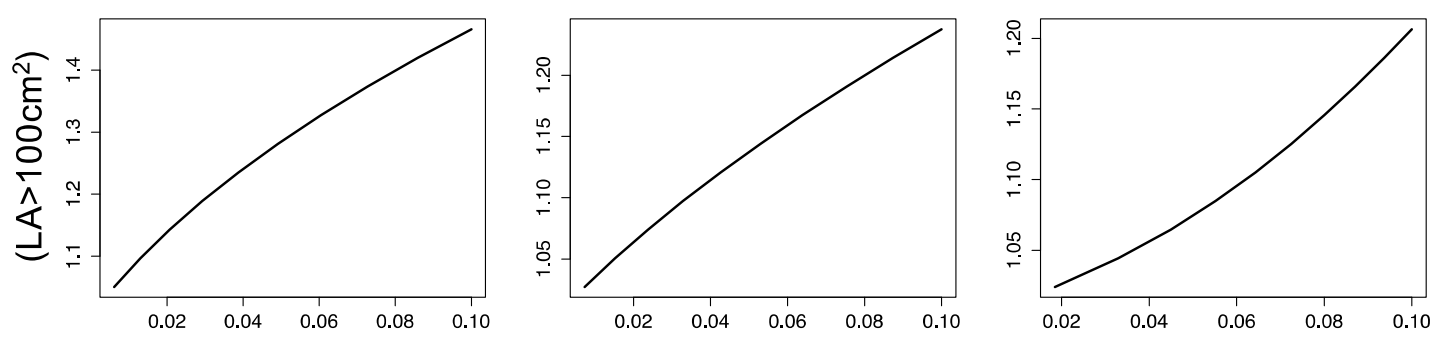

Perturbation magnitude (p) 
Figure S5 (cont.) Period 2011-2012
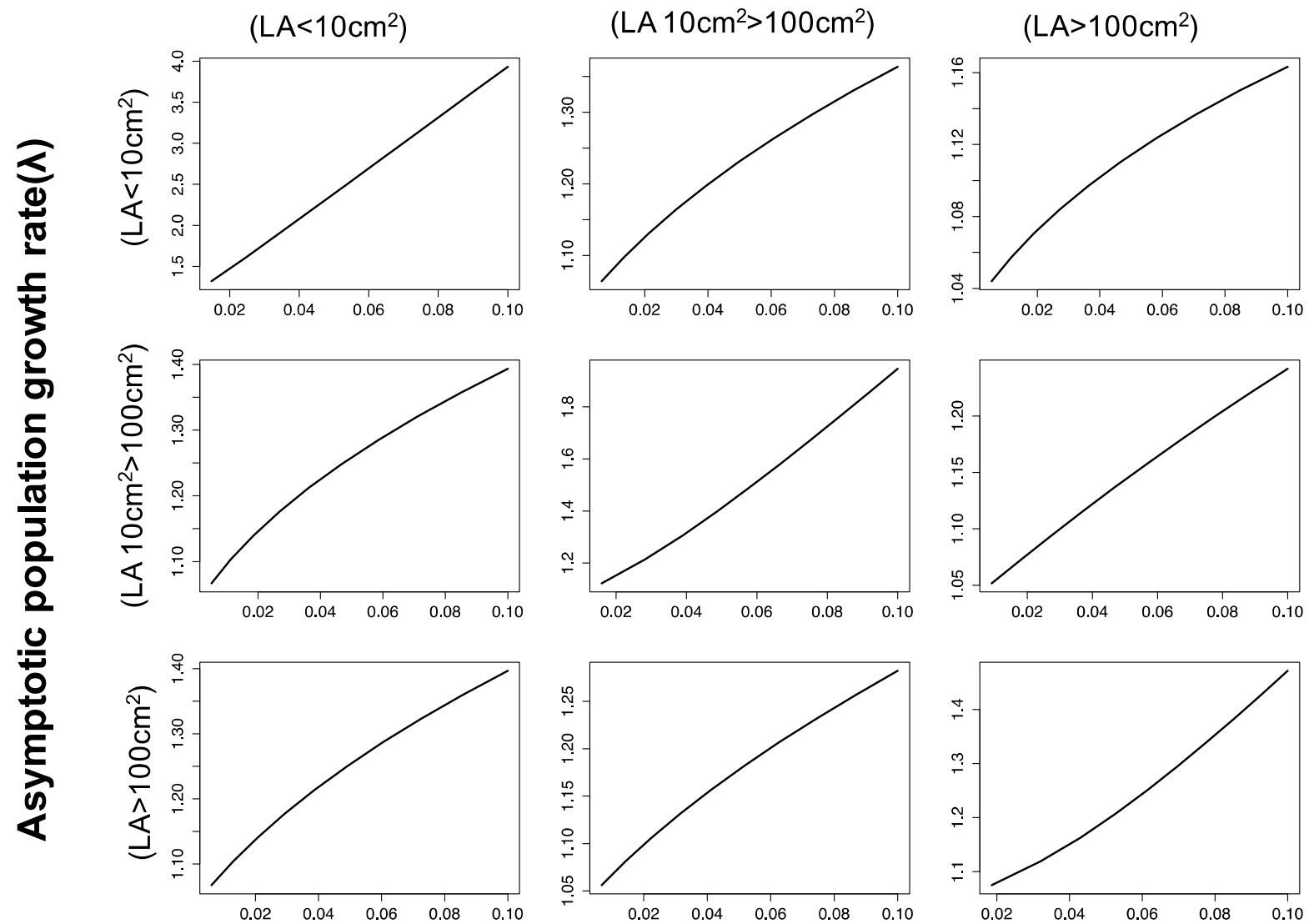

Perturbation magnitude (p)

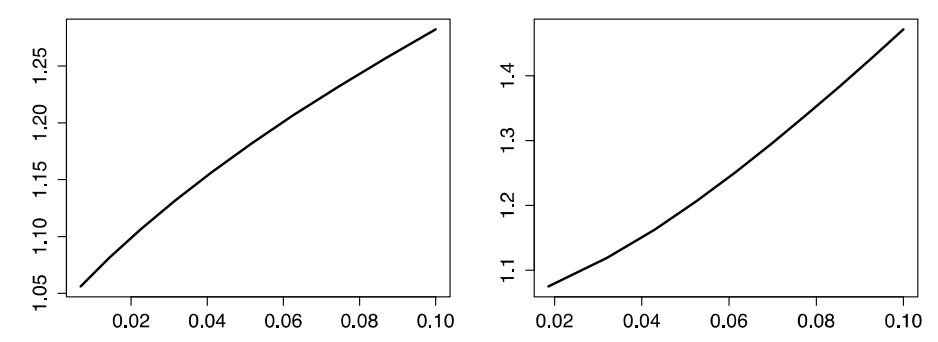


Figure S6. Spatial patterns between Enclyclia bocourtii and other orchid species at

Guanahacabibes, Cuba. Bivariate pair-correlation function $\left(g_{12}(r)\right)$, points above the upper envelope indicate positive association between the two orchid species (aggregated pattern), points between the envelopes indicate no spatial association (random pattern), and points below the lower envelope indicate negative association between the two orchid species (overdispersed pattern). The test statistic g1,1+2-g2,1+2 was used to detect density dependence between the two orchid species. If the test was below the simulation envelopes, the two species showed a positive density dependent (i.e., facilitation). Conversely, if the test statistic was above the simulation envelopes, we observed negative dependent (i.e., competition). In all cases, blue points indicate ring statistics; red lines being the 25th smallest and largest values of the 999 simulation of the null random model. The expectation of the null model is indicated with black line.

A Encyclia bocourtii-Encycliasp.
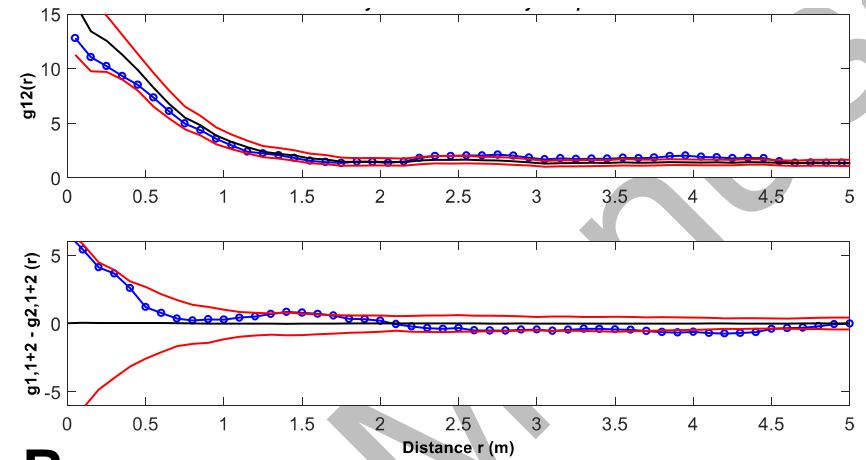

$B$ Encyclia bocourtii- Tolumnia sp.
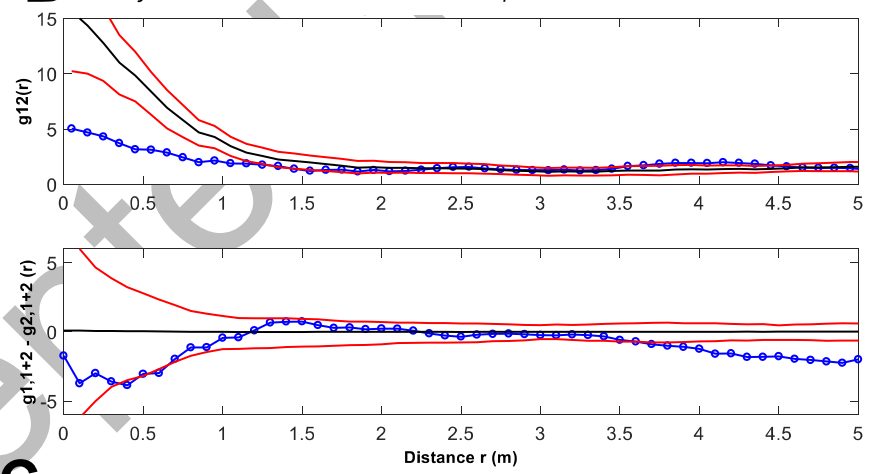

C Encyclia bocourtii- Broughtonia cubensis
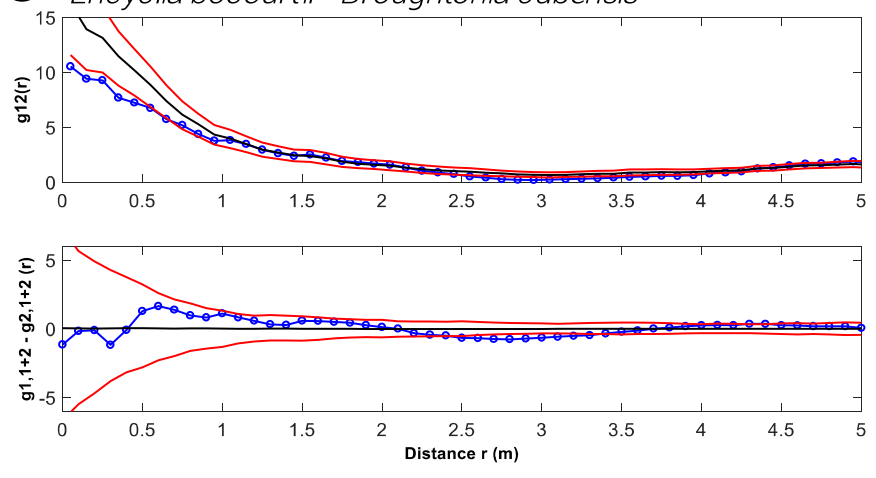